\title{
Copyright
}

by

Catherine McBride Robichaux

2002 
The Dissertation Committee for Catherine Mcbride Robichaux Certifies that this is the approved version of the following dissertation:

\section{THE PRACTICE OF EXPERT CRITICAL CARE NURSES IN SITUATIONS OF PROGNOSTIC CONFLICT AT THE END OF LIFE}

Committee:

Angela P. Clark, Supervisor

Robert Connelly

Joy Hinson Penticuff

Lynn Rew

Catherine Kohler Riessman

Alexa Stuifbergen 


\title{
THE PRACTICE OF EXPERT CRITICAL CARE NURSES IN SITUATIONS OF PROGNOSTIC CONFLICT AT THE END OF LIFE
}

\author{
by \\ Catherine McBride Robichaux, B.S.N., M.S.N. \\ Dissertation \\ Presented to the Faculty of the Graduate School of \\ the University of Texas at Austin \\ in Partial Fulfillment \\ of the Requirements \\ for the Degree \\ of \\ Doctor of Philosophy
}

The University of Texas at Austin

May, 2002 


\section{DEDICATION}

This work is dedicated to the critical care nurses who participated in my study.

I admire their ability to care for patients during the end of life and appreciate their willingness to share the stories of those experiences. 


\section{ACKNOWLEDGEMENTS}

Many people helped and guided me throughout the doctoral program

and during the process of completing this dissertation. I am especially grateful to my dissertation chairperson, Dr. Angela P. Clark, for her knowledge, unlimited patience, and enthusiasm. Dr. Clark has the unique ability to offer suggestions and provide a critique in a stimulating, constructive manner. She serves as a model for my own interactions with students. Similarly, I am thankful for the other members of my committee: Dr. Joy Penticuff for her expertise in ethical issues; Dr. Lyn Rew for her creative teaching ability and thoughtful advice; Dr. Alexa Stuifbergen for her assistance when I was initially formulating the substance and design of this research and for her continued encouragement; Dr. Robert Connelly for his philosophical insights; and Dr. Catherine Riessman for her participation, affirmation, and insightful commentary throughout the data analysis process.

I am deeply appreciative of the expert critical care nurses who took the time to participate in this study. Their ability to provide extraordinary care to patients and family members inspiring.

Completion of my studies was possible due to the support of the staff, students, and faculty members of the University of the Incarnate Word and The University of Texas Health Science Center at San Antonio., especially Dr. 
Ann Garner and Dr. Nancy Girard. I appreciate their tolerance and willingness to adjust their schedules to meet my needs.

Finally, I am grateful to my family for their love and encouragement throughout my doctoral study. I am particularly thankful to my husband, Hugh, for his uncompromising love and affection. As I often struggled throughout the process of writing this dissertation, he provided acceptance and comfort. 


\title{
THE PRACTICE OF EXPERT CRITICAL CARE NURSES IN SITUATIONS OF PROGNOSTIC CONFLICT AT THE END OF LIFE
}

\author{
Publication No.
}

\author{
Catherine McBride Robichaux, Ph.D. \\ The University of Texas at Austin, 2002 \\ Supervisor: Angela P. Clark
}

The purpose of this qualitative study was to explore the phenomenon of poor patient prognosis and actions taken by expert critical care nurses when their perceptions of the usefulness of aggressive medical therapies differed from those of family members or physicians. In addition, an exploration of the reasons given for their actions was conducted.

Twenty-one critical care nurses nominated as experts by a clinical nurse specialist or nurse educator were interviewed. The participants practiced in adult critical care units in one of three urban teaching medical centers, three urban private facilities, and one community hospital in Southwest Texas. The intent of the interviews was to elicit the nurses' 
narratives, as narrative thought and understanding are essential to an elucidation of ethical knowledge and agency (Vitz, 1990)

The interview questions generated both narrative and non-narrative data each of which required different analytic approaches. The narrative data were analyzed using techniques suggested by Riessman $(1993,2000)$ and Labov $(1972,1997)$. Identification of recurring narrative plots was accomplished using analytic strategies described by Polkinghorne (1995) and Ayres (2000). Thematic analysis (Coffey \& Atkinson, 1996) was used to analyze the non-narrative responses.

Analysis of the narrative exemplars yielded three recurrent plots while three main themes and thirteen subthemes emerged from the thematic analysis. The data revealed a compelling and diverse range of expert nurses' experiences responding to patient situations of extreme vulnerability with actions to prevent further technological intrusion, honor patient and family wishes, and facilitate a good death. The ability to effectively advocate in these situations was enhanced by professional responsibility, maturity, communication skills, and having personal experience with dying and death. In contrast to previous research, the expert nurses in this study believed they exerted a powerful influence on the clinical and ethical components of patient care.

The experience of expert critical care nurses in humanizing end of life care and shaping decision making processes around the event revealed 
opportunities for both improving and informing education and practice.

Creating an ethical environment in the ICU will necessitate introduction of a new model that emphasizes collaborative decision making and integrates palliative care. 


\section{TABLE OF CONTENTS}

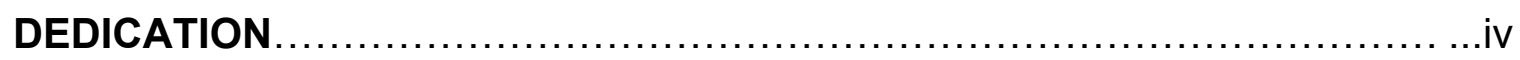

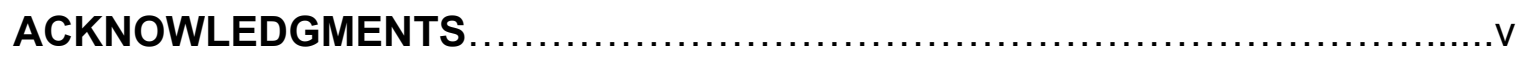

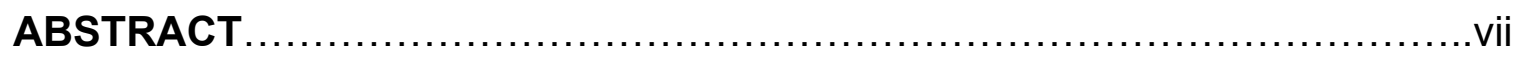

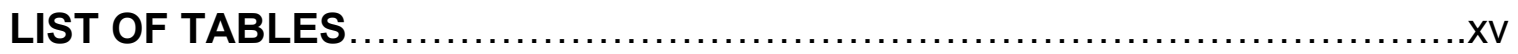

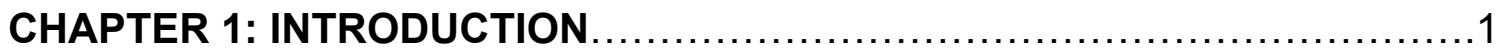

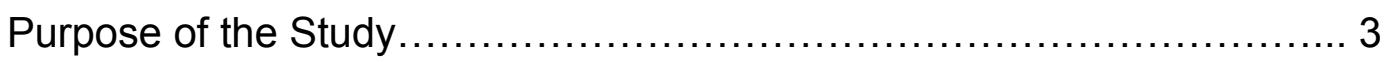

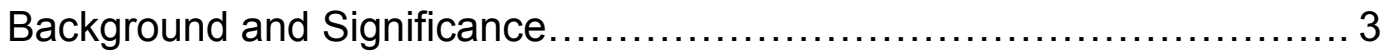

Research Questions..................................................12

Sensitizing Framework.................................................12

Cognitive Elements............................................. 13

Intrinsic Elements................................................... 16

Moral Elements...................................................... 18

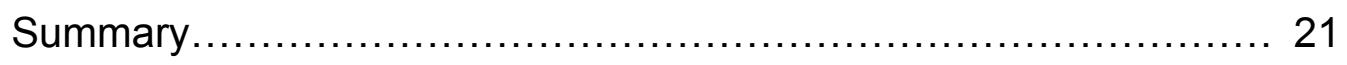

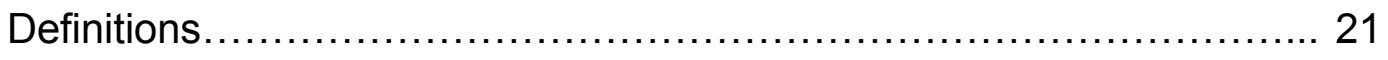

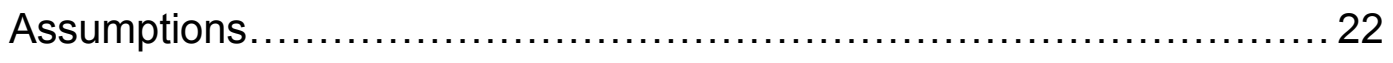

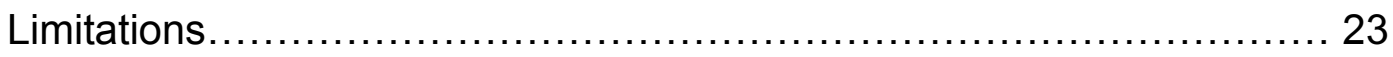

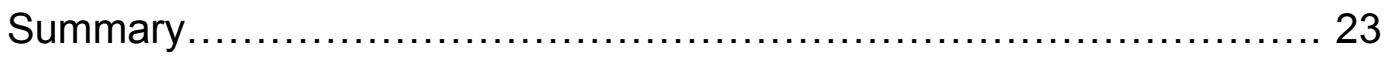




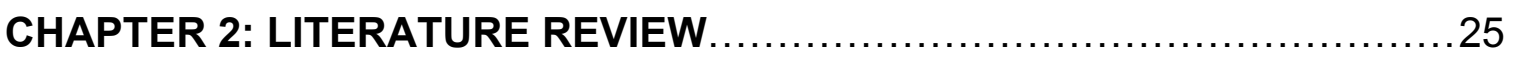

Foundational Nursing Ethics Literature .............................. 25

Empirical Ethics Literature.............................................. 33

Studies Utilizing Bioethical Theory ................................... 34

Studies Utilizing Moral Development Theory.......................... 39

Studies Utilizing Role Conception Theory........................... 43

Studies Exploring Expertise in Nursing ................................45

Studies Utilizing an Intuitive/Qualitative Model........................ 47

Studies Exploring Ethical Practice .................................... 67

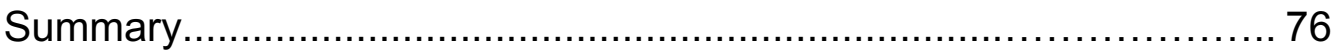

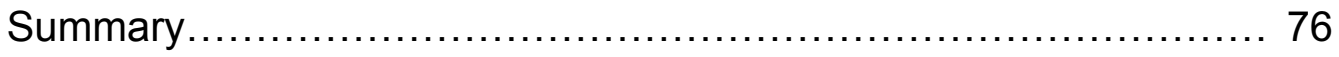

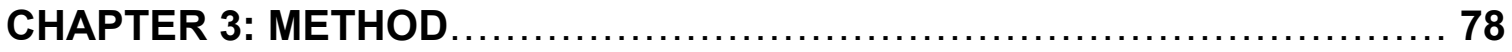

Research Design and Rationale for Methodology ........................ 78

Identification and Selection of Participants .............................. 81

Protection of Human Subjects .......................................... 84

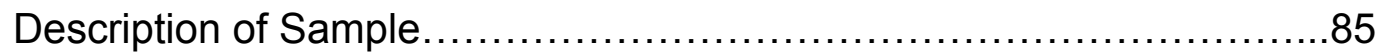

Data Collection Procedures ............................................. 86

Data Analysis........................................................ 92

Trustworthiness ........................................................ 100 
Summary. 104

\section{CHAPTER 4: PRESENTATION, ANALYSIS, AND}

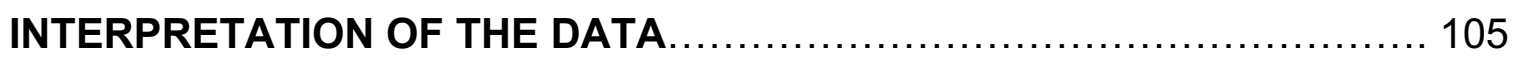

Nature of the Interview Responses and Narratives.....................105

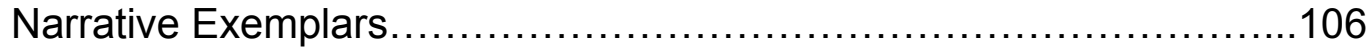

Protecting or Speaking for the Patient............................ 107

Presenting a Realistic Picture.................................... 138

Narratives of Resignation and Frustration......................... 151

Thematic Analysis.................................................. 161

Theme: Assessment or Seeing the Big Picture........................ 162

Subtheme: Clinical Assessment....................................162

Subtheme: Relational Assessment.................................. 164

Subtheme: Ethical Assessment...................................... 166

Theme: Actions ..................................................... 168

Actions With Family Members

Subtheme: Presenting a Realistic Picture........................ 170

Subtheme: Determining Patients' Wishes............................ 176

Subtheme: Consulting Additional Resources........................178

Subtheme: Tempering Involvement/Distancing..................... 179

Actions With Physicians 
Subtheme: Communicating Perceptions to Physicians. 181

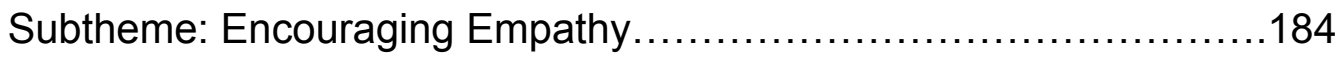

Subtheme: Consulting Additional Resources.........................185

Theme: Reasons ........................................................ 187

Subtheme: Professional Values..................................... 187

Subtheme: Personal Values......................................... 189

Subtheme: Personal Experiences..................................190

Interpretation of the Data Through the Research Questions.............. 192

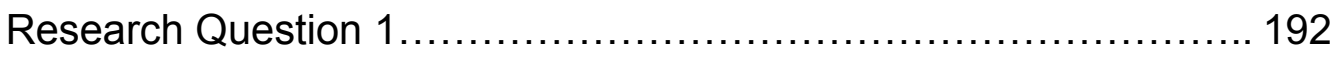

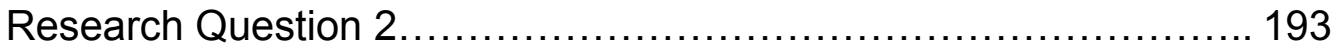

Research Question 3............................................. 194

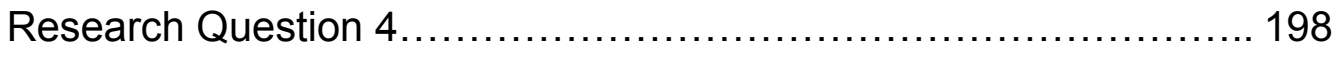

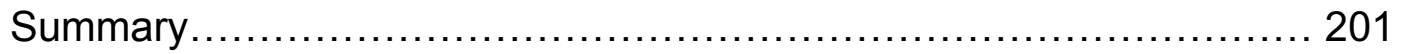

\section{CHAPTER 5: SUMMARY, CONCLUSIONS,}

AND RECOMMENDATIONS .............................................. 204

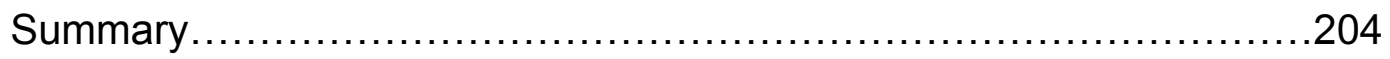

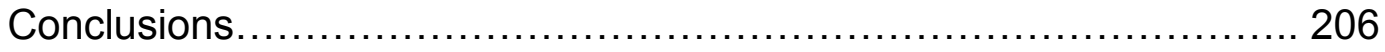

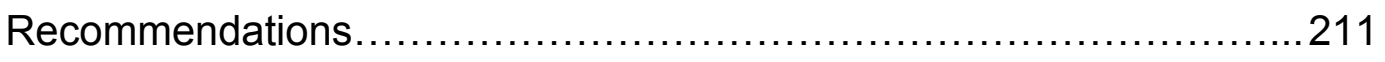

Improving End of Life Care in the ICU.............................. 211

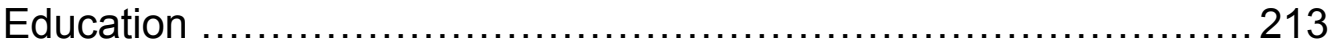


Practice. 215

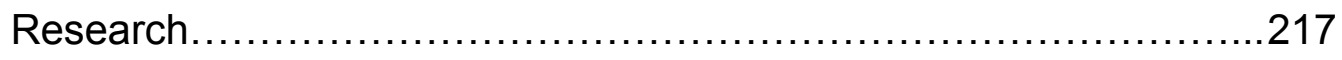

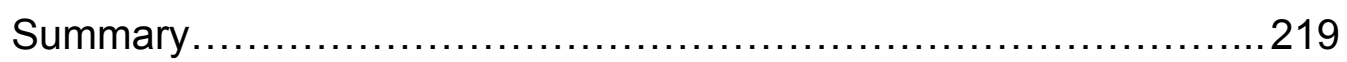

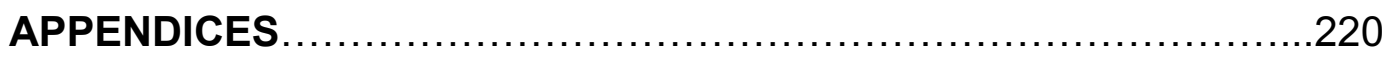

Appendix A: Studies Exploring Expertise in Nursing Practice............221

Studies Using Information Processing Theory as a Framework........221

Studies Using an Intuitive/Qualitative Framework....................234

Studies Exploring the Ethical Practice of the Expert Nurse............ 242

Appendix B: Letter to Consortium......................................244

Appendix C: Cover Letter............................................. 246

Appendix D: Demographic Data Form:................................ 249

Appendix E: Interview Introductory Statement........................ 250

Appendix F: Example of Field Note/Analytic Memo.....................251

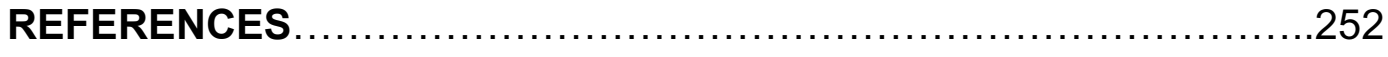

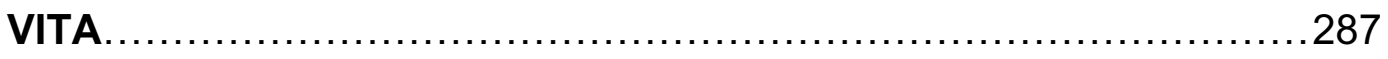




\section{LIST OF TABLES}

1. Demographic Data: Study Participants................................... 89

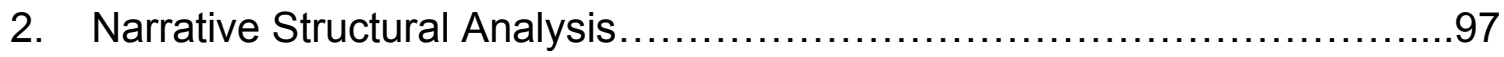

3. Expert Nurses' Indicators of Poor Patient Prognosis........................195

4. Expert Nurses' Actions When Perceptions of Poor

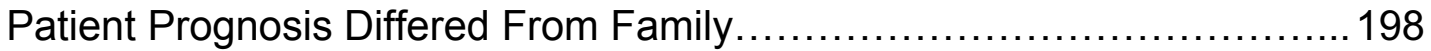

5. Expert Nurses' Actions When Perceptions of Poor

Patient Prognosis Differed From Physicians............................... 201

6. Expert Nurses' Reasons For Their Actions...............................202 


\section{CHAPTER I}

\section{INTRODUCTION TO THE STUDY}

The expert nurse has the ability to assess, predict, anticipate an impending crisis and respond immediately, thus preventing deterioration and even death. The existence and development of clinical expertise was initially explored and explicated by Benner (1982) and continues to be validated by the contributions of additional nurse researchers. In her most recent works, Benner, in collaboration with Tanner and Chesla (1996), and Hooper-Kyriakidis (1999) proposes that expert practice requires more than skillful clinical performance. Mastery of the ethical dimension is also requisite.

Perhaps nowhere is this mastery more challenged than in the critical care unit where nurses intimately witness the devastation of illness and frequently struggle to provide humane care. With the explicit focus on aggressive treatment and technological triumphs, critical care units are environments of both promise and uncertainty. In such settings, there may be a compulsion to "do everything" to "beat death", with the result that the patient as a person may disappear as the battle with the body continues. It is increasingly apparent that medical advances have not necessarily fostered human dignity, personal control, or quality of life. The prevalence of assertions to determine the time and manner of death, evident in numerous legislative and court decisions, serves as a response to the 
egregious inadequacies that often characterize care of the critically ill and dying (Lo, 1995).

Nurses are often caught in the middle, an ethically untenable position, as they attempt to comply with medical directives and simultaneously protect and advocate for their patients. Participating in interventions that contradict tacit understanding of the patient's clinical trajectory, violate patient and/or family preferences, or is unjustifiably painful and burdensome, can create tremendous conflict, including feelings of powerlessness and despair. The results of a recent study (Fry \& Riley, 2000) exploring ethical issues encountered in nursing practice, indicated that prolonging the living/dying process with inappropriate measures, was one of the most profoundly disturbing experiences for the participants. Puntillo et al. (2001) reported similar findings in a study conducted to explore the knowledge, beliefs, and ethical concerns of nurses caring for patients dying in intensive care units. The investigators (Puntillo et al., 2001) found that most nurses $(\mathrm{N}=906)$ thought aggressive medical treatments were prolonged either to a great extent (42\%) or sometimes (49\%). Though methodologically questionable, Asch's (1996) findings suggest that critical care nurses in this position frequently resort to participating in euthanasia and assisted suicide. In contrast to this description, the ethical practice of expert critical care nurses is said to be characterized by active resistance of the "technological imperative" and persistent questioning of the goals of care (Drought and Liaschenko, 1995). 
While exposition of expertise in clinical practice continues, little is known about what expert critical care nurses do when they encounter an ethically challenging situation such as use of inappropriate measures or the continued delivery of aggressive medical therapies to prolong the living/dying process. An exploration of their perceptions, actions, and reasoning in these situations was conducted to enhance understanding of ethical practice in critical care nursing.

\section{Purpose of the Study}

The purpose of this study was to explore what indicators expert critical care nurses describe about poor patient prognosis and what they communicate about their perceptions to the patient, family, physician(s), or peers. A description of what these nurses do when their perceptions of the usefulness of aggressive medical therapies differ from those of the patient, family, physician(s) or peers and the reasons they give for their actions was also explored.

\section{Background and Significance of the Study}

Approximately half of all deaths in America currently occur in hospitals and those final days are often spent surrounded by the impassive technologies of health care embedded in the highly specialized, sophisticated setting of an intensive care unit. While seriously ill people and their families generally enter hospitals in the hopes of staving off death, the anticipation of a "hospitalized death" engenders special concerns. There is a fear that dying will be caught up in a medical juggernaut driven by its own innate logic, one less focused on human dignity than on the struggle to maintain vital functions (Prendergast, Claessens, 
\& Luce, 1998). While several studies have examined the number and type of interventions used before death, such as mechanical ventilation and cardiopulmonary resuscitation (Koch, Rodeffer, \& Wears, 1992; Gindes, 1989), none had explored the overall experience of dying in the hospital (Danis, 1998).

The failure of advance directives and various guidelines issued by professional societies such as the Society of Critical Care Medicine (1990) and the American Medical Association (1991) to improve end-of-life-care in the hospital led to the development of the SUPPORT project or the Study to Understand Prognosis and Preferences for Outcomes and Risks of Treatment. Funded by a multimillion-dollar series of Robert Wood Foundation grants, the SUPPORT investigators sought to achieve a clearer understanding of dying in American hospitals. Beginning in 1989, SUPPORT enrolled over 9,000 patients suffering from life-threatening illnesses in five U.S. teaching hospitals over a fouryear period. Diagnoses of the participants included congestive heart failure, cancer, chronic obstructive pulmonary disease, cirrhosis, and acquired immune deficiency syndrome. These diagnostic categories were chosen because they are common and have a six-month mortality rate of 30 to $80 \%$. The most crucial research goal identified was to determine just what is feared about the experience of dying in American hospitals and then to devise, implement, and evaluate an intervention to improve the situation (Knaus, 1995).

The results of Phase I of the study indicated that the hospital experience of most seriously ill people was unsatisfactory. For example, $79 \%$ of Phase I 
patients who died while hospitalized had a do not resuscitate order, however $46 \%$ of these were written within two days of death. Thirty one percent of Phase I patients expressed a preference not to be resuscitated, but fewer than half of their physicians understood this preference. Of all the Phase I patients who died while hospitalized, $38 \%$ spent ten or more days in an intensive care unit. Surrogates indicated that half of all Phase I patients who could communicate had moderate or severe pain at least half of the time during their last three days of life (SUPPORT Principal Investigators, 1995).

The SUPPORT investigators proposed several explanations for these problems. First, physicians were uncertain about patient prognosis and this prognostic uncertainty contributed to the overuse of technology. Second, physicians did not know patients' preferences for life-sustaining interventions. Third, physicians failed to discuss options for care with patients and families. Poor communication resulted in many patients receiving aggressive lifesustaining treatments that they did not really want. The interventions designed and implemented during Phase II of the study attempted to address each of these problems (SUPPORT Principal Investigators, 1995).

During Phase II of the SUPPORT investigation, attending physicians received computer generated prognostic estimates and information about patients' preferences for life-prolonging treatments. Specifically trained research nurses facilitated discussions among physicians, patients, and family members. These strategies were developed to increase opportunities for discussion about 
treatment in the hope that informed patient decision-making would be enhanced resulting in fewer high technology interventions and more humane dying for patients. The effects of the implemented strategies were analyzed in Phase III. None of the problem areas identified in the study's first phase showed any improvement that was substantial or unambiguous. Decisions to withdraw or withhold interventions still occurred only two days before death and patient's wishes to withdraw care were often overlooked. Among patients who did not want resuscitation attempted, less than one-half of their physicians understood that preference. Many patients still experienced pain during their final days and/or spent many days in the intensive care unit. These findings do not depict gentle, peaceful death, but high technology run rampant with inadequate communication, insufficient relief of symptoms, and little respect for patient preferences (Lo, 1995).

During SUPPORT's four year span, several events occurred that bore relevance to end-of-life issues. The Patient Self Determination Act (Congressional Record, 1990) which mandates that each patient be informed of the right to exercise treatment preferences including choices about life sustaining measures, was passed in 1990. The Clinton Administration's attempts at reform sparked intense debate about the cost, accessibility, and quality of the health care system. Dr. Jack Kevorkian attained equivocal prominence and several states began grappling with the question of physician-assisted suicide. Yet, none of these phenomena seemed to have any impact on the care of the seriously ill, 
hospitalized patient (Lo, 1995). Because of the magnitude of the study, in both the expense and number of patients studied, the Robert Wood Johnson Foundation requested that the Hastings Center commission a series of papers to examine the unexpected, startling conclusions. (Moskowitz and LindemannNelson, 1995). The findings of SUPPORT and the commentaries of the contributors published in a special supplement of the Hastings Report reveal much about the care provided to dying patients and the position and impact of nurses within the hospital culture. Not surprisingly, the authors of these papers were attorneys, philosophers, physicians, ethicists, administrators, and educators; conspicuously absent were analyses from nurse ethicists or clinicians.

George Annas (1995), a bioethicist, maintained that SUPPORT's failure to effect change was due to several reasons, the principal one being that "physicians have never taken the rights of hospitalized patients seriously" (1995, p. S12). In the modern teaching hospital, patient care is often a distant third goal after teaching and research. There is minimal room for thoughtfulness, the intrusion of human values, or conversation with the patient or family in a high tech, high-pressure environment. The imperative is to use all available technologies for the patient or for practice and, as hospitals become more like large intensive care units (ICUs), this technological emphasis increases. With escalating cost and reimbursement pressures, treating patients as quickly as possible is required. Consequently, Annas (1995) observed, medical students and residents are taught that talking is a waste of time, distracting from time 
available to do "real medicine". When doing "real medicine" fails, Annas (1995) asserts, students and residents quickly learn that the attendings are often uninterested in having discussions with patients or families about death or pain. These attitudes are such a pervasive part of contemporary medical culture "that the only realistic way to improve care of dying patients is to get them out of the hospital or prevent them from going to the hospital" ( Annas, 1995; p. S14).

Patricia Marshall (1995), a philosopher and associate director of the Medical Humanities program at Loyola University Stritch School of Medicine, proposed that SUPPORT failed to produce the intended results because it created an intervention that kept a cultural system intact. Patients, their surrogates, physicians and nurses all participated actively in Phase II, the experimental stage of the project. However, the responsibility for implementing the interventions in Phase III rested heavily on the project nurses who spoke with patients about their concerns and desires for medical treatment and became the conduit of information about preferences and prognostic status. Marshall (1995) maintained that this is "business as usual in a medical environment where nurses are relied upon to 'talk' to patients and their families and relay messages to physicians 'in charge' " (p. 66). Consequently, the knowledge generated by the nurses concerning advance care planning for end of life decision-making was contained in "an all too familiar package" (p. 67).Thus, Marshall asserts, the historical context of biomedical authority and social dominance was maintained. She continues, "do physicians read the patient charts or listen to nurses' 
requests on behalf of patients? ...if the physician reads the chart or discusses the issues with nurses, is the material taken seriously? Is it granted legitimacy and credibility?" (Marshall, 1995, p. 68). Solomon (1995), another contributor to the Hastings Report supplement, questioned whether insufficient assertiveness of the project nurses contributed to the failure of physicians to respect patients' decisions about their terminal care. These authors' comments suggest that the nursing discipline's perception of the role of the nurse as patient advocate may be an illusion.

In an article entitled "The Message of SUPPORT: Change is Long Overdue", Oddi and Cassidy (1998) proposed that the lack of collaboration with nurses in the design and implementation of SUPPORT presaged its outcomes and is illustrative of much that is problematic in today's health care system. Although the roles of the nurses in the study were described as typical of those of a clinical nurse specialist, only $19(22.4 \%)$ of the 85 nurse participants were educated at the master's level. Despite the principal investigators' assertion that these nurses were free to shape their own roles, all of the nurses' involvement with patients and families required the approval of the attending physicians. Oddi and Cassidy (1998) also observed that of the 40 nurse interviewers, 15 held no academic degree and 18 were prepared at the baccalaureate level. The authors questioned the knowledge of these nurse participants regarding patient care issues and noted the absence of nurses as co-investigators or project directors. Analysis of the report suggests that nurses, the professionals most uniquely and 
intimately involved with dying patients and their families on a day to day basis, are not recognized as having the knowledge and skill necessary to address complex issues surrounding end of life care (Oddi and Cassidy, 1998).

Despite evidence that interdisciplinary collaboration improves patient outcomes, (Knaus and Draper, 1986; National Joint Practice Commission, 1979), and is requisite to ethical decision making in the intensive care unit (Baggs 1993; Grundstein-Amado, 1993; Luce, 1990), nurses are not typically viewed as equal partners in this process. Rather, the literature of nursing ethics describes the position of nurses as "being caught in the middle" between patients and physicians or patients and hospitals (Jameton, 1977), "not free to be moral" (Yarling and McElmurry, 1986) and "powerless in influencing ethical decisions" (Erlen and Frost, 1991). While nurses have traditionally served as interpreters of patients' physiologic cues and translators of their concerns, this knowledge is devalued (Oddi and Cassidy, 1998). As a society, we have been conditioned to see the work and knowledge of medicine as most significant in patient care (Liaschenko, 1997).

Studies exploring nurses' participation in ethical decision making in various intensive care unit settings have reported conflicting findings. Martin (1989) and Omery and Henneman (1995) found a positive correlation between level of education, clinical experience and participation. Erlen and Frost (1991) found no relationship among these same variables while Kennard, Speroff and Puopolo (1996) described a negative correlation between years of experience 
and amount of participation. Organizational or administrative support, the existence of an "ethical climate", has also been shown to be associated with participation in ethical decision making (Olson, 1998). In their study exploring perinatal nurses' responses to ethical dilemmas, Penticuff and Walden (2000) found that practice setting characteristics were the primary predictor of the respondents' involvement in dilemma resolution.

Since publication of the SUPPORT findings, there have been several investigations that indicate end-of-life decision-making practices and care remain unchanged. In a study comparing patients dying in ICUs in community hospitals with those in large, academic teaching centers, Keenan, Busche, and Chen (1998), found that practices varied widely and were less than optimal. The authors reported that physicians in community hospitals were less likely to discontinue vasopressor agents, initiate discussions on withdrawing life support, and write DNR orders. Subsequently, patients died after a longer period of time.

Goodlin and Teno (1998), examined symptoms and treatments in the last two days of life among patients $(n=104)$ who died in the ICUs of an academic medical center and an affiliated Veterans Affairs hospital. Similar to the SUPPORT findings, the investigators reported that pain, dyspnea, and agitation were documented in approximately $50 \%$ of the patients. Thirty-three percent had DNR orders written within two days of death, while $10 \%$ were written on the day of death. 
The transition from possible recovery to an understanding that further efforts will not achieve the desired outcome can be unevenly recognized and acknowledged by those involved in the situation. Perhaps nowhere is the link between clinical and ethical reasoning more apparent than during this transition (Benner, Hooper-Kyriakidis, \& Stannard, 1999). The role of nursing in recognizing and communicating this transition may contribute to a practice-based account of nursing ethics.

\section{Research Questions}

The following research questions were investigated in this study:

1. What indicators do expert critical care nurses describe about poor patient prognosis?

2. What do expert critical care nurses communicate about their perceptions of poor patient prognosis to the patient, family, physician(s), and/or peers?

3. What do expert critical care nurses do when their perceptions of the usefulness of aggressive medical therapies differs from those of the patient, family, physician(s), or peers?

4. What are the reasons expert critical care nurses give for their actions?

\section{Sensitizing Framework}

Strauss and Corbin (1990) and Munhall and Oiler (1986) describe sensitivity as a personal quality of the researcher that is dependent on previous reading and experience with or relevant to an area. This sensitivity can generate insight, understanding, and the ability to derive meaning from the data. A 
sensitizing framework of knowledge can emanate from several areas, such as literature, and professional and personal experience. The sensitizing framework for the present study includes literature examining the construct of expertise in nursing and other disciplines. In addition, the researcher's professional and personal experience with the issue is also recognized as both enhancing sensitivity and as a source of possible bias.

As discussed in the scientific literature, attributes, characteristics, or behaviors associated with expertise, can be categorized as cognitive, intrinsic, and moral. These elements are discussed in the following section.

\section{Cognitive Elements}

An extensive domain knowledge base is a requisite cognitive attribute for the development of expertise. In one of the first studies exploring expertise, Chase and Simon (1973) estimated that an individual must spend between 10,000 and 20,000 hours studying chess positions to become a chess master. This translates to approximately ten years of intense practice and preparation. In discussing the evolution of expertise in nursing, Dreyfus and Dreyfus (1979; 1986) also propose that progression from novice to expert may take five or more years.

While manifestations of expert knowledge are evident in explanations and performance, "tacit" or hidden knowledge profoundly distinguishes the expert from the non-expert (Polanyi, 1973; Bereiter \& Scardamalia, 1993). This 
impressionistic knowledge may form the basis of the expert's initial action and is comparable to Carper's (1978) discussion of personal knowledge in nursing.

To retain the vast amount of knowledge they acquired in the course of their experience and practice, experts store and organize the information in longterm memory as structured patterns (Chase \& Simon, 1973). This internalized representation allows them to compare idealized performance standards with present events. Experts' knowledge is structured in sophisticated, complex ways that make it easy and economical to recall and apply. Elements, concepts, and other forms of information are organized in branch fashion, that is, interconnected and linked like a road map. These knowledge structures enable experts to recognize relationships and meaningful clusters of information during performance (Chase \& Simon, 1973). When making decisions or solving problems, they sort, identify, and analyze the essential factors with precision and efficiency (Chi, Feltovich, \& Glaser, 1981).

The ability to see details or information that other people either miss or dismiss, is another behavior associated with cognitive expertise. Experts are able to recognize patterns during their performance that allow them to draw on their sizable knowledge store. This process of pattern recognition involves the identification of critical cues including words, sounds, movements, or appearances as the event or performance unfolds. These cues are then matched to the expert's knowledge base (Cooke, 1992). In nursing, the relevance of pattern recognition to expert clinical decision-making has been discussed by 
Pyles and Stern (1983), Jenny and Logan (1992), and Benner et al. (1996; 1999).

Greeno (1977) maintains that experts expend time identifying, defining, and analyzing a problem before searching for a solution. During the initial analysis, they rely on their extensive knowledge base to construct a mental representation of the problem, which can take a variety of forms. Some correspond closely with the problem as stated, or can contain embellishments, inferences, and abstractions. Embellishment refers to a rich, qualitative representation, which results from the expert's ability to form strong impressionistic connections thereby contributing to ease in problem solving. Indeed, modern theories of memory suggest that we do not so much recall information as re-live events (Sloboda, 1996).

The reasoning process of the expert is described as forward or inductive when contrasted with that of the novice or experienced non-expert who reasons backward in a deductive manner. Thus, when solving problems, experts tend to work forward from the given information to the unknown whereas the novice/nonexpert works from a hypothesis regarding the unknown back to the given information (Patel, 1996). With the attainment of a high degree of mental and/or physical skill, comes both automaticity and unconscious behavior. The efficiency of performance is enhanced by the expert's ability to assess a problem accurately and chose solutions from a wealth of field-tested alternatives (Saariluoma, 1994). Similarly, in nursing, the technical practice of the expert 
nurse is characterized as seemingly unconscious, remarkably skilled performance (Benner, Tanner, \& Chesla, 1996).

Experts remember and can recall a great deal about their subject, both short and long term often in minute detail. This superior capacity for recollection results from the automaticity of many of their behaviors and subsequent increase in short term memory capacity. Knowledge is stored in recognizable "chunks" organized in strategically significant ways (Miller, 1956).

\section{Intrinsic Elements}

The development and cultivation of expertise requires more than just superb cognitive skills. Additional intrinsic elements identified as requisite to the development of expertise include: self regulation, reinvestment, motivation, and an heroic element.

The notion of self-regulation is derived from child development research and is defined as the management of one's self in order to obtain desired goals. Self-regulation includes the ability to monitor, negotiate, self-instruct, and thus adjust performance based on one's own feedback. Wagner and Stanovich (1996) suggest that self-regulation is greatly enhanced as the expert develops automaticity which leaves time available for higher level processes. Bereiter and Scardamalia (1993) maintain that self-regulatory knowledge may be thought of as knowledge that controls the application of other knowledge. Consequently, it is often referred to as metaknowledge or metacognition. 
Self-monitoring is considered a metacognitive process and was found to be characteristic of experts in physics who possessed a greater ability for elaborate explanations of their own solution processes than did non-experts (Chi, Feltovich, \& Glaser, 1981). The investigators concluded that learning and problem solving in physics is not based solely on induction from working on many examples but also involves an elaboration of the process based on what the participants believed they do not know about the domain.

Moving beyond the plateau of competent or average requires reinvestment of available mental resources in the domain activity thus leading to further growth in skills and knowledge. The often endless practicing that athletes and performing artists do represent reinvestment as does the time that professionals put into keeping up with the journals in their field and attending training workshops in new procedures. Reinvestment also refers to the expert's inclination to seek out problems that are more difficult or engage in more complex representations of recurrent problems. Bereiter and Scardamalia (1993) assert that the difference between the expert and the non-expert is not that one does things well and one badly, but rather the expert addresses problems while the non-expert carries out practiced routines. Thus, the career of the expert is one of progressively advancing on problems constituting a field of work while the career of the non-expert is one of gradual constriction of the field so that it more closely conforms to the routines he/she is prepared to execute. 
The expert's need to pursue answers to problems is compelled by motivation. Motivation is described as the experience of "flow" or sustained pleasure in the activity, total absorption, a loss of self-consciousness, and a feeling of being in control (Csikszentmihalyi (1988). In caring for a patient, the expert nurse may experience a level of involvement and attunement that enables him or her to "know " the patient. Themes associated with "knowing the patient" include an understanding of his/her pattern of responses, coping resources, fears, and required comfort measures. This phenomenon is believed fundamental to expert clinical judgment, ethical comportment, and a salutary outcome (Jenny \& Logan, 1992; Radwin, 1998; Parker, Minick, \& Kee, 1999).

Bereiter and Scardamalia (1993) propose that the progressive problem solving associated with expertise requires working at the edge of competence. The expert must push his or her creative limits and perhaps risk failure and the loss of self-esteem. Thus, a certain amount of daring or heroism is necessary.

\section{Moral Elements}

There has been relatively little exploration of moral elements as part of the construct of expertise. Even in those professions with a history of ethical codes, standards, and adherence to principles such as nursing and medicine, articulation of the centrality of moral characteristics and behaviors to expert practice is a relatively recent phenomenon.

Benner, Tanner, and Chesla (1996) state, "the development of clinical expertise inherently demands the development of ethical expertise" (p. 160). 
While the authors' conception of ethical expertise incorporates Aristotle's notions of excellent everyday behavior, virtue, and skill (1953), it differs in the recognition of emotion as essential. Rather than being considered a source of interruption or error, emotional attunement is requisite to ethical practice. Callahan (1998) concurs and states: "Emotions energize the ethical quest; a person who wrestles with moral questions is usually committed to doing good and avoiding evil. A case can be made that what is specifically moral about moral thinking, what gives it it's imperative 'oughtness' is personal emotional investment" (p.13).

The possibility of ethical expertise is, however, a contentious matter. Within the realm of philosophy where the majority of discussion occurs, the existence of expert status and expertise in general, is disputed and criticized. Caplan (1989) notes that the negative or skeptical reaction of primarily academic philosophers to the notion seems to stem from a combination of factors including: (1) the incompatibility of ethical expertise with the discipline's norms concerning the appropriateness of claims about knowledge, whether the subject is morality or something else; (2) the incompatibility of ethical expertise with democracy since doubt is cast on the ability of each individual to be his or her own best judge of values, and; (3) the lack of a comprehensive theory of ethics that can ground all moral beliefs and practices thus making the possibility of applied or practical ethics meaningless. Despite these objections, Caplan (1989) and others believe that ethical expertise doses exist and can be acquired without having any contact with moral philosophers or formal training in philosophy. 
Bayliss (1989) asserts that there is a distinction between ethical experts and ethical expertise. He maintains that, although the degree of difference cannot be measured in any absolute terms, "it is as significant as that between a novice and an expert" (p. 98). Employing Ryle's conception of "knowing that" and "knowing how", Bayliss describes ethical expertise as knowledge of the major ethical principles, concepts, and theories (knowing that) and the expert as one who is able to identify and individuate an ethical problem (knowing how). The expert knows how to demonstrate understanding and empathy and is involved in the situation. Similarly, Szabados (1978) asserts that the individual possessing moral expertise has "extra insight into life, a certain measure of affection, breadth of experience, familiarity with oppression, moral imaginativeness ("imagine how he/she must feel"), insight into basic human needs and wants, and an ability to predict the consequences of actions and their effects on agents" (p. 121).

In nursing, Benner, Tanner, and Chesla (1996) and Benner, HooperKyriakidis, and Stannard (1999) identify characteristics and behaviors associated with expert moral agency as: (1) excellent moral sensibilities or a vision and commitment to good clinical and caring practices; (2) perceptual acuity or the ability to identify salient moral issues in particular situations; (3) embodied knowhow or the combination of skilled performance, timing, and anticipations; (4) involvement or the ability to establish respectful collaborative relationships with 
co-workers and caring relationships with patients and families that enable advocacy; and (5) managing technology and preventing technological intrusions.

\section{Summary}

The scientific literature discussing expertise and expert practice provides a sensitizing framework that will, hopefully, enhance understanding and insight in the present study. The researcher's professional experience as a critical care nurse for thirty years is also acknowledged as contributing to awareness.

\section{DEFINITIONS}

For the purposes of this study the following terms are defined:

\section{Expert Nurse}

(a) has been practicing for five or more years

(b) is sought out by others for advice in solving problems

(c) is considered an excellent preceptor by colleagues

(d) possesses perceptual acuity or the ability to identify and solve problems

(e) practices with embodied, skilled know-how or the ability to know how to do what is needed

(f) establishes a caring relationship with the patient/family and collaborative relationship with health care team members

(g) manages technology and prevents unnecessary technological intrusions 
(h) practices with a sense of agency or the ability to act upon or influence a situation

(Benner, Tanner, \& Chesla, 1996; Benner, Stannard, \& Hooper-Kyriakidis, 1999).

Poor prognosis: a judgment that survival and recovery from an illness is unlikely.

Prognostic conflict: differences in judgment regarding the prospect of survival and recovery from an illness.

Critical care nurse: a registered nurse who is employed in a hospitalbased intensive care unit.

Perception: the integration of sensory impressions resulting in direct or intuitive recognition.

Intervene: to come between or intercede.

Outcome: something that comes out of or follows from an activity.

Expertise: expertness in a particular field

Indicator: a sign or symptom

\section{Assumptions}

The following assumptions underlie the design and methods selected for this study:

1. The expert nurse possesses both clinical and ethical expertise.

2. Narrative is the primary way of organizing and communicating the sense individuals make of the world (Bruner, 1990). 
3. Narratives focus on people and on the reasons for their actions, their intentions, goals, and subjective experience.

4. The exploration of narratives is an instrumental way of discerning how knowledge is acquired and transmitted.

5. The expert nurse can convey knowledge of experiences through narrative retelling.

\section{Limitations}

While the intent of qualitative research is not to generalize findings but to form a unique interpretation of events (Merriam, 1988), it is recognized that the results of the proposed study may be limited by the narrative approach employed and the use of purposive sampling. Replication of the proposed investigation would enhance reliability but is somewhat restricted by the specific context and selection of participants. However, the provision of assumptions, criteria for informant identification, and data collection procedures and analysis, make replication a possibility. It is also acknowledged that the ability to convey a narrative of past events is dependent on memory, which can be faulty or forgetful.

\section{SUMMARY}

Nurses who practice in intensive care units often provide care to patients who will die despite medical treatment and the use of unlimited technology. Yet, the existing cultural system is to continue aggressive treatment even when it may contradict the patient's clinical trajectory, patient or family preferences, or is 
simply unjustifiable by humane care standards. The nature of ethical dilemmas for nurses who practice in the midst of such situations can be profoundly disturbing. The elements of expertise include cognitive, intrinsic, and moral dimensions. The contribution of expert nursing practice to the recognition and acknowledgement of poor patient prognoses in the hospital environment remains poorly understood and warrants study. 


\section{CHAPTER 2}

\section{REVIEW OF THE LITERATURE}

This chapter provides a background for the study and will be organized into three main sections. foundational nursing ethics literature, empirical nursing ethics literature and studies exploring expertise in nursing. The review of empirical nursing ethics literature will include studies utilizing frameworks derived from theories of bioethics, moral development, and role conception. Studies exploring expertise in nursing practice will be grouped into two sections, those using an intuitive and/or qualitative model and investigations examining the ethical dimensions of expert nursing practice.

Modern nursing had its beginnings in religious community life, which suggests that the ethical imperatives embedded in the care of the sick are as old as the practice itself (Donovan, 1985; Kalisch and Kalisch, 1986). The use of moral language to describe our practice continues despite secularization as evidenced by Curtin's (1979) pronouncement that it is "a moral art" (p.12) and Jameton's (1984) characterization of nursing as the "morally central health care profession" (p.15). Discourse on the nature and meaning of the ethical foundation of the discipline is, however, a relatively recent development. This section of the literature review explores the evolvement of this discourse in both the nonempirical and research literature.

\section{Foundational Nursing Ethics Literature}


The contemporary dialogue in nursing ethics began with Davis and Aroskar's (1978) publication of "Ethical dilemmas in nursing practice". As noted by the authors in the preface, the literature on nursing ethics before this publication reflected the circumscribed view of either legality or etiquette. In contrast to this restricted perception, Davis and Aroskar (1978) introduced nursing to the principle-based approach dominant in moral philosophy that was also being adopted by medicine. Although they focused primarily on ethical dilemmas, they proposed that these dilemmas occurred within the context of nursing practice. Their assertion was that there is something about the nature of nursing practice that casts a different light on traditionally conceived health care dilemmas. Consequently, Davis and Aroskar (1978) maintained nursing ethics was not reducible to medical ethics and constituted a separate body of inquiry. In addition, the authors discussed institutional constraints on nursing practice, thereby anticipating some of the major criticisms to come, particularly those of feminists.

Curtin and Carper (1979) each published separate proposals espousing a moral stance for nursing in the same issue of Advances in Nursing Science. Curtin (1979) maintained that nursing needed to be defined philosophically, not sociologically. In the latter view, nursing is seen as a series of tasks or role expectations rather than a practice. She argued that nursing is a practice whose aim is the well being of patients. This aim is actualized through a certain kind of relationship, a central concern of which is the meaning of the illness for the 
patient. In this way, Curtin (1979) anticipated much of the work to come on the importance of meaning in illness. Based on this reasoning, she called for a moral stance of advocacy, which is rooted in notions of respect for persons, freedom, and dignity. While proposing the nurse as advocate, Curtin (1979) also acknowledged the reality of institutional constraints and possible repercussions associated with this stance:

To claim that nurses can institute progressive change is not to ignore the many organizational and social barriers...to be sure, there are inflexible policies and insensitive orders from physicians. In many instances, nurses are not free to disclose certain information to patients and their families. That is, they are not free unless they are willing to pay the price, a price that may include loss of employment or even licensure (p.19).

Emphasizing that the central focus of health care is indeed care, and that increasing specialization and the proliferation of technology is eroding this care, Carper (1979) proposed "The Ethics of Caring" as the moral foundation of nursing. Citing Mayeroff, Carper (1979) discussed the process and key elements of caring noting that it is specific rather than abstract and depends on selfknowledge. In suggesting what this care should look like, Carper (1979) advanced Veatch's three models of the physician-patient relationship: the engineering, the priestly, and the contractual models. Veatch maintained that the contractual relationship, characterized by honesty, respect, and sense of obligation, is the ideal for which practitioners should strive. Carper's (1979) description of the contractual model as the basis of an ethic of care more clearly 
resembles a covenantal relationship as described by May (1969) and Stenberg (1979).

Stenberg (1979) examined the four concepts of code, contract, context, and covenant and concluded that covenant should be the foundation of nursing ethics. Covenantal relationships are characterized by mutuality and a promise by the practitioner to act in the best interests of the patient. According to May (1969), a religious ethicist, covenantal relationships originate in the biblical tradition but can also be seen in the Hippocratic oath. As a grounding for nursing, covenantal ethics is compatible with practice accounts of morality in that a high degree of skill and recognition of the uniqueness of the patient are elemental. Similar to Benner's (1996) conception of nursing expertise encompassing both clinical and ethical skill, May (1969) wrote:

Covenantal fidelity to the patient remains unrealized if it does not include proficiency. A rather sentimental existentialism unfortunately assumes that it suffices for human beings to be "present" to one another. But in crisis, the ill person needs not simply presence but skill, not just personal concern but highly disciplined services targeted on specific needs (p. 138).

Gadow (1980) also proposed that the care imperative is central to a theory of nursing ethics and is manifested in attending to the objectness of persons without reducing them to the moral status of objects. This is accomplished through advocacy, subjectivity, and embodied knowing. Reflecting themes explicated in the women's studies literature by Gilligan (1982) and Noddings (1984), Gadow asserted that the moral quality of caring emerges from the idea of commitment to a particular end and the protection and enhancement of human 
dignity. Valuing the individual within the context of life's narrative rather than a generalized other forms the basis of the ethical response.

Similarly, Fry (1989) posited that, because it is derived from the nursepatient relationship, caring is the foundation of nursing ethics. To clarify a route to the development of a representative theory, Fry reviewed three individual models of caring proposed by Noddings (1984), Pellegrino (1981), and Frankena (1971). She concluded that elements of both Nodding's and Frankena's model have relevance for an ethical theory that would provide a moral role for nursing in the delivery of health care. Noddings' assertion that (ethical) deliberation begins with receptivity, relatedness, responsiveness, and consideration of contextual particulars is congruent with a caring ethic. Similarly, Frankena's moral point of view model, which requires that ethical response be based on an attitude of respect for human dignity, reflects nursing's conception of person.

While Yarling and McElmurry (1986) concurred with Fry's (1985) notion of the nurse-patient relationship as the basis for nursing ethics, they argued that the nature of the hospital organization consistently undermined that relationship. Consequently, they concluded that nurses (specifically those who practiced in hospitals) are not free to be moral. To reclaim this relationship, the authors asserted that nurses must have a strong sense of professional autonomy and a primary commitment and accountability to the patient, not the hospital or physician. If nurses are unable to obtain more power in hospitals, Yarling and McElmurry maintained they must "terminate employee status with the hospital, 
move outside the hospital, and serve hospital patients from the vantage point of some new nursing-controlled organization" (p. 72).

Yarling and McElmurry (1986) also noted the history of nurses as social reformers and believed that an appeal to this historical tradition is necessary "if nursing ethics is to become more than a footnote to medical ethics" (p. 73). They observed the power of narratives in shaping our nursing identities:

Even older nurses volunteer stories about ethics from early in their careers about patients who suffered serious harm or injury, which they thought might have been prevented if they had acted more aggressively. They are stories in which the nurses felt helpless and painfully compromised. Why do nurses tell these stories? Because they represent the symbolic socializing events through which their moral predicament was revealed to them in its full-blown dimensions. Although largely repressed, these are the experiences around which young nurses formulate their professional identity, however fractured that image may be (p. 69).

In a paper entitled "Nursing Ethics in an Age of Controversy", Bishop and Scudder (1987) responded to Yarling and McElmurry (1986) with a moral stance based on a view of the nurse as the "in-between" person charged with the day-today care of the patient. This is a phenomenological perspective that attends to the lived moral experiences of nurses in which they occupy the nexus of connections between physicians, the institution, and patients. The authors contended that this is a powerful position based on the conception of nursing practice as care, which stands in sharp contrast to the medical model of cure. Bishop and Scudder (1987) rejected the interpretation of autonomy advanced by Yarling and McElmurry (1986) as it appeared equivalent to a principle-based ethics and note: "In our desire for nursing autonomy, we cannot ignore the moral 
stance already present in nursing, the opportunities to reform health care from within, and the privileged in-between position of nurses in reaching moral decisions" (p.36).

Brody (1988) maintained that caring is a basic nursing virtue, which is not a personal phenomenon but rather a professional obligation. In this conceptualization, the focus is on the character of the nurse as a moral agent as opposed to evaluation of specific acts or outcomes. She proposed that the actor's understanding and valuing of relationships are crucial to the identification of appropriate ethical actions. Brody used caring to demonstrate how virtue ethics, described as personal attribute, actions reflective of the nurse's personal nature, and actions that meet the nurse's role obligation, can be applied to nursing practice.

Watson (1992) incorporated the writings of the feminist moral philosopher, Warren (1989), as well as those of Gilligan (1982) and Noddings (1984) in her definition of an ethics of care for nursing. She posited caring as a moral ideal in which there is a focus and a commitment to the particular experience of specific persons in concrete circumstances wherein intersubjective sensitivities are evoked and engaged. Watson (1992) proposed that traditional principled ethics relies on the language of abstract rights and conceptions of obligation formulated independently from specific contexts. These approaches do not reflect or account for the narrative relational moral discourse or "different voice" of the feminine perspective elucidated by Gilligan (1982) and consonant with the nursing 
discipline. Within an ethic of care, choice is contextually bound, interdependence rather than autonomy is valued, and moral agency involves self with others, not self-sufficiency.

An exploration of the writings of the aforementioned authors reveals, in general, a common objective. In articulating a foundation for nursing ethics or a moral stance, they are motivated by disavowal of the relevance of traditional, prescriptive doctrine for nursing practice. Kantian (1959) and Rawlsian (1971) thought, exemplified respectively in deontology and utilitarian justice theory, is reductionist, dualistic, and positivist in nature. Individuals are perceived as dichotomous (mind/body), separate from their environment, and much like one another. Rigorous impartiality is viewed as essential to equitable moral deliberation and generalizable outcomes.

In contrast, it is evident that elements of holism, humanism, and existentialism underlie these authors' philosophical assumptions and the concepts of care and caring form the foundation of several of their arguments. As Morse et al. (1991) clearly demonstrated however, the diverse definitions of caring in nursing remain imprecise, often lack clarity, and tend to confuse. Sherwin (1992), a feminist moral philosopher, has also asserted that it is necessary to be wary of the implication of gender traits within a sexist culture and warned against the acceptance of dualism 
(caring $=$ feminine, justice $=$ masculine) in ethical thought. She maintained that perpetuation of this dichotomy limits the ability to think creatively about genderneutral ethical and power structures.

While it is evident that an ethic of care may have the potential to counter forces in health care that objectify and dehumanize patients, application of a unitary concept may be premature and unreflective of reality. Actualizing an ethical foundation for nursing that includes caring and avoids features of oppression and exploitation will depend on several factors. Among these is the emergence of caring as a political philosophy capable of transforming institutions within which nursing is practiced. To be relevant, caring must be brought out of the private realm into the public domain where it is valued as part of moral, and not just personal, life (Condon, 1992). Ten Have (1994) proposed the fundamental question for ethics is not so much "what to do" as "how to live". Perhaps the role of nursing ethics should not be to explicate and apply theories and rules but rather to interpret and evoke what is implied in lived moral experience.

\section{Empirical Ethics Literature}

Penticuff (1991) and Fry (1991) have contended that the development of nursing ethics has not coincided with that of other disciplines in terms of foundational concepts, substantive content, and empirical investigation. These authors suggested that this delay may be attributed to an inadequate conceptualization of nursing practice and the factors that influence decision- 
making. The perception of nursing ethics as a subcategory of biomedical ethics and not a distinct field of inquiry is reflected in those circumscribed theoretical frameworks that have guided descriptive nursing ethics research. As Penticuff (1991) noted, the majority of these studies attempted to explain nurses' ethical decision-making and moral behavior utilizing components derived from bioethical theory, moral development theory, or a limited version of role conception theory. A review of studies from each category will be described.

\section{Studies Using Bioethical Theory}

Studies that utilized a bioethical principles framework attempted to explain the ethical practice and decision-making of nurses in terms of four primary principles, identified in the literature as: (1) beneficence, (2) respect for autonomy, (3) justice, and (4) nonmaleficence (Beauchamp \& Childress, 1989; Englehardt, 1986). Reliance on principles to guide and justify action has been criticized by Clouser and Gert (1990), who maintained that principles are not direct imperatives representing unified, harmonious theories but merely a collection of suggestions and observations. These criticisms seem relevant to those studies that find significant transgression of these principles in nursing practice.

Akerlund and Norberg (1985) employed a phenomenological design in an endeavor to describe informants' experiences of feeding severely demented patients. The study was comprised of 39 health care workers, including registered nurses, mental health nurses, practical nurses, and nurses' aides, in a 
psychogeriatric clinic in Sweden. When severely demented patients were unable to take food or fluids voluntarily, the staff was required to feed them. This was not considered a dilemma as long as a patient was able to speak. When the patient became unable to express his/her concerns and preferences, the nursing staff experienced distress because of difficulty in "interpreting his behavior" (p. 231) and the possible necessity of force-feeding. The participants struggled with the meaning of force-feeding, which was generally equated with physical violence, i.e., holding the patient' s head while forcing the spoon into his/her mouth.

Akerlund and Norberg (1985) grouped the nurses according to which ethical rule they used to guide their behavior. Group \#1 were those respondents who adhered to the rule "Keep people alive" (beneficence), who did not experience anxiety and who did force-feed. Group \#2 followed the same rule but understood that they might be causing the patient to suffer (nonmaleficence). These nurses were concerned about choking a patient and their inability to understand what the patient felt. Those in group \#3 were guided by the rule "Don't cause the patient suffering" while at the same time realizing that the primary task was to "keep the patient alive". These caregivers had few fears of choking patients and interpreted "Keep the patient alive" as a task rather than an ethical rule. "Don't cause suffering" was the rule guiding group \#4. According to the researchers, members of this group expressed minimal anxiety and were emotionally distant from the patients. 
Akerlund and Norberg (1985) concluded that the nurses' distress resulted from their inability to reason accurately and apply formal ethical theories to resolve their dilemma. This interpretation is limited in that it does not acknowledge that care can be violated while adhering to ethical rules and that a formal deontological ethic fails to capture much of what is important in the actual practice of nursing. In a care-centered practice, the particularities of the patient are what are valued and this begins with accepting the phenomenal reality of the patient's suffering (Liaschenko \& Davis, 1991). The nurses in the Akerlund and Norberg (1985) study were concerned with the particularized knowing of their patients and experienced conflict when this knowing was made more difficult through the patients' loss of speech.

In a study designed to examine nurses' attitudes toward aggressiveness of care for hospitalized patients who did not want to be resuscitated, Shelley, Zaherchak, and Gambril (1987) found that $28 \%$ of the sample would still have admitted a patient to the intensive care unit (ICU) despite the patient's request not to be resuscitated. The 95 staff nurses (91 females, 4 males) composing the sample were employed in four urban hospitals. Forty-five percent were ICU nurses and 55\% were medical-surgical nurses. Forty-three percent had BSN degrees, $4 \%$ had MSN degrees, and the remainder of the sample was diploma or associate degree graduates. They ranged in age from 23 to 59 years and averaged 6.6 years of work experience as nurses. The respondents were randomly assigned one of four vignettes that depicted a specific patient situation. 
The nurses were instructed to read the description and then indicate how they would care for that patient by responding to a 13-item Likert scale that measured aggressiveness of the selected interventions. The investigators replicated the study with two additional samples, undergraduate, $(n=115)$ and graduate $(n=68)$ students and intensive care nurses $(n=86)$ and found similar results.

Shelly et al. (1987) concluded that more clearly delineated cardiopulmonary resuscitation policies that address provision of comfort care are required. Although the principle of respect for autonomy is not specifically addressed in this investigation, it is significant that it was not a direct imperative for nurse decision-making for many participants. Further inquiry is required to determine the reasons why nurses might feel justified in ignoring patient autonomy and the situations in which disregard for patients' decision-making prerogative occurs.

Bioethical theory has been termed "formula ethics" because the principles are applied in a prescriptive or a process-dominated manner that emphasizes impartialism and decontextualization while ignoring the primacy of human relationships (White, 1993). Penticuff (1991) maintains that studies that employ instruments derived from principles contained in the American Nurses' Association (ANA) (1994) Code for Nurses fall within this category of "formula ethics" research.

Ketefian's (1981) Judgment About Nursing Decisions (JAND) was designed to embody ethical nursing behaviors advocated in the ANA Code of 
Ethics. The JAND consists of six vignettes depicting situations followed by a list of five to seven nursing actions. Several studies have employed this tool as the standard for measuring nurses' ethical choice and ethical action. Ketefian (1985) reported a small correlation between ethical behavior as measured by the JAND and professional role conception $(r=.30 ; p<.001)$ in her investigation of 217 practicing nurses. Similarly, Cassidy and Oddi (1988) found a very small correlation $(r=.05 ; p<.02)$ between professional autonomy and ethical behavior in their study of four levels of female nursing students $(n=130)$.

The JAND applies principles to hypothetical dilemmas without consideration of those contextual factors that may enter into decision-making. The results of several studies suggest however, that a qualitative approach might be more suitable to the description of a relational nursing ethic that integrates relevant bioethical principles.

Omery (1985) used a phenomenological approach to describe the ethical decision-making of female adult intensive care nurses. Two types of decisionmaking were identified: (1) sovereign and (2) accommodating. Sovereign decision-makers used self-chosen principles to guide actions while accommodating subjects adapted their decisions to the norm of the dominant group. Care of the self and others, however, was the pervasive theme identified in the narratives. Although the principles of justice and fairness were important to the informants' decisions, they were subordinate to the concepts of honesty, 
responsibility, and care. Omery found that the most significant factor influencing the deliberative process was the context of the dilemma.

\section{Studies Utilizing Moral Development Theory as a Framework}

Research studies using moral development theory as a framework generally endeavored to correlate ethical choice with levels of moral reasoning as measured by instruments derived from Kohlberg's $(1981 ; 1984)$ justice-based model. Three instruments have been developed to determine the level of moral reasoning based on Kohlberg's identified stages: (1) the Defining Issues Test (DIT) (Rest, 1976), a multiple choice, objective, self-administered test that requires the respondent to rate and rank stage-relevant statements; (2) the Moral Judgment Interview (MJI) (Kohlberg, 1981; 1984), which requires subjects to generate verbalizations in response to open-ended questions that focus on situations of conflicting rights and distribution of scarce resources; and (3) the Nursing Dilemma Test (NDT) (Crisham, 1981) which is based on the DIT but measures moral reasoning in nursing situations.

One of the first studies on moral reasoning and ethical decision-making in nursing was conducted by Murphy (1981). She used the MJI developed and refined by Kohlberg $(1981 ; 1984)$ to explore differences in moral reasoning related to positions of authority in the clinical setting. There were 60 female subjects in the convenience sample, ranging in age from 23 to 58 years. Thirty subjects were employed as staff nurses in both hospital and community settings 
and 30 subjects were head nurses in the same areas. All subjects had a baccalaureate degree in nursing.

Murphy's (1981) findings indicated that $95 \%$ of the respondents were at level II, or the conventional stage of moral reasoning. Murphy's expectation that the nurses would be at level III (postconventional) based on their age, educational level, and occupational status was not supported. These results, Murphy (1981) suggested, corroborated Kohlberg's $(1981 ; 1984)$ assertion that females may be developmentally deficient in moral reasoning. However, they contradicted the assumption that advanced education and environmental stimulation may contribute to higher stage attainment.

Mayberry (1986) endeavored to explore the relationship between levels of moral reasoning of staff and head nurses and: (1) educational preparation, (2) length of experience, (3) age, and (4) hospital size. The volunteer sample consisted of 130 staff nurses and 37 head nurses ranging in age from 21 to 46 years. There were 163 female and four male participants. The DIT was used to ascertain the levels of moral reasoning. Educational level was positively correlated with a principled reasoning approach, most often exhibited by staff nurses with a baccalaureate degree. years in practice and work environment were negatively related, however, with the more experienced staff and head nurses demonstrating lower levels of judgment. Mayberry concluded that organizational factors, which often prescribe behavior and foster conformity, might serve as barriers to ethical decision-making. 
Ketefian (1981) also employed the DIT to describe the relationship among critical thinking, educational preparation, and moral judgment of 79 practicing nurses. The Watson-Glaser Critical Thinking Appraisal Test was used to measure critical thinking. The subjects ranged in age from early twenties to midfifties; most were female and employed in a hospital setting.

The findings were similar to those of Mayberry (1986). Those individuals with professional nursing education exhibited more principled levels of reasoning than those who had received technical preparation. Higher levels of critical thinking were also correlated positively with advanced moral judgment. Ketefian proposed, however, that the relationship between moral reposing and ethical action in actual practice remains unclear because of lack of conceptual clarity and limitations of instruments that depict hypothetical situations. She suggested that multivariate research strategies and multiple measures are necessary to explain the complex factors that influence ethical decisions.

Using the NDT developed by Crisham (1981), Winland-Brown (1983) found that critical care nurses $(n=45)$ had higher principled reasoning scores than medical-surgical nurses $(n=50)$ and nonnurse adults $(n=50)$ on two of six hypothetical dilemmas presented. Again, advanced education was positively associated with postconventional judgment. Unlike Mayberry's (1986) subjects, however, those nurses with more years of professional experience scored higher on principled thinking. 
Cox (1985) also used the NDT to determine the moral development level of 103 critical care nurses and found that those with less than five years experience had higher principled thinking scores. Education was not found to be associated with postconventional reasoning.

The inconsistent research findings cited regarding the moral development of nurses reflect the existing controversy in the literature over the efficacy of Kohlberg's $(1979,1984)$ framework for nursing and women. The controvertible empiric relevance can perhaps be attributed to several factors. These include: (1) the omission of women from the original investigation and the resulting gender bias in theory development and instrumentation, and (2) the questionable comprehensiveness of the underlying conception of morality as justice (Nokes, 1989).

The recurrent phenomenon of stage arrest of the majority of females at level II (conventional) reasoning exhibited in many nursing and other studies may be related to women's lack of representation in Kohlberg's (1981) initial sample or a different interpretation of ethical conflict. It is also equivocal as to whether or not a universal moral development model can be based on the limited portion of identified ethical principles depicted in the vignettes.

Another concern is the assumption that responses to hypothetical situations are the same or similar to the reasoning used in real-life situations. The results of several studies (e.g., Damon, 1977; Gilligan \& Belenky, 1980) indicated that subjects used a level of moral reasoning for an actual situation different from 
that which they used for a fabricated scenario. Consequently, responses to hypothetical dilemmas such as those employed in many studies using Kohlberg's $(1979,1984)$ moral development theory as a research framework may not accurately represent the elements of deliberation or ethical practice.

\section{Studies Utilizing Role Conception Theory as a Framework}

In several research studies designed to explore the nurse's role in ethical decision-making, the theme of powerlessness resonates throughout the informants' narratives and responses. Erlen and Frost (1991) employed a qualitative method to determine how nurses perceive their role when they are confronted with ethical dilemmas. The convenience sample consisted of 25 nurses (22 females and 3 males) between the ages of 22 and 49 years. Twentytwo respondents were staff nurses; the other three were employed as assistant head nurse, supervisor, and clinical nurse specialist respectively. The level of education and experience varied. Twelve informants worked in a critical care setting and 13 worked on a general medical-surgical unit.

The researchers (1991) used an interview schedule in which informants were asked to describe a situation that they considered to be an ethical dilemma and discuss the reason(s) why the situation was troubling, the nursing action taken, and the factors influencing that action. Results of the content analyses indicated that $84 \%$ of the respondents included descriptions of powerlessness. Perceived powerlessness occurred whenever there was physician dominance, lack of supervisory or institutional support, and inadequate recognition of nursing 
knowledge related to the patient. The nurses were unable to pursue collaborative decision-making because they were not viewed as colleagues and their knowledge of and contribution to patient care was devalued. The authors concluded that the nurses' inability to participate in or effect an ethical resolution engendered anger, frustration, and exhaustion. These feeling were perceived by the respondents regardless of age, educational preparation, and/or length of work experience.

Elizondo (1991) found similar results in a study conducted with 60 registered nurses employed in Level III neonatal intensive care units (NICUs) located throughout the United States. Employing an author-designed, selfadministered questionnaire that used a combination of multiple-choice and openended questions, Elizondo endeavored to determine the nurses' participation in and satisfaction with ethical decision-making. Sixty percent of the informants had a baccalaureate degree in nursing and $11.7 \%$ had a master's degree. The average amount of Level III NICU experience was 6.9 years.

The researcher (Elizondo,1991) reported that 53 subjects $(88.3 \%)$ stated that they were unsatisfied with their ability to participate in ethical decisionmaking. They indicated that the unique "particular knowledge" (p. 55) they possessed of their vulnerable infant patients was ignored or deemed insignificant. Elizondo concluded that, to prevent nurse attrition resulting from dissatisfaction, erosion of moral integrity, and burnout, nurses should be encouraged to present this particular knowledge at case conferences. 
Martin (1989) used an exploratory design to determine the extent and the nature of registered nurses' $(n=83)$ participation in the resolution of treatment dilemmas for infants with severe congenital anomalies. Seventy percent of the informants reported feelings of stress and ethical anguish related to their lack of involvement in the withdrawal of aggressive treatment and the subsequent prolongation of infant suffering. As in Elizondo's (1991) study, the nurses in Martin's (1989) study perceived that the "encyclopedic knowledge" (p.468) they gained of the patient through intense, comprehensive, primary care was ignored or considered irrelevant.

In this study, (Martin,1989) the small group of nurses $(n=13$, or $15 \%)$ who reported that they were directly involved in the decision-making process regarding life-sustaining treatment tended to be older, had more clinical experience, and had an advanced or graduate education. In a commentary that has relevance for the proposed study, Martin concluded that these nurses might be similar to the expert defined by Benner (1984) who is able to explicate tacit knowledge, has mastered the art of collaboration, and thus creates an ethical practice environment.

\section{Studies Exploring Expertise in Nursing}

Research studies exploring clinical expertise in nursing include examination of the decision-making processes of the participants, the effect of expert practice on patient care/outcome, and the influence of the expert nurse on the care provided by his or her co-workers. While experts comprise the entire 
sample in several studies, they are compared to novice or intermediate participants in others. Recipients of expert care range from the neonate to the gerontologic patient and settings encompass the intensive care unit to the patient's home. Although nurses conducted the majority of studies reviewed, several investigators from other disciplines, including sociology and medicine, have recognized and explored the phenomenon of expertise in nursing.

The forty investigations reviewed employed either information-processing theory or an intuitive/qualitative model as an organizing framework or examined the ethical practice of expert nurses. The eighteen studies exploring information processing of expert nurses analyzed influencing factors such as years of experience, education, and task complexity. The findings of these studies suggest that expert nurses demonstrate cognitive elements of expertise as discussed in Chapter I, including acute perception and superior problem-solving. While the association of cognitive elements to ethical expertise has relevance for the present study, identification of their presence is not the specific purpose. Consequently, an exhaustive analysis is not provided.

The review has two sections with the first examining clinical expertise using an intuitive and/or qualitative model as an organizing framework and the second exploring the ethical practice of the expert nurse. The studies are presented according to year of publication.

Appendix A contains a synopsis of all the studies reviewed. They are categorized by organizing framework and arranged in alphabetical order. 


\section{Studies Using An Intuitive and/or Qualitative Model}

The studies reviewed in this section explore the relationship between expert nurses' intuition and clinical decision-making and/or use a qualitative method to identify or describe processes by which nurses make decisions in the care of patients with specific problems. Several studies also describe the defining attributes of expert nurses working in a specific practice area.

The assessment and decision-making processes of twenty-eight experienced critical care nurses in the early detection and prevention of cardiogenic shock in patients experiencing acute myocardial infarction was explored by Pyles and Stern (1983). Employing grounded theory methodology, the researchers (Pyles \& Stern, 1983) described the process used by these nurses to determine whether a patient was developing cardiogenic shock as "Nursing Gestalt". The authors defined Nursing Gestalt as a "synergy of logic and intuition involving both conceptual and sensory acts..........whereby nurses link together basic knowledge, past experiences, identifying cues presented by patients, and sensory cues including gut feelings" (pg.52). While acknowledging the explanatory potential of certain elements of information processing theory in this explication, Pyles and Stern (1983) proposed that Nursing Gestalt involved much more than cue discrimination. They maintained that "gut feelings", or the ability to recognize that the patient was "falling out of the pattern", and the nurse's intuition, which is unrelated to specific clinical cues, is the essence of the 
art of nursing. This further elucidation of Nursing Gestalt suggested a similarity with de Groot's characterization of pattern recognition in chess mastery.

In addition to this early description of expert practice, Pyles and Stern (1983) also addressed the effect of Nursing Gestalt on patient outcome and the practice of co-workers. Because of the difficulty some participants experienced in communicating their "gut feelings" and/or the lack of physician belief in their perceptions, patients would often suffer adverse consequences including cardiac arrest. The investigators characterized the expert clinician's relationship as a mentor to the novice critical care nurse as the Gray Gorilla Syndrome, a reference to Fosse's (1971) depiction of the silverback primate who serves as leader-protector-teacher for his group. In concluding, Pyles and Stern (1983) suggested that the practice of the novice cannot advance without the presence of the Gray Gorillas.

Intuitive perception has been described by Benner (1984), Rew (1987), and others as characteristic of the nurse expert who acts on knowledge that comes to him or her holistically rather than in fragmented, incremental steps. Schrader and Fischer (1987) endeavored to explore when, and under what circumstances clinicians who practice in a setting that values logic, hard data, and detachment, such as the neonatal intensive care nursery, suspend their belief in biomedicine and act on their intuitive knowledge.

Schrader and Fischer (1987) interviewed fifteen staff nurses who provided care to the most critically ill newborns and were employed in one intensive care 
unit in a large university medical center. The investigators also used participant observation and examination of primary documents to identify use of intuitive knowledge.

Analysis of the data indicated that use of intuitive knowledge was characterized by four themes: in-depth knowledge and wide experience; feelings of relatedness to the infant; perception of the individual infant's physiologic cues; and, linkage of present perceptions with experiences. These investigators (1987) observed that intuitive thinking was found in the most experienced, technically proficient nurses who were not always sensitive to some of the caring dimensions of neonatal nursing such as parental support. The theme of relatedness encompassed feelings of love for the infant, loss at the prospect of the child's dying, and happy anticipation in coming to work to care for the infant. The investigators proposed that the expert nurses' ability to perceive the infant's individual, subtle cues and then make valid clinical judgments was based on "knowing" the infant. Cues were often physiologically based but difficult to quantify. Similar to the nurses in Anspach's (1987) study, these participants spoke of such qualities as color, activity level, movement, tone, and posture. Linking present perceptions with past experiences or pattern recognition also enabled these nurse experts to anticipate future events and take action, Unfortunately, Schrader and Fischer (1987) also noted that the respondents' intuitive knowledge was often denigrated resulting in feelings of self-doubt and stress. Those nurses who persisted until someone listened to their "gut feelings" 
or "nursing gestalt" (Pyles and Stern, 1983) displayed risk-taking, strength of conviction, and mastery of clinical practice.

Smith (1988) endeavored to identify and characterize the phenomenon of "deterioration" as it occurred among critically ill patients and was perceived by experienced critical care nurses. The investigator noted that the nurses' awareness of this change in patient status occurred before actual alterations in common physiologic indicators (i.e., physical assessment data, vital signs or hemodynamic findings) and was a response to a "feeling state" or an identifiable sense that the patient "just doesn't look good".

The researcher, (Smith,1988) administered an open-ended interview questionnaire to the six expert participants. The tool contained thirty-four items developed from the concept clarification techniques delineated by Norris (1982) and began with a three-sentence introductory statement describing the investigator's conceptualization of deterioration without specifically identifying the phenomenon by name. The open-ended questions addressed the expert nurses' experiences and interventions.

All the participants in Smith's (1988) study indicated that they had experienced the phenomenon described in the introductory statement of the interview. Situations exemplifying the phenomenon of deterioration included patients with gastrointestinal bleeding, respiratory failure, multisystem failure, severe abdominal trauma, and head injury. Responses indicated an initial period of stability in which no alterations were observed followed by a premonition, in 
which the nurses identified nonspecific, felt changes. When asked whether these felt changes were important to them, the nurses responded, "I'd rather rely on my gut feelings and be proved wrong than ignore it"; and "We ignore a real strong cue when we don't respond to our intuitive feelings" (p. 13). The participants attempted to corroborate their subjective awareness of change with objective evidence through reassessment and peer confirmation. Smith (1988) observed that this process of close searching resulted in gradual pattern recognition.

Comparable to the nurses in other studies in the present review, the participants in Smith's (1988) investigation made reference to the difficulty they had communicating their subjective sense of patient deterioration to physicians. More clinically expert practitioners were more likely to use confrontational strategies to achieve the physician response deemed appropriate in the situation.

Smith (1988) concluded that practice decisions require the nurse to perceive the state of the patient continuously and cues emanate from any of several domains: the physiological, emotional, spiritual, cognitive, and interactive. The transitional process of deterioration and the expert nurses' coming to know of the transition incorporated all these domains.

Brykczynski (1989) employed a phenomenological perspective to describe the knowledge embedded in the clinical practice of twenty-two experienced nurse practitioners who practiced in four hospital based ambulatory care settings. The themes identified by Bryczynski (1989) were assessment expertise, vigilance, patient advocacy, intimacy, continuity of care, and demystification of health care. 
The themes were then interpreted in terms of Benner's $(1983 ; 1984)$ aspects of practical knowledge and domains and competencies of nursing practice. As one component of clinical knowledge, (theoretical knowledge being the other) practical knowledge is that which is not necessarily explicit and addresses:

embodied ways of knowing that show up in our skills, our perceptions, our sensory knowledge, and our ways of organizing the perceptual field...these bodily perceptual skills, instead of being primitive and lower on the hierarchy, are essential to human problem-solving which relies on recognition of the whole (Benner, 1984, p.156).

This embodied way of knowing was evident in the assessment expertise of the participants that included the ability to detect subtle, context-dependent changes in patients. Bryczynski (1989) describes how one nurse practitioner used herself as a "personal barometer" by attending to feelings of anxiousness, discomfort, and incompleteness experienced with a patient whose complaint was excessive sleepiness. Although the narcolepsy work-up was negative, the nurse practitioner sensed that "something's not right here" and continued to search for an accurate clinical diagnosis that ultimately turned out to be an inoperable glioma. As a result of pattern recognition and experience with different situations involving patients with varying degrees and types of symptoms, this nurse was able to discriminate among ambiguous perceptual cues.

The purpose of Jacavone and Dostal's (1992) descriptive study was similar to that of Guyton-Simmons and Mattoon (1991), to explore the judgment of expert coronary care nurses in the assessment and management of cardiac 
pain. Jacavone and Dostal (1992) however, compared the expert participants' $(n=4)$ judgment with an additional group of novices $(n=4)$.

Each nurse was observed and informally interviewed during care for at least one patient in the coronary care unit. In addition, each nurse subject was formally interviewed three separate times by the investigators. The initial formal interview centered on a paradigm case identified by the nurse as influencing his or her practice. The two subsequent interviews dealt with a recent event in which the participant had cared for a patient experiencing cardiac pain. Jacavone and Dostal (1992) then compared the novices' descriptions of their actions and thought processes with those of the experts' in similar situations. The authors proposed that this contrast provided the opportunity for negative case analyses in interpreting the experts' descriptions.

These investigators found that the expert nurses in their study possessed an intimate knowledge of the actions of vasoactive drugs and the safe and effective range of infusion rates. They used aggressive titration to alleviate the ischemic process without compromising the patient's condition. In contrast, novices were more passive and hesitant with titration. Similar to the experts in Guyton-Simmons and Mattoon's (1991) study, these experts maintained a constant presence during episodes of cardiac pain and were able to recognize each patient's individual physiologic response to interventions.

Jacavone and Dostal (1992) used Benner's (1983) description of "qualitative distinction" as "the keen perception of subtle physiologic changes" 
(p.58) to explicate the expert nurses' observations of common patient responses to cardiac pain. Experts were fully involved in the situations and focused on the patients' experience, not their own role. In contrast, beginners frequently concentrated on their role, actions, or inaction in similar situations, rather than on the patient.

Jenny and Logan (1992) endeavored to identify contextually specific, actual expert nursing judgments, decisions, and actions during the mechanical ventilation weaning process. Data consisted of transcripts of interviews with the sixteen expert subjects based on their written descriptions of critical incidents from recent weaning experiences. During the interviews, nurses elaborated on the incident and its ramifications, including their rationales for actions and outcomes. Data analysis yielded the core process of "knowing the patient" and it's associated sub-concepts or variables. The five variables delineated were: context, causal conditions, intervening conditions, strategies, and consequences. Conditions affecting the knowing process included specific patient attributes, amount of time spent with the patient and the nurses' professional expertise and empathy.

The particularistic knowledge acquired through knowing the patient enabled the nurse experts to make a series of judgments about the nature of the patients and their clinical status that directed selection of the most therapeutic approaches and provided individualization of care. Jenny and Logan (1992) also proposed that the phenomenon appears to address the four patterns of knowing 
delineated by Carper (1978): empirics, esthetics, personal and moral knowledge. The expert nurses' scientific knowledge of disease, illness, and the technology of weaning constituted their empirical knowing and directed the focus of the knowing process. Esthetic knowing was evident in the nursing actions tailored to meet specific patient's needs while personal knowing was reflected in the nurses' therapeutic use of self. Finally, the moral knowing of the expert nurses in Jenny and Logan's (1992) study was expressed in their respect for the individuality of each patient and in their attempts to promote holistic comfort and avoid distress.

McMurray (1992) endeavored to develop a model of expertise derived from identification of the characteristics and factors influencing clinical expertise in community health nurses practicing in district nursing, school health, and child health in Perth, Australia. The thirty-seven participants included nine experts from each of the three practice settings $(n=27)$ and ten novices.

Using observation, interviews, and respondents' written retrospective accounts of critical incidents, McMurray (1992) identified emerging themes and then compared them between and within groups until the common and unique characteristics of each were circumscribed. The investigator reported that the findings related to novice-expert differences in diagnostic reasoning were similar to those of Tanner (1984) and Benner and Tanner (1987). Novices tended to stereotype situations based on pre-encounter information, often used a single cue, either very global or very specific, to trigger a hypothesis and ignored those that did not fit. In contrast, experts used cues patterns to generate hypotheses at 
varying levels of abstraction and held those cues that could not be "chunked", or did not fit, in reserve for later exploration.

The novice nurses in McMurray's (1992) offered indiscriminate reassurance to clients that resulted in controlling the conversation in the direction of their hypothesis rather than acting as a stimulus for further discussion. Experts avoided premature closure and encouraged clients to express concerns and complaints. Novices' overestimation of the value of confirming data on their favored hypothesis, and under valuation of disconfirming data, often resulted in inappropriate evaluation of hypotheses.

The researcher (McMurray, 1992) concluded that the development of expertise in community health nursing was influenced by education, experience, and personal factors. Educational factors included continuing education and formal study towards gaining a specialist credential, such as in midwifery or child health. Role models provided an additional educational factor, and according to study subjects, life experiences such as parenting and travel. Personal factors identified as instrumental to the development of expertise in these nurses included motivation, receptivity, and self-confidence.

Crandall and Getchell-Reiter (1993) endeavored to describe the intuitive, experienced-based knowledge of expert neonatal intensive care unit nurses using a knowledge elicitation method based on Flanagan's (1954) critical incident technique termed the Critical Decision Method (CDM). This technique employs recollection of a specific, non-routine event in the expert's work environment as 
its starting point followed by a semi-structured interview with specific probes designed to elicit certain types of information from the respondent. Solicited information includes: goals; options that were generated, evaluated, and eventually chosen; cue utilization; contextual elements; and situation assessment factors specific to particular decisions (Crandall and Getchell-Reiter, 1993).

The purpose of this investigation (Crandall and Getchell-Reiter, 1993) investigation was to develop a detailed, specific description of the cognitive processes that surround the assessment and care of critically ill infants. Participants were $17 \mathrm{RNs}$ employed in the NICU of an urban, regional referral center. Each nurse was asked to select an incident in which she believed her presence made a difference to the patient's outcome and also provide a second case in which her own clinical judgment had pointed in a different direction from technologic indicators. Incidents were then coded for the occurrence of three categories of information: the number and variety of discrete assessment categories attended to; the type of assessment indicator (perceptual, diagnostic, telemetry, medical history); and the type of judgment used in patient assessment (normative, ipsative, or cue discrepancy).

Across the thirty-three incident accounts obtained by Crandall and Getchell-Reiter (1993), the clinical event that nurses discussed most frequently was that of sepsis or systemic bacterial infection. These cases were then used by the investigators to examine the content of expert knowledge provided by the CDM interviews. Results indicated that almost half of the the indicators 
contained in the medical literature were never mentioned in the expert nurses' accounts of sepsis. In addition, some indicators employed by the respondents were not available in the research or training literature. Crandall and GetchellReiter (1993) maintained that this discrepancy resulted from the fact that expert nurses were alert to signs and symptoms of sepsis that occurred very early in the clinical course. Many of the literature-based indicators are symptoms of advanced sepsis such as seizures or purpura. The indicators mentioned by the expert nurses but absent from the literature, required perceptual judgments or alertness to shifts in the patient's state.

Benner (1984) has written that in regard to expert knowledge "any attempt to extract essential features and make them into guidelines is not likely to succeed" (p.177). Using the data obtained from the CDM interviews with the expert neonatal intensive care nurses however, Crandall and Getchell-Reiter (1993) were able to develop a sepsis assessment guide containing pathophysiology, cues, indicators and sepsis incident accounts.

Guyton-Simmons and Thermin (1994) used observation and interviews to determine expert critical care nurses' knowledge and reasoning in the management of acute postoperative pain. Each expert nurse was observed as she provided care to postoperative patients and was interviewed as soon as possible after pain assessment and/or interventions were observed. Data analysis consisted of categorizing the observed behaviors and the subjects' rationales according to the four stages of the nursing process. The categories 
that emerged from the data included: selective assessment; observation; behavioral expressions of pain; physiologic symptoms; questioning; predicting a pattern; differentiating pain; controlling pain; medications; comfort and emotional support; and, notifying the physician.

The authors (Guyton-Simmons \& Thermin, 1994) concluded that the overall approach used by the experts in this study was based on predicting patterns of pain and discriminating between typical and atypical pain. The respondents did not appear to use a traditional model of the nursing process but rather continually monitored and gathered data. These findings were consistent with the elements of forward reasoning, pattern recognition, and prediction discussed in the literature on expertise. Guyton-Simmons and Thermin (1994) employed Benner's model of expert practice as a guiding framework for this study and endeavored to explain the results incorporating Elstein's description of experts' problem solving strategies in cases of varying complexity.

Zerwekh (1994) interviewed thirty expert public health nurses from five health departments in Washington State in an endeavor to describe family caregiving competencies. The investigator asked the participants to relate one or more anecdotes in which they believed home visiting made a difference in the outcome of a family at risk, and to give clinical examples representing the essence of their work in public health nursing.

The researcher (Zerwekh, 1994) used the constant comparative method of grounded theory to identify three competencies described as establishing a 
foundation for their work in the home: locating the family, building trust, and building strength. While locating the family is a unique component of the work of the public health nurse, building trust and strength are essential elements of a helping-healing relationship and demonstrate the skill of involvement described by Benner (1996). The expert nurse is involved in a caring relationship with the patient that recognizes vulnerability, acknowledges emotional investment, and creates the possibility for advocacy. Similarly, Zerwekh (1994) described the competency of building trust as "bonding" and building strength as "affirming and encouraging choice".

Citing Drefus' (1985) contention that an expert does not rely on rules but upon experiences as a pattern for comparison, Buhrer and Mitchell (1996) proposed that important knowledge about risk assessment may be "embedded in expert practice" (p.42). Thus, while clinical guidelines and assessment tools addressing risk for pressure ulcers exist (Norton Scale and Braden Scale), distinct or equivalent knowledge may be gleaned from the practice of experts skilled in prevention.

Using a combined qualitative method described by Swanson-Kaufman (1986), Buhrer and Mitchell (1996) conducted a series of interviews with five expert nurses employed in various areas in one large metropolitan hospital exploring their practice in relationship to pressure ulcers. Accounts of assessment were categorized according to risk factors identified in the Norton and/or Braden scales. The final category, "Other, specify..." assisted Buhrer and 
Mitchell (1996) in sorting out those factors identified by expert nurses that were not included in the formal scales.

Age, serum albumin, hypotension, fever, and time on the operating table were items mentioned by the expert nurses that are not included in the formal assessment scales but are identified in the literature as risk factors for pressure ulcer development. Buhrer and Mitchell (1996) also identified five themes from the interview data: the interconnection of wound healing and pressure ulcer prevention; the importance of the setting of care; the anticipated trajectory of illness; the use of multisensory assessment modalities; and the inclusion of psychosocial risk factors. Similar to expert nurses in other studies, these participants possessed a clear concept of the anticipated course of the patients' problems and used subtle multisensory assessment modalities including smell and touch.

The expert participants in Daley and Miller's (1996) investigation were from one midwestern multi-site home health agency that served both urban and rural clients. In order to provide information about the characteristics of home health care practice at different stages of development, the nurses were asked to write narratives that described an incident that was meaningful to them and descriptive of their practice. Daley and Miller (1996) maintained that narratives are a tool to define nursing practice by capturing the complexity of the interpersonal, ethical, and clinical judgments involved. 
The researchers (Daley and Miller, 1996) identified four major domains of nursing practice in home health care nursing and discovered that each domain developed along a continuum encompassing four levels consistent with Benner's novice to expert schema: (1) assessing and using physiologic and pathophysiological data, (2) initiating and monitoring therapeutic interventions, (3) assessing and using family and environmental data, and (4) integrating data, interventions, and context. In the first domain, Level I nurses (novices) tended to rely on the collection of data from direct assessment of the patient and from records and secondary sources while Level IV nurses (experts) tended to think more inductively and trusted their intuitive judgment. Level I nurses followed planned interventions, communicated according to protocols, and practiced according to the rules. Nurses who were practicing at Level I viewed the family and environment in terms of how similar or different it was from their own situation. Nurses at Level III (proficient) and Level IV incorporated the family and environment in their care and demonstrated acceptance and understanding. In Domain IV, Daley and Miller (1996) observed that although Level I nurses understood the physiological, family, and environmental needs of the patient, they saw them as separate. Level IV nurses practiced holistically and provided seamless integration of individualized care activities.

The investigators (Daley \& Miller,1996), concluded that the results of their study supported Benner's (1984) view that nursing practice exists at multiple levels and develops along a continuum. They proposed that home health care 
practice is learned by immersion in the context of the home and expertise evolves when the nurse understands the multiplicity of relationships between the client, the family, and the environment.

SmithBattle, Drake, and Diekemper (1997) analyzed the narratives of twenty-four expert community health nurses in an endeavor to describe the expertise that is often unrecognized in everyday community health nursing practice. The authors employed interviews and observation of home visits. Participants were asked to describe meaningful clinical situations and experiences that significantly shaped their practice. Regardless of the setting or client focus, individual or aggregate, "the responsive use of self" was identified as a consistent theme that was crucial to the development of a partnership with the client. Responsiveness to the other enabled the expert nurse to gain a "situated understanding" of client's lives and thus identify needs and strengths. The researchers described situated understanding as including openness and respect for client's realities. Rather than prematurely defining needs, the expert nurse works to gain understanding of the client's concerns, beliefs, and values.

McHale, Phipps, Horvath, and Schmelz (1998) employed Dreyfus' model of skill acquisition as interpreted by Benner (1984) as the framework for their study exploring expert nursing knowledge in the care of patients at risk for impaired swallowing. The authors employed three narrative strategies proposed by Benner (1984) to explicate the five expert nurses' practical knowledge: themes, exemplars, and paradigm cases. Five themes were identified in the 
nursing care of patients with impaired swallowing: assessment of swallowing; clinical management; the importance of knowing the patient; quality of life; and, eating as a form of family caring and as a social and aesthetic need. The researchers (McHale et. al.,1998) focused on the first three themes in the article. Of the twelve expert nurses, only three utilized a comprehensive swallowing assessment as described in the literature. These nurses were able to describe the evaluative process they employed before and during feeding which correlated with the mechanics of a normal swallow. The remaining nine experts used creative and intuitive approaches to assess several aspects of patients' swallowing ability such as determining strength of cough reflex.

The expert informants in Radwin's (1998) grounded theory investigation were employed in a thirty-bed cardiology specialty unit. Data collection methods included interviews, participant observation, and written exemplars. The core process of "knowing the patient" occurred when the expert nurses used their understanding of patients' experiences, behaviors, feelings, and/or perceptions to select individualized interventions. This process was enhanced by the nurses' experience that was conceptually defined by Radwin (1998) as "the application of that learned from previous practice situations" (p. 594). As the nurse became more experienced, three attributes developed which related to decision-making in particular ways: a patient centered focus; confidence; and, knowledge of antecedents and consequences. 
As observed in other studies of experts, the nurses in Radwin's (1998) investigation focused on the patient in a given situation rather then on the equipment, technical factors, or other priorities. The informants related that, as experience accrued, they became less centered on their needs and more attuned to what the patient needed. In addition, the nurses developed more confidence as experience accrued. Consequently, they could manage learning about patients' feelings and perceptions, however unpleasant or unhappy. Confidence facilitated the decision-making process and enabled the nurses to consider a broader range of interventions. With experience, the experts in Radwin's (1998) study gained knowledge of what happened before, during, and after patient care situations. Each subsequent situation was no longer a unique event and they could compare and contrast knowledge of the antecedents and consequences of specific past instances with the present. Possibilities were therefore anticipated and deliberation about supportive interventions enhanced. In concluding, Radwin (1998) observed that knowledge about antecedents and consequences was necessary for the development of patterns and configurations. As noted in other studies in this review, patterns were used by expert nurses when considering diagnostic alternatives and often encompassed interventions and their resultant outcomes.

Parker, Minick, and Kee (1999) employed phenomenology to explicate the processes of clinical decision making by expert perioperative nurses, noting that few studies had been conducted in this speciality area. Participants were asked 
to describe any perioperative situation in which they intervened on a patient's behalf and thus affected the patient's outcome.

The authors identified one overriding pattern, "seeing the big picture, engendered through caring", with three themes subsumed under this pattern: making a connection; embodied knowing; and, comprehensive patient advocacy. Every expert perioperative nurse spoke of "seeing the big picture" when they described the importance of thinking beyond the care provided in the operating room area. The technology involved in the situations was mentioned only in passing, as patients were the focus of the stories the nurses conveyed. Many of the clinical decisions described showed an all-encompassing view that transcended the task-focused mind-set that is characteristic of the novice nurse.

The researchers (Parker, Minick, and Kee,1999) concluded that their study revealed the decision-making processes used by expert nurses in the perioperative area and demonstrated their ability to mange difficult technological situations while exhibiting care and concern. Despite necessarily brief encounters, experts made connections with the patients and created a caring atmosphere amidst a technological and demanding environment.

Peden-McAlpine (2000) used narrative accounts of critical incidents involving early recognition of patient problems to explicate the thinking of fifteen expert critical care nurses. Analysis of the narratives yielded common subplots or characteristics reflecting two types of information used in "thinking-in-action", universal and particular. 
The investigator found that universal thinking applied to most patients with specific trajectories of illness, while particular information was specific to a patient situation and characterized by meaningful, contextual, practical, and perceptual types of information. The expert participants were able to interrelate the information and construct temporal pictures of patients' situations. PedenMcAlpine (2000) proposed that this present and past understanding enabled the projection of appropriate possibilities for future action. The nurses then acted ethically to resolve or prevent a problem. The author concluded that the findings of this study extended the literature on "knowing the patient".

Summary

The practice of the expert nurses in this section of the review again demonstrates cognitive attributes of expertise discussed in Chapter I, including automaticity and enhanced recall. Participants also displayed several intrinsic attributes such as motivation and an heroic element. In general, emphasis on the nurse-patient relationship and consideration of context were more prevalent in these investigations of expert practice than those using an informationprocessing framework. These expert nurses often demonstrated evidence of both analytic and intuitive thinking, similar to Hamm's (1988) discussion of a decision making continuum in medicine. Analytic thinking associated with information processing and intuitive thinking have been described as opposite poles on either end of a cognitive continuum (Hammond, 1996). Hamm (1988) proposed however, that expert practice is characterized by integration of both modes.

\section{Studies Exploring the Ethical Practice of Expert Critical Care Nurses}


The authors of the studies reviewed in this section endeavored to describe the ethical practice of expert nurses or explicate expert behaviors or comportment in specific patient care situations. A qualitative methodology was used by all the investigators.

Ray's (1987) phenomenological study of eight expert critical care nurses attempted to elucidate a practice-based account of ethics and also integrate bioethical principles. In explicating the meaning of caring, the participants demonstrated attributes from both the ethics of experience and of principle. The author described the ethics of experience as arising from a moral attitude toward goodness, virtue, and character. In contrast, the ethic of principle has its origin in a respect for cause, basic truth, or the ethic of duty or obligation. Observation and interviews yielded five themes of human caring: maturation, technical competence, transpersonal caring, communication, and judgement/ethics.

In analyzing the caring experience as a whole, Ray (1987) determined that the critical care nurses were able to distinguish right from wrong in the attitudes and behaviors associated with the use of technology. They employed an experiential and principle-based ethic, which enabled them to discern how technology affected the patient. This understanding, which developed as a result of what Ray (1987) termed a maturation process, allowed the nurses to take protective actions against aggressive technological interventions when they perceived the patient was suffering needlessly. Although the nurses in this study believed in the power of technology, they served as mediators when the 
technological regimen became intrusive or futile. Ray (1987) noted that the expert nurses' response to modify the treatment occurred sooner than the physicians' because of their relationship or interconnectedness with the patient. The author designated this behavior "technological caring". Interceding between technology and the person to maintain dignity and prevent suffering is also addressed by Benner (1996) in her discussion of the ethical practice of expert nurses.

Ray (1987) proposed that the nurses in the investigation exercised three prominent bioethical principles: beneficence, justice, and autonomy. These came into play most often when the nurse realized that a patient was suffering and was not being helped by further aggressive treatment. Ray stated that the nurse's extended encounter with the suffering person enabled him/her to realize that allowing the patient a peaceful death was the most compassionate alternative. This decision, the investigator maintained, was based on moral reasoning from human response and the obligations to do good and to do no harm (beneficence and nonmaleficence), to be fair (justice), and to allow choice (autonomy).

Cooper (1993) endeavored to build on Ray's (1987) research. The stated purpose of her study was "to identify and categorize the behaviors and interactions that characterize the moral experience of ICU nurses" (p.24). Data collection included observation of the nine participants, patients, and patient families, in addition to formal and informal interviews with the nurses. Analysis 
yielded four themes, two of which, technology and care, were addressed in this article.

The researcher (Cooper, 1993) stated that several respondents were able to demonstrate technological competence in concert with care. She proposed that this integration enhanced the enactment of care as opposed to impeding it. Within a caring relationship, the competent nurse is able to monitor the impact of technology on the human spirit and temper the insults of technology with care. In concluding, Cooper (1993) noted that these nurses fit the description of the expert cited in Benner, Tanner, and Chesla (1992) who is able to mediate technological interventions in the totality of patients' needs.

Bishop and Scudder (1990) proposed that sound nursing practice has an integral moral sense that fosters the good of the patient by excellent nursing care. In their description of the ethics of practice, they asserted that nursing is concerned with bringing about its inherent good in the world through caring, not the application of science and technology. Because of this inherent moral sense, much of nursing ethics is integrated into everyday practice and comportment and is not labeled ethical decision-making. Citing this assertion, Wros (1994) endeavored to understand the notions of good underlying the excellent nurse caring practices of dying patients in critical care units.

The fifteen informants in Wros' (1994) study were employed in one of five critical care units in two hospitals. The author interviewed the nurses and bereaved family members in separate groups and also used observation. Wros 
(1994) noted that the obtained data contained many narratives describing practices and concerns socially embedded in the moral culture of nursing and specifically related to care of the dying patient. In an effort to capture the complexity of the moral tradition shaping nursing practice, Wros (1994) presented a paradigm case that summarized the meanings, concerns and issues presented by the expert nurses. The case described a young woman dying from complications of cancer treatment who was hospitalized in the critical care unit for several weeks on a ventilator and receiving dialysis. Her husband was a health care professional and very involved in her treatment. The interpretive analysis of this situation included a description of: (1) characteristics of an ethic of care; (2) the role of judicial ethics in decision-making; and (3) specific moral concerns expressed by nurses.

The values embedded in the paradigm case centered on caring and relationship. The relationship between the patient and the nurses was one of interdependence and reciprocity as each came to know the other. The moral agency of the nurses was heard in interpreting and particularizing the moral choices surrounding end-of-life issues. Wros (1994) noted that, although they did not see themselves as responsible for decisions, the nurses' issues and communications were the focus of team conferences at which decisions were made. They did not take a stand on discontinuing the patient's life support but asked the questions that shaped the resolution of how she would die. The expert nurses in this study introduced moral concerns based on involvement in the 
situation and assumed an active role in coordinating, interpreting, and translating between the patient/family and the physician. This role was based on an ethic of care and advocacy, Wros (1994) maintained, which went beyond aspects of the "in-between" position described by Bishop and Scudder (1990). Rather than equally representing the patient, the physician, and the hospital as described by these authors, the nurses in Wros' (1994) investigation relied on knowledge of the system and medical practice to clarify and facilitate the needs and wishes of the patient and family.

Similar to the nurses in Ray's (1987) and Cooper's (1993) studies, the expert participants in Wros' (1994) inquiry incorporated references to abstract moral principles in some of their narratives. One nurse contacted a member of the ethics committee because she was fearful of hurting an elderly patient should aggressive resuscitation measures become necessary. After the discussion, she was able to translate her emotional turmoil into the language of principled ethics and invoked the principle of non-maleficence. Using this language, she was able to approach physicians at a care conference and support her case not to do chest compressions if the patient should arrest.

Moral concerns, understood as what the nurses believed to be good or right in the particular context, manifested in how they focused their practice as well as in situations of breakdown when practice was interrupted. Concerns expressed in the paradigm narrative described by Wros (1994) included relief of suffering, patient involvement in choice, priority of family needs, and maintaining 
dignity. Relief of suffering addressed pain management and air hunger, but also providing distraction from the technological space in which the patient was "imprisoned". The nurses were concerned about their role in not wanting to inflict pain and prolonged torture by providing aggressive resuscitation measures.

McClement and Degner (1995) also endeavored to identify expert nursing behaviors in the care of the dying adult in the intensive care unit. The theoretical perspectives employed by the authors were derived from Quint's (1967) model of how nurses learn to care for the dying and Benner's (1984) interpretation of Dreyfus' Skill Acquisition framework

Quint (1967) maintained that nurses would limit their involvement in deathrelated situations if they were exposed to care of the dying without educational support. McClement and Degner (1995) revised Quint's (1967) model to reflect additional factors that make care of the dying in the intensive care setting difficult such as lack of empirical data to direct specific care and emphasis on recovery or cure.

The ten intensive care unit nurses who comprised the expert sample were employed in either a surgical unit in a tertiary care facility or a medical-surgical unit in a community based hospital in Canada. Semi-structured interviews were conducted with the expert nurses to elicit a description of the behaviors they associated with positive and negative attitudes toward care of the dying. McClement and Degner (1995) described these behaviors as: responding after death has occurred; responding to the family; responding to anger; responding to 
colleagues; providing comfort; and enhancing personal growth. Creating a peaceful bedside scene, offering information about funeral arrangements, and allowing time to be alone with the body were themes associated with responding after death. Providing details about medical treatment and the patient's response emerged as a theme in responding to the family. In addition, reducing the potential for future regret by encouraging family members to say what they wanted to say to the patient whether he/she was still living or had died, was deemed important.

The investigators noted that the expert nurses believed it was important to alert family members to the fact that aggressive treatment did not appear to be working and may not have the desired outcome of cure or restoration. The ability to show empathy and respect for patients and families who were expressing anger without taking it as a personal affront and supporting colleagues after a patient death were identified as expert behaviors. Being physically and emotionally available to patients, attending to basic hygiene, and alleviating discomfort were also described as vital. Expert nurses helped patients and families articulate their preferences for medical treatment, especially when sudden physical deterioration had occurred. They expressed frustration when physicians insisted on a protracted, aggressive course of treatment that patients and families did not want and noted that physicians became hostile or questioned their commitment to patient care when this issue was raised. These expert nurses indicated that it became necessary to "work" the medical system to get 
orders that were congruent with the treatment wishes of dying patients and their families. McClement and Degner (1995) concluded that despite the expert critical care nurses' often short term contact with patients and their families, their behaviors and responses may have had long term implications.

Segesten (1993) analyzed the narratives of thirty-two expert Swedish registered nurses employed as head or staff nurses on in-patient units of rural hospitals. The investigator asked the nurses to describe situations in which their actions made a significant and positive difference for the patient, in which they felt they had gained a deeper understanding, and in which they had been deeply and emotionally touched by the predicament of a patient.

Although the immediate aim of Segesten's (1993) study was not to describe patient advocacy situations, a third of the narratives included such descriptions. Of the seventy-eight narratives obtained, fifty-seven included some action on the part of the expert nurse. Twenty (35\%) of these actions involved a problem, a plea, and an adversary and these were classified as patient advocacy. Analysis of the narratives indicated that the following characteristics formed the pattern of a patient advocacy situation: a powerless patient; a problem concerning the patient's own will/what is good for him or her; and, an adversary. Segesten (1993) acknowledged that some of the findings were consistent with those found in the literature such as the vulnerability (Copp, 1982), powerlessness, and dependence (Ashby, 1987) of the patient. While the physician was often perceived as the adversary in this study and those of Ball 
(1989) and DeCoste (1990), these expert nurses also suggested that nursing staff, ward routines, and social welfare officers also acted as adversaries.

The expert nurses in this study who participated in patient advocacy situations made prompt decisions and took immediate action. Segesten (1993) noted, "The nurse always acted out of conviction. She was certain that her standpoint was the best one for the patient, and she succeeded in convincing the adversary that this was so" (p.133). The expert nurse advocates in this investigation also demonstrated additional effort, persistence, and risk taking.

\section{Summary}

The expert participants in these five studies demonstrate cognitive attributes of expertise in addition to several intrinsic characteristics previously discussed. Moral attributes including the ability to identify ethical issues, moral imaginativeness, embodied know-how, and communication skills are also evident in the nurses' narratives and actions.

Wros (1994) and McClement and Degner's (1995) studies have particular relevance to the present investigation as both discuss situations in which the transition from possible recovery to an understanding that further efforts are futile are unequally recognized or acknowledged. Further elucidation of the expert nurses' role and actions in these situations is one of the purposes of the current endeavor.

\section{SUMMARY}


In this chapter, literature that contributes to the background and context of the present study was reviewed. Foundational ethics literature provided a historical interpretation for nursing ethics. A review of empirical ethics literature was summarized, including studies using either bioethical, moral development, or role conception theory as organizing frameworks. Research literature exploring expertise in nursing practice was presented in two sections: studies employing an intuitive and/or qualitative model and investigations that examined the ethical practice of the expert nurse 


\section{CHAPTER 3}

\section{METHOD}

This chapter presents the methods used for the study, including the design, selection of the sample and data collection procedures. Analysis of the data set will be described along with the rationale for the use of narrative methodology in conjunction with thematic analysis. In addition, methods to assure study trustworthiness and protection of participants are discussed.

\section{Research Design and Rationale for the Methodology}

A qualitative design was used for the study. The method of narrative analysis incorporating Labov's $(1972,1997)$ structural approach and Riessman's (1993) analytic and interpretive guidelines was applied to those participant responses that took a narrative form. In addition, a thematic analysis of those responses that did not take a narrative form was conducted employing approaches described by Coffey and Atkinson (1996).

The articulation of ethical practice in nursing has come to include the search for the meanings of singular human situations (Vezeau, 1993). Narrative understanding and practice, as modes of thought and action with which one comprehends and responds to particularized human events and imbues them with meaning, are being recognized as integral to the elucidation of knowledge and moral agency in nursing and other disciplines (Sandelowski, 1991, b).

Narrative is the primary way of organizing and communicating the sense individuals make of the world and the interpretive process integral to shaping and 
understanding a story is at the heart of human knowing (Bruner, 1990). Thus, the investigation of narrative forms and practices is an instrumental way of discerning how knowledge is acquired and transmitted. Bruner (1990) asserts that all other forms of knowing, including the scientific, are in some fashion derived from the narrative mode. Science, he suggests, is not a rejection of narrative but a particularly sophisticated process of constructing special types of narrative for specific purposes.

Bruner (1990) notes that more is known about the logicoscientific or paradigmatic mode, with its inherent public rationality and process of verification, than is known about the narrative way of thinking. However, he provides some important descriptions of narrative thought. Narrative focuses on people and the reasons for their actions; their intentions, goals, and subjective experience. The properties of character, setting, action, and response are also essential to narrative. These contextual elements with their emotional implications are so significant, Bruner maintains, that literature achieves its power through "context sensitivity" whereas a work of science achieves significance through "context independence" (p. 50).

The significance of narrative thought to ethical determination and the development and transmission of knowledge has also been proposed by Vitz (1990), who states that, "where practical moral choice and action are concerned, narratives are better guides than rules or maxims. Rules and maxims state 
significant generalizations about experience but stories illustrate and explain what those summaries mean" (p.711). Vitz continues:

The oldest form of moral literature is the parable; the most common form of informal instruction is the anecdote. Both forms enable one to understand generalizations about the social order because they exemplify that order in a contextualized account. Secondly, narratives can also be used as tests of the validity of maxims and rules or as arguments. Narratives are natural mediators between the particular and the general in human experience (p. 719).

In nursing, Sandelowski $(1991$, a) asserts, attention to the relevance of narratives has evolved from recognition of the loss of the sense of human suffering and the dehumanization of health care. Transforming this disabling environment into one of healing and coherence is accomplished through clinical and ethical nursing expertise. She (Sadelowski $(1991, a)$ writes that the relational knowledge gained through the moral agency of the expert nurse can yield ethical wisdom and attuned caring. Embodiment allows for the engagement, compassion, and protection of vulnerability which objective, rational calculation cannot provide and acts as a source in everyday ethical comportment.

Qualitative research takes many forms and generates many types of data. These different data in turn, imply different approaches to analysis. The original intent of the interviews conducted for this study was to elicit expert nurses' narratives. It became apparent, however, that the interview questions also generated responses that did not take a narrative form. These generally shorter 
responses often answered both the interview and research questions. However, unlike identified narratives, these responses did not have a temporal ordering of events structured around a plot or framework that included character(s), context, actions, and reasons. Yet, this non-narrative data were considered essential to a comprehensive portrayal of the participants' experiences. Consequently, after conferring with an expert in narrative methodology who reviewed several of the transcripts, it was determined that a thematic analysis of this non-narrative data would be appropriate.

\section{Identification and Selection of Participants}

All twelve members of a critical care consortium in a large urban city in the southwest United States received a letter describing the purpose of the proposed research. Members of this consortium practice as clinical nurse specialists and/or nurse educators in the hospitals where they are employed. Eight members hold masters' degrees in nursing and four are prepared at the baccalaureate level. All are certified in critical care nursing (CCRN) by the American Association of Critical Care Nurses (AACN) and are members of that organization. This consortium has been in existence since 1996 and conducts a citywide critical care course on a quarterly basis and is responsible for mentoring and follow-up of participants. Because of their extensive practice background, familiarity with critical care competencies, and individual staff preparation and practice, it was believed that members of this group would be able to identify expert critical care nurses. Criteria derived from Benner, Tanner, and Chesla (1996) and Benner, 
Hooper-Kyriakidis, and Stannard (1999) were provided in the letter (Appendix B) to guide consortium members in identification of expert adult critical care nurses in their facilities. The investigator attended the next scheduled monthly meeting of the consortium to clarify questions or concerns and to emphasize the ethical components of expert practice constituting the focus of the study. prior to their monthly meeting. Three of the twelve consortium members practiced in either a pediatric or neonatal setting and thus did not participate in the identification process. The remaining nine members, representing seven facilities, expressed interest and enthusiasm and agreed to nominate experts from their institutions.

Three of the seven facilities were large urban teaching medical centers, three were private religious affiliated institutions and one was a community hospital. The number of beds in the teaching facilities ranged from 341 to 642 with 20 to 61 in adult critical care. Private urban institutions had 400 to 689 beds with 22 to 56 in adult critical care. The community hospital had 132 beds with ten in adult critical care. Only two facilities had a single, mixed unit while the remaining five had specific medical, surgical, and coronary care units. Two of the urban teaching hospitals were Level I trauma centers. Consortium members submitted names of prospective expert participants by either e-mail together with the unit in which they were employed or their home addresses. The number of experts nominated by each of the nine consortium members varied from four to seventeen and was undoubtedly influenced by both the size of the institution and their own practice area. Another possible factor affecting the number of nurses 
identified by a consortium member was his or her personal conception of expert practice.

Thirty-nine prospective participants were identified from the three, urban teaching medical centers and 39 from the three urban private facilities and one community hospital for a total of 78 possible respondents. Nominees from each of the seven institutions were assigned consecutive numbers beginning with one. It was assumed that expert nurses' communication with primarily attending physicians in private hospitals, as opposed to interns, residents, and fellows in teaching facilities, might differ. Consequently, to assure equal representation from teaching and private institutions, prospective participants were chosen in an alternate fashion from each of the seven facilities using a random numbers table (Johnson, 1976). An information letter (Appendix C) inviting participation was then mailed to the institution, the specified home address, or, as advised, sent to the clinical nurse specialist/nurse educator who placed it in the nurse's mailbox. Reminder postcards were mailed after one week. If a response was not received after two weeks, another name was randomly chosen from that institution.

Of the 39 expert nurses identified from the three teaching medical centers, 26 were mailed information letters and 17 participated in the study, a response rate of $62 \%$. Thirty-three of the 39 nominees from the three private and one community hospital were invited to participate and four responded for a response rate of $12 \%$. Explanations for these response rates could be related to several variables. The larger response rate from the teaching institutions may indicate 
more experience with the phenomena of interest, greater desire to share that information, or other unknown factors. The lower response rate from the two private, religious affiliated facilities and one community hospital may have been influenced by some lack of understanding of the study purpose or lack of experience with the issues. The investigator was known to some nurses in several facilities having had students in two of the teaching institutions, having worked as a staff nurse for twelve years in one of the private facilities, and also having taught undergraduate nursing students in the intensive care unit at the same agency.

\section{Protection of Human Subjects}

Before data collection, the proposed study was reviewed and approved by the Departmental Review Committee (DRC) of the School of Nursing and the Institutional Review Board (IRB) of the University of Texas at Austin. Participants were informed of their rights as a research subjects, including procedures for confidentiality and potential risks or benefits.

The researcher provided a detailed description of the study to each prospective participant when first contacted. The purpose and procedures of the study were explained, as well as any benefits or risks of participation. The information letter included the study's purpose, the voluntary nature of the participant's involvement, the ability to withdraw at any time, the expected duration of participation, a description of possible benefits and risks, a statement describing the investigator's plan for maintaining confidentiality and the 
participant's confidentiality, and who to contact regarding the research (Brink and Wood, 1988).

Participants were informed that all interviews would be audiotaped. To ensure confidentiality, the identity of participants was not used in any written reports, and code numbers were assigned to each interview, transcription, and field notes. A separate list linking code numbers and participants' names for the purpose of identification for subsequent interviews was kept in a locked, secure area. The researcher had sole access to the tapes, which were locked in a file and will be destroyed when no longer needed. Each participant was informed that they might have a copy of their interview transcripts as well as a summary of the study's findings.

\section{Description of the Sample}

Twenty-one expert adult critical care nurses comprised the sample for the study. Table 1 depicts the demographic data. The average age of the participants was 40 , with the majority (69\%) between $41-50$ years, consistent with typical critical care nurses nationwide (American Association of Critical Care Nurses, 1999). Seventy-two percent (17) of the sample was female. The possibility that there would be some differences between male and female expert nurses' perceptions and actions was considered but not specifically addressed in the sampling procedure. However, of the 78 nurses identified, 22 were male and four (18\%) participated in the study. The majority of the expert nurses $(14,67 \%)$ held baccalaureate degrees in nursing. Three participants (15\%) had attained 
associate degrees and two (9\%) held diplomas in nursing. Two expert nurses $(9 \%)$ were masters prepared. One respondent was enrolled in a family nurse practitioner program. The average number of years in nursing was 14 with 12 being the average time employed in critical care. The majority of respondents had been in their present position for approximately 7.5 years, a factor that was identified as enhancing their agency or perceived ability to intervene in, or affect a situation. Seventeen nurses $(81 \%)$ were practicing in one of three urban teaching medical centers while four $(19 \%)$ were employed in private nonteaching facilities. Of the latter, three nurses practiced in one of two religious affiliated institutions and one in a community hospital.

The majority of the expert nurses who participated in the study were certified in adult critical care nursing by The American Association of Critical Care Nurses $(15,71 \%)$, or had attained basic certification in either medicalsurgical $(3,14 \%)$ or geriatric nursing $(2,9 \%)$. One respondent was certified in both critical care and flight nursing. Seventy-one percent of the nurses (15) were members of The American Association of Critical Care Nurses while three (14\%) participated on the cardiovascular nursing council of The American Heart Association.

\section{Data Collection Procedures}

Those nurses who chose to participate in the study generally contacted the investigator by phone or e-mail and a mutually agreeable time and place for the interview was arranged. Most of the interviews were conducted at the nurses' 
place of employment either before or after their shift for their convenience. To ensure privacy and prevent distractions, the interviews either were held in the clinical nurse specialists' or nurse managers' office. Three nurses were interviewed at their homes and two in restaurants.

The initial interview with each participant lasted approximately one to one and one-half hours. A second interview was conducted with three participants and two other nurses were contacted by phone after the first interview was analyzed to clarify obtained information. These subsequent interviews generally lasted twenty to thirty minutes.

The initial interview began with a general greeting and introduction along with an explanation of the type and purpose of the interview. To further clarify the overall intent of the interview, an introductory statement was read (Appendix E) and a copy given to the participant. This served to convey the researcher's conception of the area of interest as an ethical dilemma and enable the respondent to disagree. All participants stated that they had experienced similar situations as the one described and perceived them as ethical dilemmas. After reading the introductory statement, each nurse was encouraged to recall and reflect on one or two patient situations she/he had experienced in an effort to generate narrative accounts. Informants were then asked four open-ended questions specifically developed to answer the following research questions: 
1. What indicators do expert critical care nurses describe about poor patient prognosis?

2. What do expert critical care nurses communicate about their perceptions to the patient? family? physician(s)? or peers?

3. What do expert critical care nurses do when their perceptions of the usefulness of aggressive medical therapies differ from those of the patient? family? physician(s)? or peers?

4. What are the reasons expert critical care nurses give for their actions?

At the conclusion of the initial interview, participants completed a demographic data sheet (Appendix D) employed to describe characteristics of the sample. Respondents were also informed that a second interview might be requested to clarify information. In addition, they were advised that their participation in a focus group might be sought after completion of the data analysis.

The interviews were collected over a period of nine months from September 2000 to May 2001. Problems with recruitment and the holiday season accounted for this extended interval. The second interview, if required, generally occurred within two weeks. The first two interviews were used as a small pilot study to determine whether the planned data collection procedures, especially the interview questions, were adequate to answer the research questions posed. It was deemed important to ascertain whether participants understood the questions, had experienced situations as described 
in the introductory statement, and could articulate their experiences. Based on the two interviews, the researcher continued the study as planned and no changes were made. After the completion of all interviews and preliminary analysis of the data, the investigator met with four participants in a focus group format to present tentative findings and obtain affirmation and alternative impressions.

Table 1

Demographic Data: Study Participants ( $\mathrm{N}=21)$

\begin{tabular}{lll}
\hline Characteristic & $\mathrm{n}$ & $\%$
\end{tabular}

\section{Age Range (years)}

$30-35$

$36-40$

$41-45$

$46-50$

$56-60$

Gender

Male

4

17

Female
9

18

22

47

4

18

72

Highest degree obtained in nursing

Diploma

2

9 
Associate Degree 3

Bachelor of Science

Master of Science
14

2
15

67

9

Characteristic

$\mathrm{n}$

$\%$

Number of years in nursing

$5-10$

7

34

$11-15$

4

19

$16-20$

2

9

$21-25$

7

34

$26-30$

1

4

Number of years in critical care nursing

$5-10$

9

43

$11-15$

4

19

$16-20$

5

24

$21-25$

3

14

Number of years in present position 
$1-5$

$5-10$

$11-15$

$16-20$
8

10

1

2
39

48

4

9

\section{Type of critical care unit employed in}

Medical

Cardiac

Surgical

Combination

Type of facility

Private

4

17

15

5

5

6

5

24

24

28

Teaching

CCRN Certification

Other certification

Medical-surgical

3

2

1

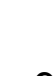




\section{Current enrollment in nursing courses}

$\begin{array}{lll}\text { F.N.P. } & 1 & 4\end{array}$

\section{Professional Organization Membership}

American Association of Critical Care Nurses

American Heart Association
15

3
71

14

Field notes about data collection were recorded, documenting environmental circumstances, nonverbal behaviors, affect, communication processes, rapport, power dynamics, researcher impressions and any problems (Mishler, 1986). Field notes were taken during and after each interview. Notes taken during the interview included key phrases or interesting remarks made by the participant to help the researcher further probe these issues. Notes taken after the interview included a condensed account of the interview, the researcher's reaction to the interview, mistakes made, and any other pertinent data. Theoretical notes or analytic memos (Miles and Huberman, 1994; Maxwell, 1996) were also kept to record reflections on ideas, understandings, readings and insights (see Appendix $\mathrm{F}$ for example of field notes and analytic memos).

\section{Data Analysis}

Interview audiotapes were listened to before transcription and beginning ideas noted about what was heard in the data. These were compared with field notes to identify possible tentative relationships and analytic memos recorded. The audiotapes were then professionally transcribed with the data generally 
received within a week. Each transcript was checked against the audiotapes for accuracy and to note any nuances in the conversation such as tone of voice, speed of speech, long pauses, or laughing. Although linguistic analysis was not the methodology for this study, these observations were recorded and often enriched the ensuing interpretation. For example, it was noted that the several participants' rhythm of speech appeared to take on the tempo of their work in the intensive care unit characterized by a pressured, rapid pace or delivery.

The initial transcripts were scrutinized across a number of interviews to gain an overall impression of what the expert nurses were saying in response to the interview questions. They were then re-read to select segments that took a narrative form. These were often identified when the participant began a description of a particular patient experience stating, "well, we had this patient" or "I remember this one patient". It was noted that several respondents provided lengthy narratives in response to the first interview question that often answered all four research questions. Other participants narrated longer accounts in response to the third interview question. These accounts conformed to Labov's $(1972 ; 1997)$ definition of personal experience narrative as a "report of a sequence of events that have entered into the biography of the speaker by a sequence of clauses that correspond to the order of the original events" (p. 3). That is, the narratives had a temporal sequence and a typical structure with a recognizable beginning, middle and end. Further analysis of the identified narrative segments involved four levels of analysis and representation: (a) 
narrative segments were re-transcribed and parsed into numbered lines containing clauses, (b) the narrative clauses were organized as scenes, (c) narrative clauses were analyzed using Labov's structural framework, and (d) and a narrative typology was identified.

The identified narrative segments were re-transcribed and parsed into numbered lines according to transcription conventions suggested by Riessman (2000) and adapted from Gee (1986). The numbered lines consisted of clauses that were generally short and contained one piece of information or "idea unit" which was identified by discourse markers that typically started with "and", "then", or "so". The numbered lines were then organized as "scenes" (Riessman, 2000) that depicted a single event or portrayed a particular topic in the nurses' evolving narratives. While many narratives had various scenes, several had only one. As Coffey and Atkinson (1996) have suggested, alternative forms of data representation can be seen as part of the analysis and as a process of discovery. When re-transcribed using Gee (1986) and Riessman's (2000) format, the narratives had a poetic structure that emphasized the rhythms of the original speech and illuminated some of the personal and emotional content. While this format allowed for close examination of the text, Gee (1991) has observed that other listeners might transcribe and parse the same texts differently. Although line parsing and scene organization of several interviews were reviewed with an expert consultant, it is acknowledged that it is primarily the investigator's representation and interpretation of the material (Mishler, 1991). 
After numbering the lines and organizing them into scenes, the narrative clauses were initially analyzed using Labov's $(1972,1997)$ structural framework. Labov maintains that a "fully-formed" narrative generally has six common elements, each of which has a specific function that serve as a series of answers to underlying questions. The abstract (what was this about?), considered optional by Labov, initiated the narrative by summarizing the point or by giving a statement of a general proposition, which the narrative exemplified. Orientation clauses (who, what, where, when?) provided contextual information including time, place, situation and participants. This is the background information that the participant indicated was necessary to understand the narrated events. Orientation information was typically followed by complicating actions, which were a series of narrative clauses that gave the event sequence and provided content (responding to the listener's implicit question "and then what happened?"). Complicating actions were often ascertained by noting a turning point, crisis, problem, or a series of these. In evaluation clauses, the participant stood back from the unfolding action and related how he or she had chosen to interpret it (what was the conflict for you?). Evaluative statements "infuse the account with values and meaning" (Attanucci, 1991), emphasize why the story was told and reveal the attitude of the narrator toward the narrative. The resolution or result described how the conflict or crisis was resolved (what finally happened?), and the coda, when present, ended the narrative by returning the listener to the present moment. As Labov proposed $(1972,1997)$, these elements 
often occurred in an invariant order in the participants' narratives and there were multiple occurrences embedded and recurring within a single narrative. Clauses were identified using the following notation: abstract $(A B)$, orientation $(O R)$, complicating action (CA), evaluation (EV), resolution (RE), and coda (CO). An example of structural analysis using data from the present study is provided in Table 2.

Labov's framework provided an analytic perspective on how the expert nurses' narratives were structured and also offered a perspective from which to reflect on the types of stories related by the participants and their meanings. After consulting with an expert in the methodology (C. Riessman, personal communication, January 29,2001$)$ it was determined that interpretation and presentation of the participants' often lengthy, complex narratives would be better accomplished by identifying recurring plots or a typology. Reducing each respondent's narrative to a "core" narrative as originally proposed, would have required deleting discourse considered essential to understanding the nurses' experiences.

Polkinghorne (1995) has observed that narrative analysis relates events and actions to one another by configuring them as contributors to advancement of a plot. He defined narrative plot as "the organizing theme that identifies the significance and role of individual events' (p. 16). The plot is the design and intention of the narrative or what shapes and gives it a certain direction or intent of meaning. Without recognition of a plot, each narrated event appears as 
discontinuous and separate. Within the plot, there may be a number of central themes or stories that, when woven together, provide a greater depth of understanding of the people and events being studied. Some narratives may parallel one another, others may merge together to illuminate the complexity of events and characters, others may overlap, and some even may clash.

Analysis of several narratives allows identification of commonly recurring plots and has been used in nursing and other disciplines. Frank (1995) has analyzed accounts of chronic illness and identified a typology of three plots based on the overarching themes of restitution, chaos, and quest. In nursing, Ayers (2000) has described a typology of family caregiving organized around the plots of ideal, normal, and compromised lives. Similarly, Benner, Tanner, \& Chesla (1996) have identified the two pervasive plots of constitutive and sustaining narratives in their research on expert nursing practice.

The identification of recurring plots or a narrative typology of participants' moral experiences was accomplished using techniques suggested by Polkinghorne (1995) and Ayres (2000; personal communication, August, 2001). The narrative data were analyzed through an iterative process that involved moving back and forth between individual elements of the text and the whole text in several cycles. Each cycle integrated three levels of analysis: (1) multiple readings of the narrative segments to identify significant meanings with particular attention to Table 2 Narrative structural analysis 
Narrative elements Definitions Illustrative quotes

\begin{tabular}{|c|c|c|}
\hline $\begin{array}{l}\text { Abstract }(A B) \\
\text { (optional) }\end{array}$ & $\begin{array}{l}\text { Summarizes point } \\
\text { of the narrative }\end{array}$ & $\begin{array}{l}\text { This is about a patient who } \\
\text { did not want any more surgery }\end{array}$ \\
\hline Orientation $(\mathrm{O})$ & $\begin{array}{l}\text { Provides time, place } \\
\text { situation, participants }\end{array}$ & $\begin{array}{l}\text { When I came in that morning } \\
\text { she had been in the unit over } \\
\text { a week }\end{array}$ \\
\hline $\begin{array}{l}\text { Complicating } \\
\text { action (CA) }\end{array}$ & $\begin{array}{l}\text { Provides sequence, } \\
\text { content; turning point, } \\
\text { crisis, problem }\end{array}$ & $\begin{array}{l}\text { And this patient went into } \\
\text { ARDS...his face was so } \\
\text { broken down...it was pathetic; } \\
\text { So I called the pulmonary } \\
\text { fellow and told him my concern }\end{array}$ \\
\hline $\begin{array}{l}\text { Evaluation } \\
\text { (EV) }\end{array}$ & $\begin{array}{l}\text { Narrator's } \\
\text { interpretation }\end{array}$ & $\begin{array}{l}\text { And to me this was just like an } \\
\text { abuse...totally futile }\end{array}$ \\
\hline $\begin{array}{l}\text { Resolution } \\
\text { (RE) }\end{array}$ & $\begin{array}{l}\text { How the conflict/crisis } \\
\text { was resolved }\end{array}$ & $\begin{array}{l}\text { And so we ended up } \\
\text { extubating her and she passed } \\
\text { away about forty-five minutes } \\
\text { later }\end{array}$ \\
\hline
\end{tabular}

Coda (CO) Ends narrative; returns So now we tend not to go to (optional) listener to present the ethics committee because it has not proven useful for us

evaluative statements and striking features of the conversation including verbal emphasis and word repetition; (2) comparison across narrative accounts to 
identify similar or dissimilar elements; and (3) comparison of one whole account with another to identify overall common organizing themes of meaning and significance. The integration of findings from within and across the expert nurses' accounts facilitated the development of a narrative typology organized around identified recurring plots.

An additional method was necessary analyze the participant's responses that took a non-narrative form. Thematic analysis, a process appropriate for use with all qualitative data (Boyatzis, 1998), was therefore employed applying techniques described by Coffey and Atkinson (1996). These authors have described thematic analysis as coding data to develop concepts or categories and then developing themes (and sub themes) to help explain the phenomena under investigation.

Coffey and Atkinson (1996) defined the initial sorting or coding of data as a descriptive process that involves "tagging text segments with information about the category into which it belongs" (p.30). The authors noted that the research or interview questions guiding the study can often provide these organizing categories. Consequently, each participant's responses was reviewed multiple times for words, phrases, or statements that had common properties or elements and appeared to be instances or examples of the following: (1) what indicators he/she described about poor patient prognosis, (2) communicated about these perceptions, (3) what he/she did when perceptions of the usefulness of aggressive therapies differed from others, and (4) the reasons given for his/her 
actions. These responses were underlined with different colored pens and categorized as indications, communication, interventions, or reasons. The data related to each category was then entered into a standard word processing program for ease of retrieval.

Transformation of the categorized data into themes and sub themes is considered an explanatory or inferential process (Coffey \& Atkinson, 1996). This second-level analysis was accomplished by noting repeated observations, activities, metaphors, meanings and feelings in the categorized data, in addition to temporal or causal relationships between or among emerging themes. For example, several participants used the metaphor "painting a realistic picture", to describe how they communicated their perceptions of poor patient prognosis to family members. In addition, an endeavor was made to identify contrasting or negative experiences and overlapping categories were also condensed as indicated. The final analysis consisted of formulating coherent explanations and descriptions of the identified themes and sub themes with selective quotes to illustrate the expert nurses' experiences with the particular themes.

\section{Trustworthiness}

Mishler (1991) asserts that traditional notions of reliability do not apply to studies that employ narrative analysis and Riessman (1993) suggests that validation, the process through which we make claims for the trustworthiness of interpretations, is the critical issue. She (Riessman, 1993) emphasizes "trustworthiness" not "truth" as the key semantic difference, a criterion reiterated 
by Bailey (1996) in her review of those studies in nursing employing narrative analysis. The latter assumes an objective reality, whereas the former moves the process into the social world. Riessman (1993) proposes four approaches to validation in narrative analysis: persuasiveness, correspondence, coherence, and pragmatic use.

The criteria of persuasiveness and plausibility refer to whether the interpretation is reasonable and convincing. When theoretical claims are supported with evidence from the informants' narratives and alternative explanations of the accounts are considered, persuasiveness is enhanced.

Riessman (1993) suggests however, that persuasiveness ultimately rests on the rhetoric of writing or literary practices, and the reader response. In the present study, the criteria of persuasiveness and plausibility were addressed by including segments of the structural analysis of informants' narratives for reader review and appraisal.

Correspondence can involve taking the results back to those studied. If the investigator's reconstructions are recognized as adequate representations then credibility is increased (Lincoln and Guba, 1985). Thus, after analysis was completed, the researcher met with a focus group to establish the representativeness of the narrative exemplars and identified themes and sub themes.

Agar and Hobbs (1982) describe three levels of coherence that interpretations should possess in order to be considered more than ad hoc: 
global, local and themal. Global coherence refers to the narrator's overall aims in speaking, what he/she wants to accomplish, beliefs and goals. Riessman (1993) provides an example from her divorce study in which the informant's global goal in developing an account was to justify an action (divorce). Local coherence is what an individual is trying to effect in the narrative itself, such as the use of linguistic devices to relate events to one another. Thus, the narrator employs contrasts and juxtaposes events and actions to make his/her point. Themal coherence involves content, that is portions of interview text about particular themes figure importantly and repeatedly serving to unify the narrative. An example is again provided from Riessman's (1990) divorce narratives in which individuals developed their stories around a set of common themes (lack of intimacy and companionship) to which they returned repeatedly. The criterion of global coherence was addressed in the present study by attempting to identify participants' reason(s) for relating their narratives. providing several narratives exemplifying common themes or recurring plots.

The final criterion of validation is pragmatic use or the extent to which a particular study becomes the basis for others' work. Unlike the previous criteria, this one is future-oriented and collective.

In concluding, Riessman (1993) suggests that the investigator can make it possible for others to determine the trustworthiness of narrative analysis by: (a) describing how the interpretations were produced, (b) making what was done visible, (c) specifying how successive transformations of the data were 
accomplished, and (d) making primary data available to other researchers. These recommendations were incorporated in the present study.

Narrative analysis is appropriate for oral, first person accounts of experience that correspond to a specific form, what Labov and Waletzky (1967) call a "natural narrative". Because of the nature of the analysis, sample sizes are small and generalization difficult. Riessman (1993) observes however, "there is tradition in science of building inferences from cases" (p. 70).

Atkinson (1997) cautions against assuming that narratives provide a "hyper authentic" version of the respondents' experiences or selves. He asserts "the collection and reproduction of narratives and the celebration of voices through that work are not guarantees of anything" (p.10). Atkinson states that the modern hospital is a "densely narrated environment" and observes that both medicine and nursing are characterized by innate oral traditions. He suggests, however, that in a culture which stresses and rewards self-revelation, it would not be prudent to assume that narrative accounts are privileged kinds of data with greater or different claims for authenticity. While acknowledging these limitations, this investigator concurs with Atkinson's conclusion that narratives can, nevertheless, illuminate the "moral and invisible craft work" of the nursing discipline.

Validation of themes derived from the non-narrative data were accomplished using strategies suggested by Polit and Hungler (1998) and Maxwell (1996). To ascertain whether the themes and sub themes accurately 
represented the perspectives of the participants', three strategies were employed. These included: corroborating identified themes and sub themes derived from several interviews with a consultant; using an interative approach in which the interviews were re-read to ascertain the fit of the themes and sub themes which were then revised as necessary; and presenting the themes and sub themes to four members of a focus group to elicit support or contradiction. This last strategy, known as "member checks" (Lincoln \& Guba,1985) is considered an important step in avoiding misrepresentation and establishing validity (Maxwell, 1996). Several of these participants commented on the centrality of their own religious beliefs and those of patients and family members as reasons for some of their actions in situations described. These observations were subsequently included in the presentation of the data.

\section{Summary}

This qualitative study was designed to answer four questions about the ethical practice of expert critical care nurses in situations of prognostic conflict. Narrative analysis was described as an appropriate method to explore ethical experience and the technique was provided together with the rationale and use of thematic analysis for the non-narrative data. Sample selection and data collection procedures were addressed. The discussion also included a description of sample characteristics, data analysis techniques and methods to ensure trustworthiness of the study. 


\section{CHAPTER 4 \\ PRESENTATION, ANALYSIS, and INTERPRETATION OF DATA}

This chapter is focused on presentation of the data with analysis and interpretation. The data set from the twenty-one nurse experts is complex and various methods of presentation were considered. In an endeavor to best portray the richness of findings, the following order of sections will be included: (1) a description of the nature of the interview responses and narratives related by the

participants; (2) intact narrative exemplars; (3) thematic analysis of non-narrative responses with illustrative quotes; and (4) interpretation of the data through the four research questions which guided the study:

1. What indicators do expert critical care nurses describe about poor patient prognosis?

2. What do expert critical care nurses communicate about their perceptions of poor patient prognosis to the patient, family, physician(s) or peers?

3. What do expert critical care nurses do when their perceptions of the usefulness of aggressive medical therapies differ from those of the patient, family, physician(s) or peers?

4. What are the reasons expert critical care nurses give for their actions?

Nature of the Interview Responses and Narratives 
For this study, a narrative was defined as a discrete story of personal experience characterized by a temporal ordering of events with a recognizable beginning, middle and end structured around a plot that had a point or moral (Polkinghorne, 1988, 1995; Bertaux \& Kohli, 1984; Riessman, 1993). To facilitate narrative accounts, participants were encouraged to recall one or two representative patient situations after reading the introductory statement. Their responses took a variety of forms. Many respondents provided lengthy narratives in response to the first interview question but provided some data that answered additional research questions in responses that did not take a narrative form.

These non-narrative responses were generally short and did not portray a specific personal experience but rather reflected the nurses' general orientation to practice. Consequently, to fully describe the nurses' experiences, a thematic analysis of those responses that did not take a narrative form was conducted in addition to the analysis of the narrative segments. While the themes are described separately, the narratives often contain examples of how some themes could be interwoven and elaborated as the stories unfolded. Although several narratives exemplify certain themes, no one narrative is representative of, or reflects all of the themes and sub themes. In addition, some narratives offer distinct experiences that are not reducible to themes.

\section{Narrative Exemplars}

The multi-level analysis of the narrative data yielded three story types organized around the central plots of: (1) Protecting or speaking for the patient; 
(2) Presenting a realistic picture and (3) Experiencing resignation and frustration. To illuminate the personal, emotional content of the exemplars and allow the reader to enter into the situation, narrative exemplars will be presented using stanzas organized into scenes as suggested by Riessman (2000) and adapted from Gee (1986). Coding of the narratives using Labov's $(1972,1997)$ structural method is indicated on the right employing the following abbreviations: abstract ( $A B$, optional); orientation (OR); complicating action (CA); resolution (RE); evaluation (EV); and coda (CO, optional).

\section{Protecting or speaking for the patient}

In narratives of protecting or speaking for the patient, expert nurses discussed patients whom they perceived as vulnerable. The notion of vulnerability of people is ethically significant in its own right as it refers to the fact that people are inherently capable of being injured. In the situations related by the participants, injury is conceived as occurring in additional domains of human experience besides health to include the individual's agency or their ability to initiate meaningful action and determine the ends of life (Liaschenko, 1995). The situations of vulnerability described by the participants concerned preventing further technological intrusion and honoring patient/family wishes thus permitting a dignified death. While several patients presented in the narratives could communicate in some way, many others were sedated or chemically paralyzed. 
In the following scene, this expert nurse described a young woman who had suffered massive internal injuries complicated by sepsis after being kicked in the abdomen by a horse:

When I came in that morning

she had been in the unit for over a week

and when I came in, actually there was two things

One is she didn't have a look in her eyes any longer

because I had taken care of her before

this was like there wasn't anything there.

She had that blank look.

Before she was pretty much out of it

but when you opened her eyes

CA

she looked she knew what was going on.

This last time she didn't look around

there was just kind of a blank stare.

The second thing is that she had had abdominal surgery,

an open wound

and she'd been going back and forth and back and forth

to open it up, clean it out, close it back up.

And when I took the dressing off to look at it

it had an unusual color to it

I knew that wasn't right 
It wasn't going to get any better.

This introductory scene contained several elements described by Labov $(1972 ; 1982)$ as indicative of a formal narrative including an orientation, complicating actions and evaluation. A temporal context or orientation that depicted the patient and the expert nurse's interpretation of her situation is provided in the first two lines. Complicating actions, which are a series of turning points or crises (Riessman, 1993) were evident in the nurse's assessment of the patient's lack of responsiveness and status of her abdominal wound. The nurse discussed her clinical perception of the status of the abdominal wound, which she believed had deteriorated since she examined it before but focused on relational knowledge in this scene. The nurse had spent time caring for the patient and knew how she interacted and responded. Knowledge gained through relational assessment is more than routine evaluation of level of consciousness. The nurse described the young woman's "blank stare" and indicated that this represented a dramatic change in her understanding of the patient's prognosis and ability to survive as indicated in the evaluative statements "I knew that wasn't right" and "it wasn't going to get any better." The narrative continued:

CR: And so at this point things were still pretty aggressive?

Yes, and she was going back to surgery that afternoon CA to clean her wound out again $\quad$ CA they would undo the mesh and clean it out again. And it wasn't going to make any difference 
that they continued to do that.

CR: And so was your perception differing from the physician's at that point?

Yes. I find that physicians will always say

"well, it looks pretty bad but let's go try again."

But they never want to say

"there's no sense in trying any longer."

While this nurse spoke very softly during the interview, her frustration was

evident in the repetition of several phrases "back and forth to surgery" and "clean it out again". She indicated that she perceived further technological intrusion to be unwarranted as stated in the evaluative phrase, "it wasn't going to make any difference." Her clinical and relational assessment of the situation set the tone for her actions:

So, I called Dr. $\mathrm{H}$ and said

"Why are you taking her back to surgery?"

"Because we need to clean it out some more" (Dr. H).

"But she's doing really bad" (nurse)

"Yeah, I know.

She probably won't make it but we're going to go back." (Dr. H)

CR: When you said that she was doing really bad

did you quantify that or say that you felt she was doing really bad?

Yeah, because I've known them (trauma surgeons) long enough OR 
that they knew I knew what I was talking about.

And they all agreed.

CR: They all agreed?

Yeah. But then (Dr. H said) "let's take her back

and open her up again."

They just want to continue until she loses her blood pressure

CA

And it would not have made any difference at this point.

We were just prolonging the inevitable, that's what we were doing.

And they all knew that.

Similar to other participants in this study, the expert nurse communicated her perception of the patient's deteriorating status and directly questioned the necessity of further interventions in the above scene. She attributed her ability to communicate to experience and the recognition of her knowledge by this team of trauma surgeons. Although there seemed to be a tacit understanding that the patient was not going to survive, the certainty of this outcome was not evenly recognized by everyone involved at this point. The nurse seemed aware of the response she would receive from the surgeons and indicated moral distress in the evaluative comments "It would not have made any difference" and "we were just prolonging the inevitable".

When the expert nurses in this study did not receive a satisfactory response to their concerns from physicians, they would often attempt to communicate their understanding of the patient's poor prognosis to family 
members or significant others. As this narrative continued, the nurse explained that no one had been in to see the patient for several days and "no one was around to question anything." Consequently, she initially contacted the patient's boyfriend and informed him that the patient "was very sick and may not make it." He stated that he did not want to be involved any further because "they were just living together". The nurse then called the patient's mother who "lived up north":

So, when I got done with that, I called the mother and explained that I'm the nurse taking care of her. CR: When you take this responsibility to call, is that something you usually do?

It was to update, to update them

CA because no one had called, nobody had checked on her. I tried to get a feeling of if somebody has to make a decision who is it going to be? Who is active here?

Because that's part of the responsibility I feel protecting the patient, doing what's right for the patient.

Or because it was a personal thing like what if it was me and there was no one here to make my decisions and I was lying here like this? I wouldn't want to do that. So...to get the ball rolling 
bring people in here who need to make a decision who need to say bye to her.

CR: And the physicians had no part in this? Is that common?

For the trauma surgeons, they're very surgery oriented.

And I really feel most physicians would just continue on as long as somebody would let them.

In the above scene, the nurse shared her ethical discernment of the situation and demonstrated empathic projection into the patient's experience as evidenced in the phrase "what if it was me". Nussbaum (1990) has noted, ethical discernment is "the ability to see a complex, concrete reality in a highly lucid and responsive way...taking in what is there with imagination and feeling"(p. 152) and is requisite to ethical expertise as discussed in the sensitizing framework. This expert nurse's responsiveness did not result in over identification with the patient but engendered further understanding, compassion, and the protection of perceived vulnerability. The nurse also conveyed the reasons for her actions stating that it was her "responsibility" to protect the patient and do what she thought to be "right" in this situation, creating a dignified death with possibility of closure for loved ones. Her decision to intervene did not seem to be based on articulated ethical principles but rather on sensing what was good or not good for this particular patient. The nurse indicated that additional surgical intervention was not warranted and that the physicians would continue because, as she stated later in the interview, "that is their job." Having validated her perception of the 
patient's poor prognosis with the charge nurse, she persisted in attempting to contact a family member who could make an informed decision:

I spoke to the mother and explained who I was.

CA

She told me she was very poor and could not come down here OR and now she had those two young kids up there.

And she knew the patient was very sick

but hadn't heard from anybody in three or four days.

And I kind of updated her.

I said "would you like to talk to the physician taking care of her?" CA and she said she did.

So I got her number and told her to be expecting a call.

Then I called Dr. H and said, "Come down here"

because I know them very well.

EV

I took him in there and said

CA

"look at her, look at this abdomen."

I said, "It looks like there's mold growing on it."

"What are you going to do if you take her back to surgery?"

And he hem hawed around and stuff.

CA

And I said, "I think it's about time to say enough is enough."

"Well, I know", he said.

"Everything's lost, everything's failing, nothing's working", I said.

Her kidneys had already failed and she was on dialysis.

OR 
And just everything was failing.

And I said, "The family, the mom would like to talk to you." $\quad$ CA

"We need to talk to her about what she wants to do", I said,

"But enough is enough."

CA

And I said, "You need to call the mom

and tell her what's going on,

you need to make a decision.

Because I swear there's mold on there."

And I said, "Look at her, look at her face

she doesn't even look at you anymore."

And he goes "I know, you're right."

$\mathrm{CR}$ : Is he always so agreeable?

Well, he knew. He just needed somebody to tell him to stop.

In the above scene, the expert nurse and physician unevenly acknowledged recognition of the transition from possible recovery to an understanding that further efforts would be futile. The understanding that death was a probable outcome occurred in incremental stages and was negotiated by the nurse thorough communication, presenting reality, and engendering empathy. She brought the physician into the young woman's room and urged him "look" and really see the patient. Sandelowski (1998) has maintained that, unlike the medical or nursing "gaze" which is organized around scientific objectification, the 
nursing "look" involves sustaining an embodied relationship with patients that enables resistance of the technological imperative.

As the narrative concluded, the participant described how the physician had contacted the patient's mother who then called the nurse:

She said that she had talked to $\mathrm{Dr}$. H

CA

and that she didn't want anything else done.

I don't know how she came up with those words

EV

but l'm sure it was from Dr. H.

She said she wanted her to be taken of the ventilator

CA

and everything stopped.

The whole situation was kind of bizarre.

EV

CR: There's a difference between saying you don't want anything more done and

Yeah, taken off the machine.

CA

But she wanted to withdraw everything.

There is a consensus among ethicists and members of various task forces convened to examine the issue, that no moral distinction exists between withholding and withdrawing care (Callahan, 1993; American Thoracic Society Bioethics Task Force, 1991). The withdrawal of treatment however, implies that nurses and physicians take responsibility for allowing death to occur which can contradict personal and professional values. In withholding treatment, the locus of responsibility for the occurrence of death lies with the patient. The patient's 
physiological state will determine whether he/she lives or dies. While this expert nurse had argued for no further surgical intervention, the decision to extubate the patient appeared to cause her some additional conflict which she attempted to resolve in this final scene:

And she told me to tell her (the patient) that she loved her

CA and that she wanted it over with and didn't want her to suffer any more.

Then I called Dr. $\mathrm{H}$ and said, "What are you going to do?" And he goes "she wants to stop everything."

And I said, "Did she know that you're going to pull the tube out?" "Did you explain all that to her?"

Because I wanted to make sure everyone was clear on what's about to happen.

And so, we ended up extubating her.

She passed away about forty-five minutes later.

All by herself. No one else was there.

And that was really sad for her.

It was just me and her.

You know, but it was good.

This final scene depicted the resolution and the nurse's evaluation of the experience. While tragic, the young woman is permitted what the expert nurse 
considered a "good" death without further technological intrusion. Later in the interview the nurse reflected on her actions in this situation:

To believe in yourself and have confidence to make those kind of judgments. Because they are judgments. I mean you have to live with that. You took her off the ventilator; you're going to have to live with that. But I knew.

Similar to the narratives related by the other participants in this study, the preceding narrative represented the interrelationship between cognition, emotion and action in the context of a particular kind of lived moral experience (Tappan, 1990). This term captures the lived experience of an individual faced with a situation that requires a moral decision and a moral action in response to that situation. Tappan (1990) has suggested that, moral thinking and feeling both influence moral action and moral action influences both moral thinking and moral feeling. Consequently, one might assume that the expert nurse, having authorized her moral thoughts, feelings and actions, (I knew) would again act on behalf of her own moral perspective and convictions when faced with a similar situation.

The expert nurses in this study related several narratives concerning providing continuing aggressive treatment to oncology patients in the intensive care unit. The patients discussed by the participants were generally young and had been recipients of bone marrow transplants. In the following narrative, this 
expert nurse presented such a patient and provided an orientation that included time, place, persons involved, and what she considered in the situation:

We had a patient that was a cancer patient

who had gotten a bone marrow transplant.

He had gotten all kinds of chemo.

He had all those treatments.

And he was brought into our unit

and he was pretty much in the last stages.

We had some doctors at the time

who were very aggressive.

And this patient was really critical

and he had gone through all the strains of chemotherapy

all the strains of everything.

And we had some doctors who were very into doing procedures.

When I came in that morning

CA

I could see that he was maxed out on all this stuff.

He was $100 \%$ on the ventilator

They were still wanting to do some CAT scans

and some PT scans.

Whereas already for the past couple of days

he had been like totally gone. 
The nurse's clinical assessment of the patient's poor response to vasopressor support and maximum oxygenation is evident in the above scene. She indicated her conflict with the decision to perform more scans and proceeded to describe her relational and ethical assessment:

And to me this was just like an abuse.

EV

I felt it was above and beyond what the patient wanted.

Because he had been here previously when he was still alert and he had voiced his wishes to me.

And I brought this to the doctors.

CA

One of the attendings is very much into teaching procedures

OR so he wanted to know what other things were available and to just keep doing them.

But I thought that was really going against the patient's wishes and the wife's.

CR: The patient had an advance directive?

He had advanced directives that if he was terminal

OR and there was nothing more that could be done he didn't want to stay very long on machines.

Similar to several other expert nurses who were interviewed from the facility where this participant practices, patient and family members are often known from previous admissions. This relational knowledge enabled the nurse to articulate what she believed to be the patient's wishes concerning continued 
aggressive medical intervention which she deemed "abuse". Although she indicated that the patient had an advance directive, the reasoning behind the attending physicians' apparent decision to disregard it and continue treatment at this time was not clear. While principles of non-maleficence and respect for autonomy were expressed in the nurses' ethical assessment, those terms were not stated explicitly. The narrative continued:

And this patient went into ARDS

And at that time one of our doctors

was into putting patients in the prone position.

And he had been like that for two days already.

And his face was so bloated and so broken down

from the foam under the face

and under the skin it was just pathetic.

And I talked to the wife.

CA

And she was beside herself too

EV

because of all that was going on.

We are provided with a compelling visual image in the participant's description of the patient in the above scene. Although intended as a therapeutic intervention to enhance oxygenation in acute respiratory distress syndrome, prone positioning appeared to result in more harm than benefit. Similar to the expert critical care nurses in Ray's (1987) study, this participant endeavored to take "protective actions" against the continued use of aggressive technological interventions 
when the patient was believed to be suffering needlessly. The nurse validated her observations and concerns with the patient's wife and proceeded to intervene:

So I called the pulmonary fellow and at that time I think he was still conscientious about all of this but he had been going along with the attending's wishes to do so many other things.

And I had a talk with the fellow.

RE

He stood up for me to him.

And I actually told him my concerns

and what the family was thinking.

That what was going on was totally, totally unnecessary.

EV I mean, futile.

There was nothing that could be done.

There is strong ethical, conceptual, and empirical support for collaboration among health care providers, patients and families in many types of decision making in the intensive care unit including limitation of treatment and other end of life issues (Luce, 1997; Dowdy, Robertson, \& Bander 1998; Baggs \& Schmitt, 2000). The reality of the hierarchic authority of the attending physician in such decision making however, is evident in this narrative and in those of other participants. Several nurses interviewed for this study spoke about using the 
"chain of command", or initially communicating their concerns about continuing aggressive medical treatment to the intern followed by the resident and then the fellow. In the above scene however, this expert nurse, serving as both interpreter and negotiator, bypassed the usual communication lines. She spoke to the person with whom she felt comfortable, and who perhaps had the most influence with the attending physician.

CR: The wife didn't feel like she could verbalize her concerns to the doctors?

She did.

But the only thing is that a lot of families

are so wishing that something different will be found

and that they will come up with a better thing.

Something that will cure them.

And I think some of the doctors tend to give false hope

you know, if we do this CAT scan we might find something.

And this is what is presented to some people.

Whereas we already know

there is nothing that a CAT can find

that will bring this patient back.

And the families just hold out.

Some families just hold on.

The conveying of "false hope" or "false optimism" to patients and families by physicians regarding the efficacy of various treatments or interventions and 
patients' prognosis was discussed by several participants in the present study. Kirchoff and Beckstrand (2000) reported a similar finding in their investigation of critical care nurses' perceptions of obstacles and helpful behaviors in providing end of life care to dying patients.

Mei (2000) has suggested that false optimism is associated with "medical activism" or a strong need for control over death which is prevalent in the western world. The author (Mei, 2000) observed that use of ambiguous words such as "treatment" by healthcare providers contributed to medical activism and may have a more positive meaning for patients as it implies that "something can be done about it". Mei, 2000 also discussed forms of non-verbal ambiguity inherent in medical activism including the often unquestioned and automatic performance of $\mathrm{x}$-rays and CAT scans on a "routine" basis as depicted in the above narrative. The author (Mei, 2000) asserted that patients and their families cannot comprehend that the efforts and expense involved in these and other, often daily procedures, could be "useless" so consequently "false hope" is reinforced. Medical activism and false hope may make it more difficult for the patient and family to accept the patient's imminent death, obstruct saying farewell, and delay making arrangements.

The unintentional communication of false hope by health care professionals to patients and family members of differing cultural backgrounds is also possible. Blackhall et al. (1999) noted that asking a Mexican American patient or family member "Should we do CPR" may be interpreted as meaning 
that CPR is being recommended when the opposite is likely to be true. Blackhall et al. (1999) observed that Mexican Americans expect healthcare providers to suggest or use life support only if there was hope that the patient would survive, and thus would tend to favor continuing it.

In narratives of protecting the patient, several nurses related situations similar to the preceding narrative in which the patient had an advance directive which was not being followed:

Well, we did have a patient.

OR

It was about six months ago.

He had an advance directive.

And what he had specified is

that he wanted to be kept on a ventilator for seven days

and after that seven days, he wanted it turned off.

And the doctors questioned it and said

"Well, you know, seven days is not enough

because a lot of people live past seven days".

And he was an extremely ill man anyway.

He had very bad heart disease,

his ejection fraction was like $13 \%$.

OR

His daughter had the power of attorney

CA

and the seven days came and went.

And the daughter wanted the machine turned off 
because he had told her "please promise", and had put it in writing and all.

But when I got to talking with the family

OR

because I was trying to understand

what the magic seven was, why seven days?

That didn't seem like very long.

And she said that two years ago

his wife had been on a ventilator for eight weeks

and he watched her suffer

and he knew he didn't want that.

So, the issue was between the doctors and the family.

Because I could see where the family was coming from

the patient had said he didn't want it.

Yet the doctors were having a hard time understanding why.

I mean the man was still alive.

So, they thought if we can leave him on a little longer

maybe we can get him to come around.

Rushton (1995) and Prendergast (2001) noted that, with few exceptions, empirical studies indicated that the presence of advance directives does not increase the likelihood that patients' wishes will be honored or change the amount or type or care given. Among eight hundred and seventy nine physicians practicing in adult intensive care units, Asch (1995) found that thirty four percent 
would continue life-sustaining treatment despite patient and surrogate wishes that it be discontinued. Similar to the situation in this scene, the physicians surveyed by Asch acted on the belief that the patient had a reasonable chance to recover from the critical illness.

In the present study, the expert nurse indicated that although the patient had extremely poor cardiac function, she initially understood the physicians' motives in continuing treatment since "the man was alive" and apparently responsive. The nurse also attempted to clarify her understanding of the patient's and family's views of appropriate goals of care and the value of ICU treatment in attaining those goals through effective communication. The narrative continued:

But it went on and on.

And the nurses and doctors were really at each other.

We were trying to stand up for the patient and family and the doctors did not want to give up.

And of course they kept doing all this stuff

And it was like I felt so guilty, I felt so guilty.

I thought am I just going through something here?

Maybe I'm being emotional and I ought to just back off and do my job.

But I thought, God, you know he said he didn't want it 
and the family is saying "no" too.

And you know you have your breaking points

CA

And finally the daughter asked me

"Why do you keep doing that to my father

when I begged you not to?"

And that was it.

You wonder, where does your position end?

EV

Don't I have the right to say

you know, I'm sorry that I just can't do that anymore?

We don't have a problem if the doctor tells us

give five-hundred milligrams of Lopressor

We don't have a problem saying,

well, you're nuts, I'm not going to do that

it will hurt the patient.

But yet, if they tell us to just keep doing this other

it's like, we can keep doing that.

We don't think it's right, but we'll keep doing that.

It gets to the point where you're not caring for them

EV you're inflicting suffering on them.

So, I told the resident

CA

"You can call the ethics committee or I will

because they have to be involved." 
We have only the expert nurse's interpretation of this situation, but it was apparent there was inadequate communication among the physicians, patient and family regarding the goals of care. Various authors have suggested that health care professionals may avoid end of life conversations because they view death as a disease to be conquered (Kaufman, 1998), an enemy to be defeated (Callahan, 1993) or a failure of modern medicine (Larson \& Tobin, 2000).

Although the expert nurse initially appeared to be in agreement with the continuation of treatment despite the presence of an advance directive, she indicated her distress that it had gone "on and on" and she was "inflicting suffering". The nurse's ethical reasoning is evident in the above scene and she questioned her possible "emotional" response which Callahan (1988) and Blum (1994) have suggested are requisite to moral action:

The resident was in favor of stopping the treatments but I called the ethics committee

They read through the chart RE and talked to me and talked to the doctors They talked to the family and the other nurses. And it was so clear. because I knew it wasn't right.

So it was a relief to know that it was okay to stop the treatments, 
that it was OK to turn it off.

Because the patient and family wanted it over.

And after that discussion

it seemed like the doctors were at rest

because they finally understood too.

RE

And they did turn the ventilator off

and explained to to him (the patient)

what would happen with the sedation

because he was still conscious.

So, his daughter was with him

EV

and it was good.

This expert nurse's decision to call the ethics committee was not made without difficulty. During the interview, she stated that she had initially believed ethics consultation was indicated for "maybe some horrible, horrible mistreatment of a patient" but then "had done some reading on it" and became aware of other indications such as "this patient". Although she thought that "maybe l'll be getting in trouble for doing this" and "maybe the doctors will get mad" she decided that "it was so overwhelming to me I couldn't just keep doing it."

The expert nurse participants' perception of the usefulness and availability of various consultation services such as pastoral care/chaplaincy and ethics committees varied considerably in this study. Three of the four respondents interviewed from the teaching facility where the expert nurse in the preceding 
narrative practices, reported satisfaction with ethics committee consultation. The fourth participant had not yet called for a consult.

There was minimal empirical research found on nurses' access to and satisfaction with resources such as ethics committees and pastoral care. Based on the overall high rankings related to perceived obstacles in working with families of dying patients, Kirchhoff (2000) concluded that critical care nurses need access to resources including pastoral care, ethics consultation and bereavement counseling.

In the following narrative, a patient is again considered vulnerable:

This was about a patient

$A B$

who no longer wanted any more surgery.

The patient wrote a note saying,

OR

"No more surgeries, no more, you're hurting me, this is killing me."

She had been through twenty five surgeries at that point.

But her doctor kept saying, "No, you need these."

And I felt uncomfortable

because the patient was alert and oriented

I'm doing my neurological assessment

so what l'm documenting on a legal document

says that she is alert and oriented. 
And then I felt that the things I was being asked to do were things that were against her will.

And so I refused to do those things.

In this opening scene, we are provided with an abstract or summary of what the narrative will be about followed by an orientation that briefly described the situation, participants, and what the nurse considered. Receiving mechanical ventilation and effectively being without a voice, the patient attempted to communicate her wishes through writing. It is not known how long the patient had been in the intensive care unit, but presumably after twenty-five surgeries, it had been a considerable length of time. Although not directly referring to ethical principles in the evaluative statements, the nurse indicated concern that the patient's autonomy was being violated and she was participating in that violation. The narrative continued:

And I actually stood there CA while he (attending physician) told a mistruth not a total fabrication of the situation but just some misleading information to try to make them sway his way. And then finally I just spoke up right there because I have to live with myself and he practices his medicine and my role as a nurse is patient advocate. 
It is unethical for a person that tells you "no"

just because they're not doing

what we would like them to do

doesn't demean their decision not to do that.

They still have a right to refuse.

And he said "But she's a little confused

CA

she's been ill for a long time."

But those are excuses to me.

EV

And I said, "Well I look at her

CA

and she's clear of mind."

And I mean a patient has a right to say no.

EV

Liaschenko (1995) has suggested that the end or aim of nursing is helping the patient to have a life, which nurses do by acting and speaking for patients. Helping patients have a particular life, one they consider their own, means enabling their agency or their ability to initiate meaningful action. Liascheno further maintained that the ethical significance of acting for the patient lies at the center of three linked concerns: the domain in which the need for acting arises, the vulnerability of the patient, and the potential for the abuse of power. Acting for the patient poses the greatest ethical challenge at the intersection of two manifestations of power, the personal and the institutional since the nurse can chose to act for institutionalized medicine as well as for the patient. In the above, scene the seriousness of the domain of sickness, the extreme vulnerability of the 
patient, and the inequality of power among the patient, the nurse, and the physician created the real possibility of coercion. The narrative continued:

So we stepped outside the room

CA

and then he was furious with me

for not being supportive of him.

Because several times she looked to me

because l've been with her

and she was looking for some support.

Her husband was trying to say it

EV

but he wanted her to live at any cost.

So when somebody offers a ray of hope

then why wouldn't you go for it?

He was doing it out of love.

And he (physician) told me that

I was just the nurse

and who did I think I was saying things

when he is trying to tell the patient what is going on.

CA

And I said, "Well, I'm a patient advocate

and what the patient is telling me

is that she is not in agreement with what you say".

And then he said I work for the hospital

and I work for him. 
And I said, "No I don't, I work for the patient".

And so I think I am very protective of my patients

EV

as if they were my own children.

Because sometimes we are the only thing as nurses

that stand between something that can be good for them

or something that can be bad for them.

The patient "looked" to the nurse for support because she had "been with her".

Their mutual engagement resulted in what Falk (1998) has described as

"empowered caring". As an ethics, empowered caring is contextual and

relational involving responsibility for others. Being responsible however, does not

imply paternalism but rather mutuality and helping patients to discern and make

choices that reflect their values and enhance their dignity. In the above scene,

the patient's agency had been essentially disavowed. Consequently, this expert

nurse identified herself as a patient advocate, one of only two participants in this

study to use the term, and spoke for the patient. Risk is inherent in advocacy and

this nurse risked incurring institutional reprimand in addition to the physician's

diatribe. In the evaluative statements, she described the reasons for her actions

as being "protective" of the patient and assisting her to attain what was "good".

This reasoning of what constitutes the "good" in this and other narratives

presented in this study, perhaps illustrates what Gadow (1996) has described as

essential to a "relational narrative". She has maintained that a relational

narrative is "not a solution to an ethical problem but a form of shelter, a 
provisional account of the good constructed by the patient and nurse as a way of making the situation inhabitable" (p. 9). The narrative continued:

So, I called the ethics committee.

It seemed like they came with their minds already made up.

The physician still really has the final say.

I felt very underserved by the whole situation.

They did not give any guidance.

So, the patient went for one more surgery.

RE

And then finally, because a group of us

felt good about speaking on her behalf,

he just kind of got worn down, the surgeon.

He realized this was all he could do.

And then she quietly passed away.

And that is sad.

EV

Because we did not expand her quality of life

and the time she had left.

We sure could have made it better.

If she hadn't had so many surgeries 
where she had sedation hanging on.

Each time it took longer and longer

for her to come back to us.

And we never changed the outcome one iota.

Rushton and Brooks-Brun (1997) have noted that although the ethics committee is designed to educate, promote dialogue, and resolve disputes, access is often limited to certain members of the healthcare team or the committee merely functions to maintain the status quo. In this large, urban, teaching facility, the other four participants' perceived usefulness of the ethics committee was similar to the above expert nurse's description. Consequently, when encountering ethically challenging situations such as the one depicted in the prior narrative, these nurses have limited supportive resources as all indicated they would hesitate to request another consult. Similar to other participants, this nurse spoke of gaining support from a core "group" of her peers to attain what she believed to be the best result for the patient. Wlody (1994) noted that nurses identified other nurses as their strongest support for their advocacy and Rushton (1995) has observed "nurses must create a supportive community that exercises their individual and collective authority to achieve optimal outcomes for patients and families" (p. 395).

Falk (1999) has also maintained that nurses are empowered when they recognize their own authority and expertise. Throughout the interview with the expert nurse in the preceding narrative, it was evident that she recognized 
herself as powerful stating at one point she was "blessed to be in the right place with the right skills". Later in the interview when questioned whether she would do anything differently should she encounter a similar situation as the one described above, the participant replied:

I think I would probably start vocalizing a little sooner about maybe this isn't such a good thing. Because the only regret I have about that particular woman is we all have our doubts but if you are a really good nurse, you have your instinct. And I just didn't really listen to it for a couple of weeks. My gut was saying this isn't right. I probably should have spoken up sooner. So now I listen to my instincts.

\section{Presenting a realistic picture}

In the second central plot emerging from the data, narratives about presenting a realistic picture were seen. Here, expert nurses spoke of assisting family members to reframe their sense of the potential for recovery of their loved one. The first exemplar presented concerns a woman with chronic obstructive pulmonary disease who had been admitted to the medical intensive care unit of a private hospital and intubated several times in the past:

She knew she did not want to be on a ventilator again

OR even though she wasn't very old.

She had no advance directive or living will.

But when I was admitting her she had said

“I don't want to be on a ventilator again, (nurse's name), 
"I have done this for too many years."

I said "I understand that."

And I knew she was not going to do well.

And within half an hour I realized

she was not going to survive if we didn't put her on a vent.

And I said

EV

“Do you realize if we don't put you on the ventilator, you'll die?

She said, "Yes, I don't care."

Although she couldn't speak that freely

OR

she needed to take a breath every half syllable.

I called the physician and gave him a rundown

and what she had said.

The RT was there to give her a treatment

so I went to suction my other patient.

OR

And before I knew it he (physician) was there.

CA

He told her it's just pneumonia

and we can get you through this.

But she was shaking her head no.

Now there were two other nurses

and a respiratory therapist in the room

because she had gone into an SVT of 150

and her pulse ox was dropping. 
They were trying to put in another IV

do an EKG and give her more oxygen.

Her CO2 (carbon dioxide) was going up

but she was still shaking her head no.

The doctor said "Your ABGs are very bad,

you're not going to live if we don't put you on the machine".

Then the daughter came in and she was screaming

"You've got to save her, don't let my mother die!"

I said "She doesn't want this, she's had enough."

But no one seemed to be listening.

EV

It was out of control.

Then the doctor said real loud

CA

"Do you want to live or do you want to die?"

So she kind of nodded her head

and they intubated her.

In expert clinical nursing practice, many crises are anticipated before the patient's condition actually deteriorates. This expert nurse realized that the patient's pulmonary status would necessitate mechanical ventilation and, having known her from prior admissions, attempted to clarify her wishes and communicate them to the physician. As the scene evolved however, we are again provided with a situation in which the patient's agency was denied resulting in what could be construed as coercion. Beyond the guilt expressed in the expert 
nurse's narration of this event, there appeared to be remorse and perhaps anger at an institutionalized system of health care that does not merely tolerate the above actions, but reinforces them. Liaschenko (1995) has maintained that nurses are socially and politically positioned in the spaces of health care authority and power to be the instruments of the "scientific totalitarianism" that pervades our way of life. A term attributed to Aldous Huxley (1974), scientific totalitarianism refers to a complex set of beliefs that science (and technology) will solve all human problems through the economic and institutionalized structures that ensure those beliefs are enacted. Some nurses share in this vision and thus do not feel any moral distress at the above scene. Other nurses, while rejecting the beliefs, find they are embedded in the intensive care unit culture and realize that resistance can incur criticism and institutional reprimand. As Benner et al. (1996) and Drought and Liaschenko (1995) have observed however, questioning the appropriate use of technology in achieving the goals of care, is characteristic of ethical expertise in nursing. The narrative continued:

And I got back in the morning

CA

and she wrote me a very firm note

that said "I told you no."

And this is what I think I did right.

EV

I had an opportunity to talk to the daughter.

And I said "Before you go in there

I want to let you know that your mother's very angry 
that she's on a ventilator again."

"Oh, but it makes it so much easier to breathe" (she said).

I said, "No that's a misunderstanding you have

it only ensures that she will breathe.

It doesn't make it easier to breathe.

It's very difficult to breathe on a ventilator.

You're used to breathing through this much

and now you're breathing through that" (using fingers).

And I tried to give her a realistic picture with those explanations .

But this is her mother and even when it was myself

it's not the same when it's your mom and your dad.

So when they (family) comes in and they're hopeful

EV

they're hanging on some bit of hope

I give them that moment for themselves

because they need that.

I'll say yes, that's a positive thing

but you have to be aware of the negative.

So I said to the daughter

CA

“You have to realize this isn't your decision, it's hers.

Make judgments for your mother she would want you to make.

She's not living a life that's consistent with life for her,

it's mere existence". 
So a few more days went by

OR

and she wasn't getting any better.

And I talked to the daughter a few more times

because it takes more than one conversation.

EV

And I didn't ask her to leave the room

OR

when I doing various things.

I didn't want to scare her (daughter)

but she needed to see what was happening,

the suctioning, turning, she had a decubitus too.

Because they were talking about putting in a trach and PEG.

And I think she came to understand it.

That we were just prolonging it.

EV

So they decided to extubate her soon after that.

RE

And her daughter was with her.

And she died peacefully.

In the above scene, the expert nurse used several strategies employed by other participants in this investigation to assist family members to reframe their sense of their loved ones' potential for recovery. She provided information about the reality of being on mechanical ventilation in plain, understandable language and encouraged reflection on what the patient would have wanted or valued in this situation. As have other respondents, this expert indicated her understanding that 
reframing and acceptance of probable death was an evolving process that took time.

Although the patient in the preceding narrative had a chronic disease with a high mortality rate, it appeared there had been minimal communication with her family and private physician regarding her preferences for aggressive interventions near the end of life. This lack of communication is not uncommon and has numerous reasons (Prendergast, 2001) and, as we have seen, the presence of an advance directive does not ensure the patient's wishes will be followed. Tolle, Nelson, \& Fields (2001) have noted however, that an advance directive, whether in written or verbal form, does influence how families reason about end of life decisions. In their study exploring reasoning about the decision to withdraw life-sustaining treatment, these investigators concluded that, in the presence of an advance directive, family members $(\mathrm{N}=97)$ were less likely to endorse prolonging life at all costs.

In the following narrative of presenting reality, the expert nurse discussed an elderly woman with cardiogenic shock who had been in the coronary care unit for three weeks:

The interns and residents believed that the treatment was futile $\mathrm{OR}$ but the cardiologist was being really vague with the family. He'd say "I have seen things like this improve" and "We have a few more things we can try." he had a problem with death. 
She was already on the balloon pump

and was probably going to lose her leg.

I think he had a problem with death,

he never wanted to give up.

And the family was really hanging on

because of what he was telling them.

I tried to give them basic information.

CA

l'd explain the patient is in renal failure

but they'd look down and see all the urine in the bag.

and say "Oh good, mama's kidneys are functioning."

But she's on a bumex drip and a dopamine drip.

Each time a family member came in

CA

I would explain it over again.

There were so many of them

EV and they all had different levels of understanding.

Kaufman (1998) has noted that family members of patients in the intensive care unit experience a kind of "existential crisis" as they are totally unprepared for the complexities of multi-system illness, the inherent technological possibilities, the language used, and the decision-making role required of them. Many of the nurses in this study expressed concern that family members did not understand the practical implications of the biomedical choices and treatments presented to them. Consequently reframing the potential for recovery was delayed. In these 
instances, nurses indicated that they often felt morally compelled to clarify for the family what the frequently "silent" patient was experiencing as a result of their daily interventions:

So a group of us got together and said

"We're not going to do this anymore."

Because the patient was suffering for no reason.

CR: Was she on sedation?

She was sedated and probably had some anoxia

OR

but she would respond if you let her wake up.

So we got the family together and sat them down.

CA

CR: When you say "we", what do you mean?

There are maybe three of us

who have been here for a number of years.

We are generally not afraid to state our opinion.

So I tried to paint a realistic picture and said

"This is what we do to your mother every day

we put these tubes to suction her

and stick her with these needles.

Her skin is peeling off because of the trauma.

We do this every day and it hurts.

We give her medicine for pain

but we think this is torture for her. 
She is not getting any better

and we're sorry you're being led to believe she will".

The language used by the expert nurse to "paint a realistic picture" in the above scene may be considered blunt and uncompassionate. However, several participants indicated that this candor was sometimes necessary with families in order to transform hope and allow the patient the possibility of a dignified death. Many nurses in this study seemed to value the notion of restoring the patient's dignity in the situations they described. The presence of invasive equipment, "tubes" and "lines" appeared to heighten their sense of patients' dependency and vulnerability, making his or her humanity or personhood, less recognizable. This finding was also discussed by Wros (1994) who noted that maintaining patient dignity was an important moral concern expressed by the expert nurses in her investigation. The narrative continued:

CR: Were there any problems with the cardiologist after that?

No. I think he finally accepted it. EV

The family got together and decided not to do anymore. RE They were able to spend some time with her.

They came to me and the son said

"Thank you for telling us what was really going on". Steinhauser, Clipp, McNeilly, and Tulsky (2000) explored patient, family, and provider descriptions of the components of a good death. While patient and family members valued the theme of "preparation for death", the investigators 
found that providers often avoided end of life discussions because they did not want to remove hope. Patients and families however, feared "bad" dying more than death. Bad dying was characterized as being in pain, and lacking opportunity to plan ahead, be together and say good-bye. With the support of her peers, the expert nurse in the preceding narrative endeavored to allow the family time for preparation. Preparation did not preclude hope, but reframed it to include the hope of a good death.

Kaufman (1998) has observed that family members of patients in intensive care units are often so overwhelmed by the technology and interventions continually performed, that they lose sight of what is actually happening to "the person in the bed." In the following brief narrative, this expert nurse endeavored to present a realistic picture of the patient as "person":

There was this mother of a very young boy who had cancer.

And what I have found very helpful with families,

I will tell them "tell me what you see."

I'll have them stand in front of the patient

and I'll say, "Tell me what you see."

And the family member will be looking at them

and they'll start crying.

It's almost like they hadn't realized.

And so I told this mother

to stand right here with me 
and tell me what you think.

And we just stood there for about five minutes. OR

And five minutes is a long time EV

when you're waiting for somebody to answer.

And she said, "He's dead." CA

I said, "Yes m'am."

She said, "The doctors told me we should do all this stuff."

And I said, "Well, you have the right to say no." CA

She said, "What should I do?"

I said, "Well, I can't tell you what to do

but I can tell you if it was my son

we would not be doing any of this."

So I feel that families really appreciate me.

EV

I feel that this is what they want to do,

to be helped to let go of their loved one.

And she sent a very nice letter to Mr. C (hospital administrator)

RE

she said that I helped her realize

what was going on with her son.

By definition, all patients are admitted to critical care units in an attempt to save their lives. It is not unusual therefore, for treatment options to be presented in terms of what can be done without clearly presenting the probability of success for the treatments offered. In addition, medical interventions and curative 
therapies have become our symbolic language of caring and valuing and not to do them may be construed as "writing someone off". Nurses are the ones who are most often present, who bear closest witness to the patient's and family's plight during the family's process of trying to understand how to proceed. In the above narrative, the expert nurse's simple action of encouraging the mother to actually "see" the patient, allowed acknowledgement of the transition from possible recovery to acceptance of death. In addition, the nurse shared her belief that further technological intervention would be intrusive and the mother had a right to say "no". Later in the interview, this participant indicated that assisting families to let go of their loved one was central to her ethical practice and shared the reasons for her actions:

I'm a firm believer in compassion and families because l've had to go through so many of these things myself. It makes it easier to understand what the families are feeling and why they need to be there. And I have seen where some of us in the nursing profession are not as compassionate about having the families come in and stay there. I like to do that because I know how they feel especially after my own husband passed away and we had to turn him off. I was able to appreciate the fact of being able to be there, to be there to the end. Instead of having somebody just come out there and say, it's over.

Stannard (1997) has observed that it is possible for nurses to work in critical care environments without attending meaningfully to patient and family member's 
concerns beyond the perfunctory "guest relations" level of being courteous and polite. However, when one experiences firsthand the human side of critical illness, dying, and death, it is seldom possible to return to previous levels of distance. Similar to the nurse in the above narrative, several participants in this study described how being a patient or family member of a hospitalized loved one changed their patient and family care practices.

\section{Narratives of resignation and frustration}

The third central plot from the narratives dealt with issues of resignation and frustration. Corley (1995) has noted that moral distress is a common response of nurses to the ethical challenges of critical care. Unlike an ethical dilemma where one does not know the right thing to do, moral distress occurs when one knows the right thing to do, but the institution or one's coworkers make it difficult or impossible to do what one knows is best (Jameton, 1993). Anger, guilt, and despair commonly result as the nurse feels morally responsible but is unable to change what is happening. In narratives of resignation, participants used several practices and behaviors described previously, such as presenting a realistic picture, but were unable to affect the patient's situation. This inability to reduce what was perceived as the patient's suffering, appeared to result in his or her own suffering initially experienced as moral distress and finally, resignation:

This patient came in for a liver transplant.

$A B$

She was here for six months.

She had a lot of complications. 
They had to take her back to the OR

because she couldn't breathe.

They put in a longer trach

then she went into renal failure.

CA

The nurses knew that she wasn't going to do well

but the doctors kept saying

she's going to do fine.

CR: What about the family?

The family hardly ever came.

CA

They came in the beginning

but it was like "Mom is going to do well

and we're going to take her home."

CR: Did anyone explain anything to them?

We're really not supposed to.

When she coded again

we (nurses) thought they'd make her a DNR

but they were like "No, there's viable life in this woman."

CR: This was the physicians?

The main one on the transplant team.

He won't make anybody a DNR.

CR: That is my next question. What do you do when your

expectation of the usefulness of aggressive therapies differs 
from the physician(s)?

We pretty much do the best we can.

EV

They pretty much have the higher power kind of thing

because they do make the last decision.

EV

We tell them our opinion,

CA

ask why they are continuing with this.

But they'll flat out tell you

because the life is viable.

And the ethics committee

won't buck up against Dr. (name).

The language used by the participant in the above scene indicated her perception that she and her peers, as evidenced by consistent use of "we", lacked enough power to affect the patient's course of treatment. Although she "knew" the patient was not going to do well, the physician had "the higher power kind of thing" and thus possessed ultimate decision-making authority. This nurse and other participants regarded the ethics committee in this institution as ineffective and unhelpful. The narrative continued:

CR: Did anyone talk to the family about making the patient DNR?

We tried in a round about way CA but the husband was just listening to the doctors. EV We told him that if she codes

OR 
we'll have to put her on medication

she might never come off of.

She was so thin

when you did compressions

OR

you could hear her ribs crack.

But they wanted to continue, they wanted to keep going.

And it was very hard on her

because time and again

she expressed that she didn't want this anymore.

And the doctors kept saying

she's not in state of mind to make those decisions

because she's been so sick.

We were keeping her alive

EV

and she was very angry at us.

She was so mad that we brought her back.

Worked on her for half an hour,

shocked her three times.

She was so totally mad,

EV

she would hardly look at us.

CR: Why did she code?

We think she stopped her breathing.

CA 
Put her finger in her trach.

She was so tired of it

EV

and she was hurting all the time.

She was like a little skeleton.

We had to rotate care

CA

because we would go insane.

I mean enough is enough.

EV

I felt so tired for her

and I would never have my loved one like that.

But our hands were tied.

When she arrested again this last time

RE

we worked on her for a long time again

but she was too far gone, too anoxic.

So she finally got what she wanted.

EV

This narrative evolved into one of resignation and, ultimately, moral failure with the patient as victim. One might question whether this nurse could be viewed as possessing expert moral agency as described by Benner et al. (1996 \& 1999) and discussed in the sensitizing framework. The ability to advocate has been identified as requisite to effective moral agency. While influenced by the nurse's personal characteristics such as self-confidence, this ability is also promoted or undermined by the culture of the unit and institution where he/she works (Rushton, 1995; Olson, 1998; Penticuff \& Walden, 2000). Morality is not 
hierarchical in nature however, nurses often work in systems that confer authority based on one's position in the organizational hierarchy.

Traditionally, the analysis of moral problems has been directed to physicians, and nurses have been marginalized and often excluded from the discourse. This tendency for nurses to be viewed as subordinates has often undermined their authority and hence their moral agency. In the unit where this nurse practices, several participants indicated that they were "listened" to when expressing concerns about the moral implications of continuing aggressive treatment, but essentially ignored. Indeed, during the interview this nurse stated that this attending surgeon frequently gave an hour-long lecture regarding his "ethical outlook" on such matters. This unit was without a nurse manager at the time of the interview, so administrative support in addition to perceived usefulness of consultation resources, was also lacking.

Critical care nurses suffer when treatment goals are unclear or unchallenged, when they believe they are performing procedures that are viewed as harmful or of low efficacy, and when their advocacy is ineffective (Rushton, 1995). Rushton has maintained that prolonged, unrecognized suffering can be detrimental and lead to disengagement and silence. Habitual silence or silencing in the face of perceived wrongs can result in permanent, deleterious changes in ethical values (Dwyer, 1994). 
The following narrative was related by this nurse in response to the question "What do you do when your perceptions of the usefulness of aggressive medical therapies differs from the physicians?"

We're very limited in that.

We had the perfect example $A B$

what went on down there in the corner.

A patient who had a subarachnoid hemorrhage

and for some reason his colon dilated.

We pumped in over a hundred units of blood.

The family's wishes were to do everything possible.

And the physicians weren't going to do anything less.

CR: If you perceive the family isn't understanding what's going on, is there anything you to help them realize?

Basically we just escalate awareness.

OR

If the residents aren't doing anything about it

we can take it to the faculty.

But that faculty, Dr. T, did few patients

and they all have great outcomes.

She does not normally have patients die here.

So they said "There is a possibility

and we've got to get him better because we don't know.

He had an anoxic injury but we don't know what his level is. 
He's in a coma but it might be from his kidneys".

They didn't want to say it's over. EV

They wanted to keep on going, keep on cutting. CA

Cut out more bowel, do another resection.

But this patient was going to have a horrible outcome.

EV

And it's a crime what we're doing.

But the family wanted everything done.

CA

And so, I said to the renal doctors,

"This is ridiculous, we should call the police on you

because this is a crime."

CA

And they weren't giving the family an update

EV

they were tippy-toeing around it.

They weren't telling them his prognosis is horrible

and he's had an ischemic stroke.

So, the family wanted everything done.

CA

The physicians will never say he has a $0 \%$ chance of survival. EV

The doctors here will never say that.

They'll give them a 1 or $2 \%$ chance.

So I said to the family

CA

"You know this is his function,

he is bleeding so bad into his head

that it is shutting his brain stem down to his spinal cord 
that's why his heart rate is so high."

But it didn't matter.

And we could have called the ethics committee

but the ethics committee is being chaired by a neonatal doctor and she won't do anything about it.

The ethics committee has very little power in the hospital.

They'll do whatever the physician wants to do.

They will not take a stand

They will not get involved.

And that patient finally died

RE

after all those resources were wasted.

EV

So I think I am really frustrated now.

From lack of nurses

and the number of nurses who are leaving.

Our ability to get supplies

I mean, that is the biggest frustration now.

You get to work and we're keeping these people alive.

I mean I can transfuse this person

and all it's doing is running off onto the floor.

We're sucking up resources

and all our energy for this uselessness.

There are five other people waiting for this bed. 
We don't have nurses, no one wants nursing.

Last week we had five nurses quit.

We had another nurse quit yesterday.

We have no supplies.

The above narrative illustrated several conflicts expressed by other participants in this study including the use of ambiguous technical language, the conveying of false hope to family members, and the perceived ineffectiveness of the institutional ethics committee. In addition, this nurse employed several actions explored in previous narratives including presenting a realistic picture to family members and communicating perceptions of poor prognosis to physicians. The essential focus of prior narratives presented appeared to be the promotion or restoration of patient dignity and provision of comfort. In contrast, the central focus of the above narrative seemed to be the nurse's frustration regarding the use of scarce resources with no apparent benefit.

In analyzing this narrative and comparing it to others, I recalled Gilligan's (1982) discussion of the two moral "voices" or "orientations" of "justice" and "care". Gilligan et al. (1989) observed that the distinction between justice and care as moral perspectives pertains to the ways in which people conceive and define moral problems and reflects two different dimensions of human relationships that give rise to moral concerns. A justice perspective reflects concerns with problems of inequality and principles of fairness. A care perspective draws attention to problems of attachment and abandonment by 
holding up an ideal of attention and responsiveness in relationships. Identifying the predominant perspective reflected in the expert nurses' narratives was not the intent of this study, however one might conclude that the preceding narrative reflected primarily a justice perspective characterized by rational, objective detachment. Gilligan et al. (1989) noted that the perspectives are not dichotomous, or mutually exclusive, and may shift over time.

Recently, Gadow (1999) proposed a dialectical framework for nursing ethics in which the care/justice perspectives might coexist and inform one another as expressed through a "relational narrative". Characterized by intersubjective engagement between patient and nurse, a relational narrative does not entirely negate interpretations of rational detachment or ethical certainty. Rather, it reflects a postmodern alternative to both as "it portrays the good that is being sought and is a story that the patient and nurse construct together to reinterpret a situation in a way that alleviates vulnerability"(Gadow, p. 65). I would offer that many of the narratives related by the expert nurses in this study exemplify that reinterpretation.

\section{Thematic Analysis}

Thematic analysis of the nurses' responses that did not take a narrative form yielded three main themes and twelve sub themes. The theme of assessment addressed what the expert nurse assessed or perceived that indicated poor patient prognosis and included the sub-themes of clinical, relational, and ethical assessment. The theme of actions addressed what the 
expert did when his/her perceptions differed from the family and/or physician(s).

Participants' actions with family members included the sub themes of: presenting a realistic picture, determining patient wishes, consulting additional resources, and distancing. The expert nurses' actions when perceptions differed from the physician(s) included communicating perceptions, encouraging empathy, and consulting additional resources. The third theme of reasons addressed the participants' reasons for their action and included the sub themes of professional values and personal experiences. Each theme will be discussed.

\section{Theme: Assessment or "seeing the big picture"}

In describing what they assessed or perceived about the patient that indicated poor prognosis, participants frequently mentioned, "seeing the big picture". The knowledge derived from the integration of clinical, relational, and ethical assessment was seemingly prerequisite to taking action in the situations described.

\section{Sub theme: Clinical Assessment}

Initially, many of the nurses stated that they associated probable poor outcome with the patients' medical diagnoses including multiple organ dysfunction syndrome (MODS), adult respiratory distress syndrome (ARDS), and renal and/or liver failure. In addition, the patient's age and concurrent illnesses were mentioned as predictors of survivability:

Well, I guess the first thing would be the pathophysiology and the diagnosis. Kind of knowing what the diagnosis is and the morbidity and 
mortality rate. And the age of the patient. I mean an 87 year old compared to a 35 year old person. The 35 year old, his body is able to fight a lot more.

Clinical assessment data discussed by the participants also included information obtained by means of diagnostic technology, such as cardiac and respiratory values and other indicators from monitoring devices, in addition to the results of laboratory tests. Continual need for escalating medications such as vasopressors, sedative agents and neuromuscular blockers was discussed as indicative of poor prognosis. Similarly, inability to maintain adequate ventilation and oxygenation even with maximal support was associated with eventual poor outcome:

He has multi-system failure. His lungs are gone. We can't decrease his FIO2. He has something going on in his stomach and he has no bowel sounds. He's been off sedation for three days and hasn't woken up.

Clinical information obtained through physical examination and observation of parameters such as color, tone, skin or wound status and activity level were also described by the respondents when discussing indicators of poor prognosis:

They're losing their muscle tone, getting more flaccid. Even the patient who can move a little bit, they just lose the tension in their muscles. They are having to stay on sedation therapy too much and 
having short bursts when they need vasopressors.

Pattern recognition was also evident in several of the nurses' responses: At this point in my career, it's a case of what I'm seeing and what I've seen before, that's what it's pretty much based on. Usually it's the patients with pneumonia or ARDS. They're just not progressing.

Similarly, this nurse comments:

I think what brought me to an understanding that the patient would not do well, some of it was based on the amount of injuries I saw and what I've seen in the past. How many patients I might have had that actually recovered from those type of devastating injuries.

Further analysis of the responses regarding indicators of poor patient prognosis revealed that most of the expert nurses used distinct types of data or perceptions that are similar to those identified by Anspach (1993). In her ethnographic study exploring ethical decision making in two neonatal intensive care nurseries, Anspach (1993) determined that estimating infants' prognoses was based on the integration of technological, perceptual, and interactive information. In the present discussion of the expert nurses' responses, technological and perceptual data is subsumed under clinical assessment and interactive information is considered relational perceptions. In addition, a further distinction is made between clinical and ethical perception.

\section{Sub theme: Relational Assessment}


Despite the often hectic environment of the intensive care units, knowledge derived from relational assessment appeared to develop over time. The expert nurses frequently referred to "being with" or "knowing" the patient and/or family members for several eight or twelve hour shifts. For the patient who could not communicate, relational knowledge appeared to reflect the nurse's understanding that the individual as a person had disappeared:

The other thing was staying at the bedside with the patient, the kind of interaction with the environment I would expect, I didn't see evidence of that from the patient. I didn't see them responding to me. It was almost like he was there in body only.

Similarly, another nurse commented:

This patient had gotten septic over a few days and I had been with her for each twelve hour shift and knew how she was. She couldn't communicate of course but I had felt she was in there and participating. Now I didn't see that anymore.

Several nurses also described previous conversations with patients in which they related their concerns regarding continued aggressive medical treatment. These discussions often enabled the nurses to communicate their knowledge of patients' wishes when they were unable to:

Knowing what he was like before. He looked over at another patient and said "(name) don't ever let them do any of that stuff to me if it comes to that. I don't want to live that day after day no matter what anybody says." 
Although they referred to knowledge derived from clinical assessment when determining poor prognosis, the neonatal nurses in Anspach's (1993) study consistently mentioned interaction data. Anspach (1993) noted that interaction data was based on perception of infant responsiveness, level of awareness, or "human hood" and evolved from the close nurse-infant relationship. The author observed that the neonatal nurses were the first to integrate clinical and interactive knowledge and conclude that an infant would not recover. Similarly, the expert nurses in this investigation described objective clinical data but also discussed knowledge gained from their relationship with the patient and/or family, which seemed essential to their ethical perception.

\section{Sub theme: Ethical Assessment}

To take action in the situations described in this investigation required more than expert clinical assessment skills. Knowledge derived from the nursepatient/family relationship also did not appear sufficient. As discussed in the sensitizing framework, expertise involves not only clinical observations and relational understanding but also the ability to identify a situation as an ethical problem or ethical perception. Indeed, many of the nurses in this study provided narratives or responses that indicated other nursing colleagues and physicians were aware of but did not (or could not) acknowledge the patient's poor prognosis and the futility of further interventions.

Emotional attunement appeared central to the expert nurses' ethical perception. Emotions such as compassion and empathy are crucial to 
"particularity", the understanding of particular persons in particular situations and essential to accurate perception of a situation and its component morally significant features (Blum, 1994). Empathy involves an ability to see and listen which means paying attention to or receptivity, a prerequisite to action. As evidenced by the expert nurses in this study, empathy engendered an appreciation of how the patient experienced his or her situation and facilitated reaching out and gaining access to that experience:

It's like what if it was me and no one was here to make my decisions and I was laying here like this? I wouldn't want to do that. We're not doing anything here but prolonging the agony of the patient and doing horrible things to her.

Another nurse commented:

Being with the patient eight hours, you see what they go through and you suffer with the patient and the family with what we have to do to them, the humiliation. We're putting in foleys we're attempting IVs, suctioning, all that stuff. You put yourself in their position and say, "God if it was me, I wouldn't want this stuff done."

Similar to other participants, this nurse reflected an embodied awareness in which she remained fully connected to the patient. This embodiment enabled her to be aware of her own body and aware of how it must be for the patient. Compassion, described by Blum (1994) as "not just a feeling state...but an active 
regard for the other's good" (p.87), is reflected in the respondent's quotes or evaluative statements and in their subsequent actions.

\section{Theme: Actions}

When requested to describe what they did when their perception of the usefulness of aggressive medical therapies differed from the patient, family members, physician(s) or peers, the expert nurses primarily discussed situations involving family members and/or physician(s). Actions when perceptions differed from patients generally involved determining wishes for life-sustaining treatments, providing information, and obtaining advance directives. Several nurses from one facility with high recidivism indicated that they were very proactive in this regard and patients often felt more comfortable talking to them because of their long-standing relationship:

I talk to the patient and ask them if this is what they really want...if they're alert and this is their end stage, I ask them if they want to be intubated, explain dialysis; I try to find out before they get to that end point, talk to them about the quality of life.

Similarly, this nurse commented:

There's two of us in here that really monitor. This may sound kind of morbid, but when somebody comes in and they're really sick and have a lot going on, we look at their status, if they're a DNR (do not resuscitate). And we ask them "What do you want us to do?" Because the doctors will get in a situation when they're already giving treatment. And once the 
three ring circus starts, it's very hard to stop. So we tell them if something were to happen, and we give them scenarios, what would you want?

If the patient could not communicate, several nurses stated that they would provide support and comfort but avoid conveying "false hope":

I try to speak positive and comforting things, not so much things like false reassurance like you're going to get better and this kind of stuff but more like rest now and things the patient can be comforted by; I will encourage the patient even though I think they will do really bad but not be too overly optimistic.

None of the nurses interviewed related situations or narratives in which their perceptions of poor patient prognosis differed from peers. They frequently mentioned validating their assessment with a "core" group of co-workers to gain support in approaching physician(s) and family members and to present a "solid front":

A lot of the nurses have been here a long time, some for twenty-five years. So it is a very cohesive group and we work together really well. That day (name) was in charge and I brought her into the patient's room and said "look at her, what are we going to do?" So she knew and agreed that I should call the doctor.

Another nurse commented:

There is a core group of us, about five, and we are the ones who will usually question and take the initiative. Some of the newer nurses aren't 
comfortable speaking up so I think it is our responsibility to establish a relationship with the doctors and intervene.

Expert nurses' actions when their perception of poor prognosis differed from family members included presenting a realistic picture, determining patient wishes, consulting additional resources and distancing. The participants' actions when their perceptions differed from physicians' consisted of communicating perceptions, encouraging empathy, and consulting additional resources.

\section{Sub theme: Presenting a realistic picture}

If asked directly for their opinion of the patient's prognosis by family members, the majority of participants acknowledged that they felt obligated to state what they believed as evidenced by the following:

It is hard to look a mother in the eye when I have my own children at home and say, "I'm sorry, I don't think Johnny is going to make it." But I have to do that because when a mother looks at you desperately in your eyes and it's just you and she standing there you know she's asking you for the truth. She is not asking you to tell her something that is not true. And she will know.

The nurses in this study consistently attempted to provide and clarify information about the patient's medical condition and treatments. The participants indicated that this understanding was necessary for family members in order to acknowledge the transition from the possibility of recovery to acceptance of 
probable death. Several nurses referred to this transition as a "process" which takes time:

A lot of times it takes the families a while to see because sometimes these patients have been healthy. They've been out mowing the grass, they have a heart attack, they code and then you're telling the family his mind is gone. They don't understand. So it takes time and acceptance.

Another nurse stated:

Another thing is to always be there because it takes more than one time to help a family realize they are losing their loved one. They don't just deal with it and then they're fine because it is a process that takes time.

Jczewski, Miller, and Battista (1993) reported similar findings in their grounded theory study of critical care nurses $(\mathrm{N}=22)$ interactions with patients and family members during the process of consenting to DNR (do not resuscitate). The nurses in the investigation indicated that consenting to DNR is a process that "takes time and timing" (p.303). Jczewski et al. (1993) noted that the nurses' role during this time was often that of "information broker" in which they explained the patients' situation and encouraged family members to "see" the patients' condition (p. 307).

Expert participants in the present study indicated that they believed it was necessary for family members to sustain hope but maintained that it had to be "based in reality". Almost all the nurses interviewed expressed concern with the amount and type of information given to families by physicians that they believed 
frequently resulted in confusion and false hope. Consequently, family members were made to feel guilty about decisions to withdraw care and denied permission to let the patient go:

It is very wrong to tell a person that if we do one more test he will be stable. I like to make them (families) understand what it is we are butting up against. I don't like to build up all their hopes but you and I know that false hope is just as bad. To me it is very wrong to tell a person that if we do one more test the patient will be stable. And we should not ask the families do they want us to do anything because they are not going to say "no". No family member wants to say "I decided that this is the day that he's going to die". Does the family know what dopamine and levophed and all this other stuff is for? I don't think so. Talk to them and tell them he is very bad and might not make it but don't ask them do you want to do this or that. They aren't educated to make those decisions. There are a couple of attendings who have my respect because they understand that. We have a few others who will not even talk to the families. But l'll stand up for people. I cannot stand to have guilt put on families. That is one of the worst things. One of the worst things.

The nurses used various approaches to clarify what they believed was often ambiguous "technical jargon" provided to family members. Several respondents tried to always be present when the physician was discussing the 
patients' status while others questioned family members' interpretation of the conversation:

When they go off to talk with the physicians l'll ask them to tell me exactly what they told them. They docs will tell them "they're hanging in there" or they have a "30\%" chance. Well, yes maybe she's hanging in there but this is a problem and this is a problem. Those that are clinging to the $30 \%$ hope don't hear the problems so you spend 12 hours saying "but don't forget she still has these problems and this isn't a good thing".

Another nurse commented:

I tend to give the families a lot of information because if the docs talk to them they don't give them the full picture. They don't take the time to make it very clear and paint the picture of how horrendous it will be if we continue. They approach the subject so gently and I think a lot of them don't have the comfort level because we're dealing with residents. They aren't explaining in detail to the family that the patient's ribs will be broken, that this is a natural occurrence of resuscitation. So, you see the family kind of confused. They have a totally different concept of what will happen. CR: Do you feel comfortable doing that?

If it's for my patient's benefit to be able to have a dignified death. I don't want to put people through something that they shouldn't have to go through if I know in my heart what the end result is going to be. 
Many participants also attempted to provide continuity of care, which they perceived to be essential to maintaining consistent communication with the family, thus enhancing understanding and preventing false hope:

I'm very persistent when I'm giving report. I'Il say, "This is what I told them, this is what we need to say to them" so we're all on the same team. When they family doesn't understand how bad it is, we need to convey a specific message and we need to pass it on to the next nurse.

In presenting a realistic picture, participants often attempted to demonstrate what everyday care was like for the patient. They did not ask family members to leave when various treatments and procedures were performed so they could "see what was happening":

In a case where we're trying to show them how it is for the patient, I have them stay in the room. If they want they can stay through everything and I explain to them what it feels like to be on a ventilator and what it feels like to be stuck and how uncomfortable they are even though we try to make them comfortable with medications.

In addition, the respondents encouraged family members to envision what life might be like for the patient if he or she did survive:

Making them look at the long term because sometimes they're only looking at well, they're in the hospital and this is what's going on now. And so, you ask what's going to happen when they leave here? Do they have insurance to pay for a nursing home? Do they have someone at home 
who's going to be able to provide the care? And usually the first response is "oh yeah, we'll take care of it". Then you start to explain to them what it is they're going to have to take care of and it makes them stop and think. Of the twenty-one nurses interviewed, only one participant stated that he would not tell family members anything that was in disagreement with a physician's opinion of a patient's prognosis because he or she "had to have the family's trust":

Anything that I tell them I make sure it's the doctor's opinion too. I talk to the doctor about my opinion.

CR: How do you do that?

Just by asking them first, what they think and then l'Il give my opinion. CR: And what if you opinion differs? Does it ever differ from what they're thinking?

(Long pause) Sometimes. When I think about a patient we should let go. But there might be some different point I was not thinking or something I was not understanding. I mean there has to be a reason why the doctor was thinking this kind of thing and they know more about the patient.

This respondent attributed his overall conception of the nurse's role to his Filipino culture and the educational system for nurses in that country. In addition, he observed that in the Philippines "if we have the means, we try to do everything as long as the doctor believes something can be done." 
Since the 1970s numerous investigators have identified the needs of family members of critically ill patients to obtain consistent and understandable information about their medical condition, to maintain hope, and to be assured that the best possible care is being given (Moulter, 1979; Swigart et al., 1996). Although family members rank communication as a preeminent concern, existing evidence suggests that this component of intensive care still requires much improvement particularly in regard to end of life topics. Dominance of the technological imperative and persistent use of ambiguous or confusing language delays acknowledgement of the transition from possible recovery to probable death (Johnson \& Wilson, 1998). In presenting a realistic picture, the expert nurses in this study endeavored to assist family members to reframe their sense of the potential for recovery of their loved one.

\section{Sub theme: Determining patients' wishes}

The nurses in this investigation discussed patients who often had advance directives or had voiced their wishes concerning aggressive life prolonging measures to family members. In addition, several patients had expressed their thoughts to the nurses on prior admissions. Acknowledgment and acceptance of the patients' wishes however, often occurred as part of the "process" described by the respondents in the sub theme above. Realization that recovery was unlikely first involved enhancing understanding of the critical illness and deterioration and the reasons why it could not be halted. The respondents then 
frequently encouraged family members to reflect on what the patient would have valued in the situation:

So, I try to bring it back to the patient's wishes or what would the patient do if he was up there looking down? What would he think? Would he have wanted to live like this? I'll explain all the tests and procedures that are ordered and ask them if they think their loved one would continue to want to have these things done.

Many of the expert nurses indicated they believed family members were overwhelmed by the incomprehensible language and technology that pervades the intensive care environment. Consequently, they were often incapable of making decisions regarding their loved one whether or not the patient had expressed their desires previously. Since many patients could not represent themselves, the participants often encouraged reminiscence. In this way, family members could attempt to fit the unclear end of life pieces of the "life puzzle" with the experienced and remembered life of the family member. To augment this approach, nurses encouraged family members to "see" the patient as they are now and contrast it with how they were or wanted to be or live:

You start asking them about who this person was. Sometimes we have patients who are very non-compliant and you point out to the family that this was a choice they made. This patient was in last month and signed out AMA (against medical advice) because he didn't want any of this stuff done. When he came back he was no longer able to make his own 
decisions. So the sister can look at him now and, although she wants him to live, she doesn't want him to suffer.

\section{Sub theme: Consulting additional resources}

Access to, availability, and perception of the usefulness of resources such as the ethics committee, and pastoral or palliative care varied greatly among the expert nurses and was dependent on the facilities in which they were employed. When encountering difficulties with family members recognizing or accepting the patient's poor prognosis, the respondents discussed consulting a chaplain or pastoral care most frequently or having interdisciplinary conferences:

We no longer call ethics because it has not proven useful to us...they do not seem to want to get involved, if that makes any sense. What I have found more helpful is (name) our pastoral care person. When we have difficult families, we bring her in to talk to them and sometimes she can share with us what their feelings are. She talks to them and listens to what they're saying so we know better how to approach them.

Another nurse from a different institution commented:

The chaplaincy in this system is very strong. We call on them for help with families or for ourselves if we are having a hard time. They will also intervene with the ethics committee so often we start with them. There is even a list by the phone about why you should call the chaplain. The participants frequently recognized the need for and initiated interdisciplinary conferences with family members who were having difficulty 
accepting the patient's probable poor outcome. However, the nurses were often not able to attend the conference because of staffing or were not included in the discussion:

We have family conferences so that the multiple doctors for the patient can get together and agree because one will say there's hope and the others are doom and gloom and the family's getting a mixed message. The chaplain and social worker are there also. Sometimes the primary nurse will get to go but the physicians do most of the talking.

\section{Sub theme: Tempering involvement or distancing}

Nurses who work with the very sick, suffering and dying are accustomed to the question "how can you do that?" Indeed, the nurses in this study stated that they often asked themselves the same question. It is widely proposed that nursing identity lies in the nurse-patient relationship (Gadow, 1980; 1989; Bishop \& Scudder, 1990). This simple statement, however, belies the fact that our relationships are not simple. Rather, nursing is often an "ordeal", which is a characteristic of all meaningful relationships (Maeve, 1998). Being in a relationship with a patient results in the nurse necessarily sharing the essence of each individual's experience. As discussed previously, embodied nurses recognize and associate, wholly, the experience of the other. A challenging paradox existed therefore, for those expert nurses who were unable to alter the continued use of what they considered unwarranted aggressive medical treatment that they were professionally obligated to implement. Tempering 
involvement emerged as a protective strategy in which nurses attempted to set limits on their relationships with these patients:

You can ask not to take care of that patient for awhile. We have had several patients who have been here for a long while and you know they are not going to make it and it becomes torture for both you and them to have to inflict this stuff day after day. So, you can ask not to take care of them but somebody is going to have to do it and it may not be good for them either.

Similarly, another nurse comments:

You know you can change assignments. But when it comes down to the point where many of the nurses in the ICU feel that way, then where do you go with somebody taking care of that poor soul? Even though we are not buying into the process, somebody still has to care for them.

This nurse is speaking about a patient who had numerous complications following a kidney transplant and had been in the ICU for three months:

We try to rotate care. We've talked to everybody (family members and physicians) and they just keep going and going and going. Now she (patient) is so angry after we brought her back (resuscitated) this last time. She'll beat the side of the bed to get your attention and you have to gown and glove to go in there. She tried to hit one of the girls the other day. So 
you have to set limits because we're here for twelve hours with her day after day.

\section{Sub theme: Communicating perceptions to physicians}

The majority of expert nurses in this study communicated their perceptions of poor patient prognosis in a direct manner with physicians. There appeared to be minimal playing of the "doctor-nurse" game. As originally described by Stein in 1967, in the "doctor-nurse" game nurses offer significant advice and recommendations that, in retrospect, appear to have been initiated by the physician thus appearing to passively defer to physician authority. The "game" ensures that open disagreement is avoided, the physician gains from the nurse's knowledge, and the nurse, according to Stein, experiences professional satisfaction. Passivity was generally not prevalent in the expert nurses' communication with physicians in this investigation although they used various strategies to convey their perceptions. As discussed in the sensitizing framework, one of the characteristics or behaviors associated with expert moral agency is the establishment of collaborative relationships with co-workers. The participants attributed their ability to communicate with physicians and have their assessments and perceptions respected to interprofessional relationships and amount of time in their positions:

I've been here for a long time so I know most of the attendings from when they were interns and residents and I think that helps me address them. 
When I talk to them, even though other nurses have said the same thing, they know I am not going to tell them something that is not true.

This nurse is discussing her communication with a trauma surgeon regarding a patient whom she believes has a poor prognosis:

I will always ask "why". Because I've known them long enough that they knew that I knew what I was talking about. So, I communicate well if they know who I am.

Another nurse commented:

I will listen to the doctors on rounds and if I have something to offer I'm very fortunate that the attendings and fellows will respect whatever I have to say. And I have stood there and if they say they want to continue life support, I've said, "I don't agree with this, I think we have gone far enough and have put the family through enough." And I have had the attendings say "OK".

In communicating their perceptions to physicians, expert nurses in teaching facilities who comprised the majority of the sample in this study, spoke of using the "chain of command". In this approach, participants initially voiced their concerns about the benefit of continued aggressive treatment to the intern or "the first person writing the orders because they need to have the decisionmaking, they need to learn that." However, several respondents stated that they believed interns and residents were unprepared to recognize or acknowledge the 
transition from cure to an understanding that further treatment would not achieve the intended outcome:

A lot of these young doctors pull back. They're afraid to say, "enough is enough" or "I think there is nothing more I can do here". A lot of them have never even seen someone die.

Similarly, this nurse stated:

I have spent most of my experience at a teaching hospital and those physicians who are learning about things have a difficult time knowing when enough would be enough for that patient. They are just here for a month and are more focused on interventions than on the big picture.

If the intern or resident did not intervene in the situation, participants would "move up the ladder" and communicate their perceptions to the fellow or attending, generally whomever they knew better. Many nurses related difficulties communicating with physicians in certain specialties, most notably surgeons and oncologists who were often described as "unrealistic" and "not knowing when to stop". Although the nurses persisted in communicating their perceptions, they approached other physicians who they believed were more amenable to listening to their concerns. The patients discussed by the respondents had several physicians or groups of physicians so it was often a case of determining who would listen and have influence among the others.

The content of the nurses' communication with physicians often included their perception of the patient's deteriorating physiological status and failure to 
respond to interventions. In addition, they conveyed their understanding of patient and/or family wishes as illustrated in the following excerpt:

When the physicians come in and suggest things that I know are not going to benefit the patient...I ask them to think about what the outcome of that is going to be. I told the physicians yesterday about this patient ... because all the family was waiting for was the physicians to say "enough". The family has had enough...they want him to survive but they don't want to see him like this, they don't want to torture him.

Often the expert nurses would attempt to enhance the family's understanding of the patient's deteriorating status and then facilitate discussions with the physicians:

Some doctors know we're closed from 6:30 to 8:30 and they want to come in and do their stuff and write the orders and they want to be gone before the family comes at 8:30. They don't want to answer their questions or spend time with them. And so, we tell the family to ring as soon as they get here so they will be here when the physician walks in. And the physician doesn't like that but the family has a right to know.

\section{Sub theme: Encouraging empathy}

In conjunction with communicating their perceptions of poor patient prognosis, family and patient concerns, and facilitating discussions with physicians, several expert nurses also attempted to encourage empathy. They 
spoke of bringing physicians to the bedside and asking them to "see" the person not just as a "patient" but as a family member:

I find that if I bring them in there and ask them to really see the patient because usually they (physicians) are just in and out and the patient looks good because they are all cleaned up. So I don't think they really look and see the person as they really are with all the IVs and tubes and what we are doing to them. I'll ask, knowing what they know, would they really want this stuff done to their mother or father?

Another nurse commented:

Basically one way I found to deal with it is we are all human and as opposed to being a nurse or a doctor arguing about something I try to get on a personal note with them so they can identify instead of having it be an altercation. Because I'm asking for something maybe they are not comfortable dealing with. So sometimes I ask them how would they feel if this were their grandmother or mother? To draw on their personal experience and see if we can make it better for this patient and family.

\section{Sub theme: Consulting additional resources}

Similar to the use of consultation services for family members, access to, availability, and perceived usefulness of these resources in conflicts with physicians varied considerably among the participants. Often when the expert nurses were unable to alter physicians' decisions to continue aggressive medical treatment, they would initially request the nurse manager to intervene: 
So basically if I cannot get what I want, I'll have our nurse manager call them. And when (name) calls them then they know we are tired of discussing it quietly. She will get involved and ask them "What are we doing here? This is non-survivable."

Another nurse commented:

I try to get (nurse manager) to discuss it with them if I feel like I'm not getting anywhere and the patient is suffering. She is very supportive and has been here a long time. She is also on the ethics committee so she can often talk about using more influential language or call for a consult herself.

Whether the expert nurses sought consultation from the ethics committee was frequently dependent on the facility in which they were employed and prior experiences. In one institution in which several of the respondents worked, the general feeling was expressed by this nurse:

Because you have to have the attending on line for that (to call for an ethics consult). And that's one thing that's really frustrating. It's frustrating to get ethics involved anyway because they don't seem to want to make a decision. I wish they were more active, make rounds once a month or have a meeting to discuss ethical issues. We need an actual team we can call with a beeper and a schedule.

However, the perception in another facility was entirely different: 
I have found the ethics committee to be very helpful. Any one can call at any time. They are very impartial and will listen to everyone involved. In this patient's case, I believe they made very good recommendations. So at least you feel like there is some recourse.

\section{Theme: Reasons}

In discussing the reasons for their actions in the situations described, the expert nurses mentioned professional and personal values in addition to personal experiences that appeared to enhance empathy. The participants also referred to personal characteristics, which enabled them to act including maturity, knowledge, and communication skills.

\section{Sub theme: Professional Values}

The predominant value expressed as a reason for action by many of the expert nurses in the situations described was that of responsibility to do what they believed to be right or good for that particular patient. The participants indicated what they believed to be good or right was the restoration or promotion of patient dignity and the provision of comfort:

I think it is our responsibility, part of our professional responsibility. You have to look inside yourself and evaluate what you really believe to be right in that kind of situation and then actually committing to that.

Another nurse commented:

Being here with the patient twelve hours a day, it is a responsibility I have to communicate what I believe to be right. It's the responsibility I have of 
protecting the patient or doing what is right for the patient in the end. If they are going to continue things no matter what, and I have a patient who can't communicate with me then I want him dignified. If I know in the end what the outcome will be then I take an active role because I believe in comfort and dignity.

Similarly, this nurse stated:

So, it's a responsibility I have to understand it just like I have to understand what lasix is. I'm a firm believer in patient dignity and some of the things that are done to these patients I would not do to my worst enemy. So, to allow the person to have some dignity without all these tubes and lines and continuing all these things for someone else's purpose.

The reasoning reflected in the above quotes appeared consistent with the consequentialist approach as described by Penticuff and Walden (2000) in which actions are evaluated in terms of what patient good or harm will be produced. The authors noted that, in comparison with deontologic reasoning, which emphasizes adherence to ethical principles, consequentialist reasoning is contextual as it stresses the "morally relevant aspects of individual cases and ...the consequences of acting in one way rather than another to resolve the dilemma" (p. 68). In their study exploring perinatal nurses' $(n=127)$ willingness to be involved in activities to resolve clinical ethical dilemmas, Penticuff and Walden (2000) also found that nurses who reasoned in this manner were more likely to 
take action. This finding was elucidated in several of the expert nurses' narrative exemplars in this study.

\section{Sub-theme: Personal values}

Several participants stated that the personal value of a belief in God both enabled and sustained their actions in the situations described:

If a family member asks me for my opinion of how their loved one is doing, I will tell them exactly what my thoughts are. We have a very large Hispanic population and many are very religious and tend to believe that miracles will happen so oftentimes it is difficult for them to come to an understanding or acceptance. I am Catholic and I believe in God and I will tell them that. I will say it is ultimately in God's hands but I do not think He created us to suffer so. Many of the things we might be doing would be considered extraordinary and even if you believe in the sanctity of human life, I think God expects us to treat our bodies and resources with common sense. I think that my beliefs help me to get on a common ground with some of the family members and help them understand. It also helps me be able to do what I do here everyday.

Similarly, this expert nurse commented:

Each of us has different reasons for our actions. I believe in God and that He will help not only myself but the also the patient and family to find the right answers. Many times I think that is the reason I am here. We really do know a lot of these guys (patients) from previous admissions and 
it breaks your heart. Many times l've cried my eyes out coding somebody. And I believe people should die with some dignity and God would not want us to prolong life in a cruel way.

\section{Sub theme: Personal Experiences}

Levy (2001) observed that, given how frequently patients die in the intensive care unit, critical care clinicians should be comfortable with death. The irony is, unfortunately for patients, that just because we see death all the time, we are not necessarily comfortable with it. This discomfort, Levy maintained, has resulted in delay in the acknowledgement that continued aggressive medical care might not be warranted. He has suggested that developing a personal relationship with death is requisite to accepting this transition. Several nurses in this study spoke of their prior personal experiences with illness and death as perhaps contributing to the development of that relationship:

I've lived with the experience myself. I was assaulted and I thought "this is it, I'm dying." And then I was OK, I survived it fine. But it made me really think about it and we see a lot of death and dying here and our culture does not like to talk about it. But if you've worked here for any length of time and you don't feel that you need to deal with death and dying then you are not really dealing with what goes on here. I think that not being able to do that leads to "burnout".

This nurse commented: 
From my personal experience I think it was because of my dad. I saw what he had to go through and he was in the hospital for seven months. And I was thinking he was going to get better because it was before I was a nurse. I remember one nurse who took us aside and asked if we had read the book on death and dying. She was trying in her own way to introduce it so we could accept it and that is the only time I remember anybody approaching us about it and he was in there for seven months. So now I do everything I can because continuing this kind of care, you feel like a perpetrator of it.

Similarly, this expert nurse stated:

I think I am able to do this because of my age and because I have had to go through so many of these things in my personal life. I've had a lot of death in my family that includes a husband, father, child. That helps me to explain to the families because I can understand and be more compassionate.

Another nurse shared that:

There are four or five of us who are pretty progressive. I think it's our own personal experience in our families have actually changed the way we view some of the things we do. For myself, it's my own maturity and being outspoken anyway but also having been a patient when I got really sick two years ago and had to visit the other side. I started realizing that what I 
had been doing was right; it just validated what I was doing. You realize you want to be more compassionate in the end.

\section{Interpretation of the Data through the Research Questions}

The thematic and narrative analyses yielded extensive data that will be used to address the four research questions in this section.

Research Question 1: What indicators do expert critical care nurses describe about poor patient prognosis?

In describing indicators of poor patient prognosis, nurse experts in this study appeared to integrate knowledge derived from three areas: clinical, relational, and ethical. Initial clinical assessment of poor prognosis included estimated severity of the patients' medical diagnoses, age, and existence of concurrent illnesses. Additional clinical indicators included persistent need for vasopressor support, inability to sustain adequate ventilation and oxygenation, and neurological responsiveness.

The participants also indicated that knowledge gained from their relationship with the patient/family members contributed to their perception of poor patient prognosis. These indicators were not as tangible as clinical parameters but seemingly reflected the nurses' understanding that the patient, as the person they knew before, had ceased to exist. This understanding was based on time spent with the patient and family and is similar to what Liaschenko and Fisher (1999) have described as "person knowledge" which is "knowledge of the 
individual as a self with a personal biography...it is knowing the person over time and involves the subjectivity of the nurse" (p. 38).

In describing their determination of poor patient prognosis, the expert nurses also discussed their ethical perception of the situation, which appeared requisite to taking action. While clinical and relational knowledge are important components of expertise, the ability to identify the salient moral issues in a particular situation, is also essential. Emotions such as empathy and compassion, evidenced as an active regard and not just a feeling state, appeared central to this ability.

Representative quotes reflective of these indicators are included in Table 3.

Research Question 2: What do expert critical care nurses communicate about their perceptions of poor patient prognosis to the patient, family, physician(s), and/or peers?

The expert nurses discussed communicating their perceptions of poor patient prognosis primarily with physicians and family members. With physicians, the participants communicated their perception of the patient's deteriorating status, failure to respond to interventions, and the patient and/or family members' wishes regarding continued aggressive medical interventions. The participants indicated that they generally communicated their perceptions in a straightforward manner but would often voice their concerns to those physicians with whom they had a more collegial relationship. 
If asked directly for their opinion about the patient's prognosis by family members, several participants indicated that they felt obligated to communicate their perceptions of poor outcome honestly. Only one nurse stated that he would not tell the family anything that was in disagreement with the physician's opinion because he/she "had to have the family's trust." In communicating their perceptions to family members, the participants attempted to provide information about the following: the physiologic problem that had occurred, how it was being treated, the mechanism of deterioration, consequences of the deterioration both present and possible future, and the reasons why it could not be halted.

The narrative and non-narrative responses indicative of what the expert nurses communicated about their perceptions of poor patient prognosis, are subsumed under the next research question. This was done to avoid repetition, as communicating was one of the actions taken when the expert nurses' perceptions of the usefulness of aggressive medical therapies differed from physicians and family members.

Research Question 3: What do expert critical care nurses do when their perceptions of the usefulness of aggressive therapies differs from those of the patient, family, physician(s), or peers?

For those patients who were aware, the participants provided information about the disease process, attempted to determine the patients' wishes for life- 
sustaining treatments, and endeavored to obtain advance directives. If the patient was unable to communicate in any way, the participants' indicated that they provided comfort and support but avoided conveying false hope.

Many of the patients discussed by the expert nurses in this study were sedated and/or chemically paralyzed. Consequently, they primarily spoke of what they did when their perceptions of the usefulness of aggressive therapies differed from family members and physicians.

When the expert nurses' perceptions of the usefulness of aggressive therapies differed from family members, they indicated that they attempted to present a realistic picture, determine the patients' wishes, and consult additional resources. Several participants indicated that family members' recognition of the transition from the possibility of recovery to probable death was a "process" that took time. To assist them to reframe their sense of the possibility of recovery, the expert nurses attempted to present a realistic picture. This included the provision and clarification of consistent information about the patients' medical condition and treatments that was often reinforced through continuity of care. In addition, several participants encouraged family members to consider what the patients' life might be like if he/she did survive and what they would have valued in the situation. In addition to having

Table 3

Expert nurses' indicators of poor patient prognosis 
can't keep blood pressure up with max dopamine and levophed: ejection fraction of 13; can't decrease his FIO2; no brain activity; have to keep calling a code; can't get him off the ventilator; needs to stay on neuromuscular blockers for so long; off sedation and hasn't woken up; extremities mottled.

Relational didn't have a look in her eyes any longer; staying at the bedside...I didn't see the interaction with the environment I would expect; totally gone...not there; I knew that she didn't want this any more because I had been with her; knowing what he was like before: aren't participating....aren't there.

Ethical to me this was totally unnecessary; there was nothing more that could be done; it is not right to do this ... suffering for no reason; absolutely futile...we should not do this anymore.

strategy. Rotating care of the patient was described as one self-protective strategy. Representative quotes illustrative of what the expert nurses did when their perceptions of the usefulness of aggressive therapies differed from family members is included in Table 4. 
When the expert nurses' perceptions of the usefulness of aggressive therapies differed from physician(s) they indicated that they attempted to communicate their understanding of the patients' deteriorating status and failure to respond to interventions. Many of the participants stated that they were able to communicate well and have their opinions respected because of their experience, length of time in the position, and collegial relationships with physicians. Several expert nurses spoke of using "the chain of command" when communicating their perceptions which, in teaching facilities, started with the person writing the orders. If they did not receive what they considered an appropriate response, the nurses would often "move up the ladder" to the resident or fellow or approach someone whom they believed was amenable to their concerns.

In addition to communicating their perceptions of poor patient prognosis to physicians, many of the expert nurses in this investigation spoke of encouraging empathy. They would frequently ask physicians to view the patient as a family member and then consider the implications or usefulness of continued aggressive interventions.

The participants indicated that in communicating their belief to physicians that continued aggressive medical interventions were not warranted, they often received support from a core group of peers. The majority of nurses interviewed also stated that they felt supported in their actions by their immediate supervisor or nurse manager. The perceived availability and usefulness of 
additional resources, such as pastoral or palliative care or an ethics committee in the situations described, was dependent on the facility in which the expert nurse practiced. Representative quotes illustrative of what the expert nurses did when their perceptions of the usefulness of aggressive medical therapies differed from physicians is found in Table 5.

Research Question 4: What are the reasons expert critical care nurses give for their actions?

Expert critical care nurses indicated the reasons for their actions was their professional value of responsibility to restore or promote patient dignity and provide comfort. In addition, several participants valued their personal belief in God to both enable and sustain their actions. Many nurses spoke of personal experiences with illness and death as often transforming their actions and practice in the situations described in this study. Personal characteristics such as maturity, knowledge, and communications skills were also seen as enhancing their ability to act. Both Ray (1987) and Olsen (20

\section{Table 4}

Expert nurses' actions when perceptions of usefulness of aggressive therapies differed from family 
Present a realistic picture It is important to give them a large knowledge base so they can make decisions; I will try to show them what it is like for the patient...I don't ask them to leave the room when l'm turning or suctioning; if they believe the patient is going to get better, I don't offer agreement.

Determine patients' l'll ask what would the patient do now, is this wishes what they would want?; I ask them to tell me about the patient...what kind of person they are ...it helps them think yeah, maybe she wouldn't want this.

Consultation our pastoral care person will talk to the families; ...call hospice/palliative care; our chaplain is very good in those situations.

Distancing We have to rotate care of that patient because there was nothing else we could do; ... it drives everyone crazy, so we take turns with her.

01) have discussed the influence of maturity on the development of ethical sensitivity and comportment in nursing practice.

In this investigation, the expert nurses often related narratives or provided responses that described situations of extreme patient vulnerability. Vulnerability is ethically significant as it refers to the fact that people can be 
injured, not only in terms of health, but in their ability to determine the ends of life (Liaschenko, 1995). For many of the participants, their recognition of this vulnerability, conceived as ethical discernment or sensitivity, implied responsibility. The professional value of responsibility did not presume paternalism but rather mutuality and assisting patients to actualize their choices and enhance their dignity. Promoting or restoring patient dignity often involved speaking for the patient and preventing further technological intrusion which was seen as dehumanizing and ultimately, futile. Many participants also spoke of their responsibility to provide comfort by alleviating pain and maintaining family presence.

Several nurses identified their personal value of belief in God as a reason for their actions. Communicating their religious beliefs to patients and family members was often viewed as a way to establish communality and trust. The nurses often acknowledged the ultimate power of God, but indicated an understanding that prolonging a life characterized by continued suffering and bereft of dignity was not commensurate with their beliefs.

Almost every expert nurse interviewed for this study related a personal experience with illness or death as a reason for the actions they took in the situations described. These experiences, whether their own or that of a family member, appeared to refine their moral perception and heighten the sense of responsibility to promote or restore patient dignity and provide comfort. Several participants spoke of these personal experiences as enabling them to confront 
the emotional intensity surrounding death, grief, and the prospect of loss that often permeated the intensive care unit environment. Representative quotes reflecting the expert nurses' reasons for their actions are provided in Table 6.

\section{SUMMARY}

The presentation of the data with analysis and interpretation was provided in this chapter. The interviews with twenty-one expert adult critical care nurses yielded rich findings which were described. The nature of the narratives and interview responses, and intact narrative exemplars were discussed. In addition, a thematic analysis of the non-narrative respones was given. The four research questions which guided the study were interpreted.

Table 5

Expert nurses' actions when perceptions of usefulness of aggressive therapies differed from physician(s)

Theme Representative Quote

Communicate we just tell them our opinion, we've done this, perceptions nothing is working... why are we continuing?; I will start with the intern, the person writing the 
orders; ...I try to follow the chain of command ...but if I know the fellow or attending I will go to them first.

Encourage empathy I tell them "how would you feel if this were your mother or father and you knew as a doctor that this was the reality of the situation?";...we bring them in there and tell them "please look and If this were your dad, would you want us to keep doing this?"

Consultation Palliative care is very proactive...they will talk to the doctors; I will call a consult for the ethics committee to come because to me it's an ethical problem; ...the ethics committee has no power.

Table 6

Expert nurses' reasons for their actions

Theme Representative Quotes

Professional values $\quad$...a responsibility to communicate what we know ...the futility; because it is the right thing to do; it the responsibility I have being here twelve hours a a day and knowing what I know. 


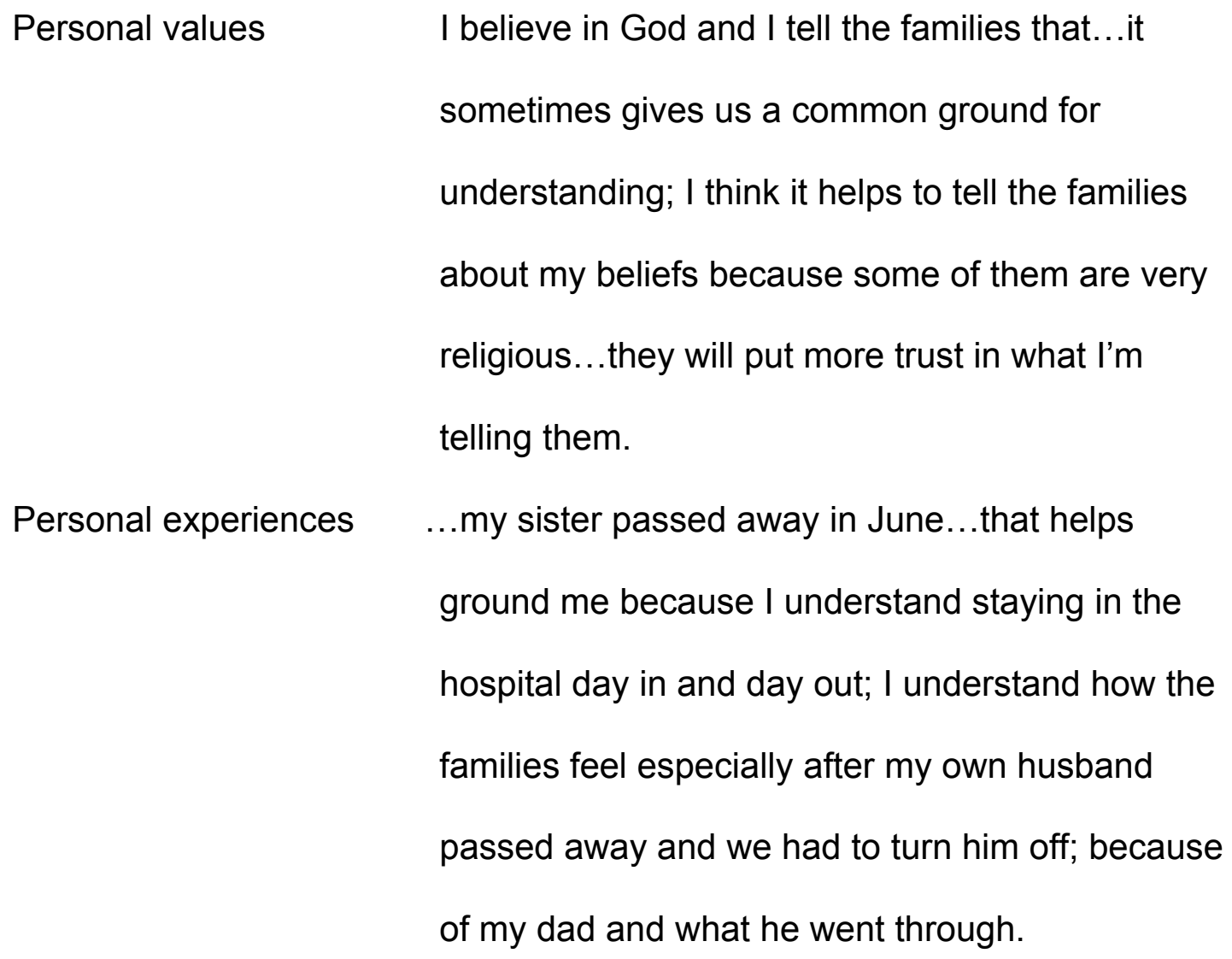




\section{CHAPTER 5}

\section{SUMMARY, CONCLUSIONS, AND RECOMMENDATIONS}

The purpose of this chapter is to summarize the study, present conclusions from the data analysis, and provide recommendations for nursing education, practice, and future research.

\section{Summary}

While exposition of expertise in clinical practice continues, little is known about what expert critical care nurses do when they encounter an ethically challenging situation such as use of inappropriate measures or the continued delivery of aggressive medical therapies to prolong the living/dying process. An exploration of their perceptions, actions, and reasons given for the actions, was conducted to enhance understanding of ethical practice in critical care nursing. The research questions that guided the study were:

1. What indicators do expert critical care nurses describe about poor patient prognosis?

2. What do expert critical care nurses communicate about their perceptions of poor patient prognosis to the patient, family, physician(s), or peers? 
3. What do expert critical care nurses do when usefulness of aggressive medical therapies differs from those of the patient, family, physician(s), or peers?

4. What are the reasons expert critical care nurses give for their actions?

These questions were explored during interviews conducted with twenty-one critical care nurses nominated as experts by a clinical nurse specialist and/or nurse educator in their employing institution. The expert participants practiced in a variety of adult critical care units in one of three urban teaching medical centers, three urban private facilities, and one community hospital. The data included audiotaped interviews, documented field notes, with analytic memos that included my reflections on non-verbal behaviors, key phrases, initial insights, and reactions to the conversations. As the original intent of the interviews was to elicit the expert nurses' narratives, participants were encouraged to recall and reflect on one or two patient situations in an endeavor to promote narrative re-telling.

The interview questions generated both narrative and non-narrative responses, each of which required different analytic approaches. The narrative data were initially analyzed using techniques suggested by Riessman (1993, 2000) and adapted from Gee (1986) and Labov (1972, 1997). Identification of recurring narrative plots was then accomplished using analytic strategies described by Polkinghorne (1995) and Ayres (2000). Thematic analysis, as 
described by Coffey and Atkinson (1996), was used to analyze the expert nurses' non-narrative responses.

Analysis of the participants' narrative exemplars revealed three recurrent plots: protecting or speaking for the patient, providing a realistic picture, and experiencing resignation and frustration. Three main themes and thirteen subthemes emerged from the thematic analysis. The main theme of assessment of poor patient prognosis included the subthemes of clinical, relational, and ethical assessment. The theme of actions taken when perceptions differed, addressed those performed with family members and those with physician(s). The expert nurses' actions with family members included the subthemes of presenting a realistic picture, determining patient wishes, consulting additional resources, and distancing. Actions with physician(s) included the subthemes of communicating perceptions, encouraging empathy, and consulting additional resources. The third theme addressed the reasons expert nurses gave for their actions and included the subthemes of professional and personal values and personal experiences.

The interview data revealed a compelling and diverse range of expert nurses' experiences with assessment and communication of poor patient prognosis and actions taken when aggressive medical interventions were perceived as prolonging the living/dying process. The following section presents conclusions derived from the data.

\section{Conclusions}


1. The expert critical care nurses in this study demonstrated an integration of the cognitive, intrinsic, and moral elements of expertise discussed in the sensitizing framework. The knowledge derived from this integration was requisite to moral action in the situations described.

2. The expert critical care nurses in this study discussed a vast array of clinical, relational, and ethical indicators associated with poor patient prognosis. Integration of these indicators, along with pattern recognition, helped to predict survivability.

3. Integration of the knowledge required for action was a process that took time. This supports Jenny \& Logan's (1992) conclusion that "knowing the patient" is affected by amount of time spent with the patient in addition to the nurses' professional expertise and empathy.

4. The expert critical care nurses in this study responded to patient situations of extreme vulnerability with actions to prevent further technological intrusion, honor patient and family wishes, and facilitate a dignified death.

5. The ability to effectively advocate for a patient was enhanced by possessing the professional value of responsibility, sharing personal values such as a belief in God with the family, possessing personal characteristics including maturity, knowledge and communication skills, and having personal experience with dying and death.

6. The unpredictable nature of the dying trajectory in the ICU creates a "vanishing line" between life and death (Callahan, 1993). This inability to identify 
a patient as terminal often results in adherence to curative regimens almost to the moment of the patient's death. The expert critical care nurses in this study were often the first to acknowledge recognition of this equivocal transition from possible recovery to an understanding that further efforts would be futile. This concurs with Curtis \& Patrick's (2001) observation that nurses frequently come to this conclusion earlier than physicians.

7. The expert nurses sought corroboration of their understanding of poor patient prognosis and support for their actions from a "core group" of peers. This is consistent with Wlody's (1994) conclusion that nurses may identify other nurses as the strongest support for their advocacy.

8. The expert nurses used a variety of direct and indirect strategies to communicate their perceptions of poor patient prognosis to physicians and family members. Concerns were initially expressed to physicians and, if the experts did not receive a satisfactory response, then communicated to family members. Painting a realistic picture to family members was valued as a particularly useful strategy that reoccurred in the narratives and non narrative comments.

9. The content of many physicians' communication with family members' was frequently seen by the participants as ambiguous and conveying false hope or false optimism. This medical activism often delayed acceptance of poor patient prognosis thus preventing the possibility of a dignified or good death.

10. The expert nurses in this study were often proactive in obtaining advance directives. The presence of advance directives, however, did not ensure 
that patients' wishes would be followed or preclude the continued use of aggressive life-sustaining interventions.

11. The expert participants did not reason using abstract ethical principles but rather in terms of what actions would bring about the good for a particular patient. This reasoning process is consistent with the consequentialst approach associated with increased advocacy described by Penticuff \& Walden (2000). 12. Expert critical care nurses will consult resources such as the ethics committee and pastoral or hospice care to assist in resolving ethical conflicts if these resources are perceived as accessible and useful.

13. Prolonging the living/dying process with inappropriate measures has been identified as a profoundly disturbing ethical issue for nurses in many practice areas (Fry \& Redman, 2000; Puntillo, 2001). Expert critical care nurses experience resignation and frustration and distance themselves from the patient and family when their attempts to advocate in such situations are ineffective. Distancing may ameliorate caregiver distress and suffering but have adverse consequences for patient and family care.

14. The majority of expert critical care nurses in this study indicated that they believed they exerted a powerful influence on both the clinical and ethical components of patient care. This conclusion contrasts with the perceived powerlessness of the nurses in Martin (1989), Erlen \& Frost (1991) and Penticuff \& Waldens' (2000) studies. This difference may perhaps be attributed to the expertise and maturity of the participants in the present study. 
15. The environment of the ICU depicted in the narratives and comments of many expert participants remains dominated by the technological imperative. The use of technology often proceeds incrementally by gradually increasing the amount of ventilator support, adding just one more vasopressor agent or ordering an additional diagnostic test. In this environment, the patient can become what Sandelowski (2002) terms a "posthuman body", a disembodied informational structure with no clearly defined self. Rather than the corporeal person in the bed, the patient becomes the hyperreal representation on screen in the form of a black and white picture, colorized image, or digital display. Thus, nurses and other healthcare providers may look to screens to find out how well or close to death a patient is and treat bad strips not sick patients (Barnard \& Sandelowski, 2001).

16. Inadequate communication and collaboration between and among patients, family members, and healthcare providers was evident in this study. The technological imperative is widely shared by health professionals and consumers alike. However, there is generally a vast difference between what providers understand and what laypersons with diverse sociocultural and educational backgrounds are able to comprehend. Patients and family members are, for the most part, entirely unprepared for the kinds of active decision making that critical illness in the contemporary ICU imposes. They do not understand what "life support" involves operationally and are not always concerned primarily with pain and suffering when they fear imminent death and hope for survival. This 
incommensurability of knowledge was repeatedly demonstrated in several of the participants' narratives and comments.

\section{Recommendations}

\section{Improving end of life care in the ICU}

Disarming the technological imperative, bridging the gulf between medical and lay knowledge, and creating an ethical environment in which worlds of understanding are shared, will necessitate the introduction of a new model. Important elements of this end of life care model include shared decision making (Karlawish, 1996; Miller, Forbes, \& Boyle, 2001) and the incorporation of palliative care (Levetown, 1998; Nelson \& Danis, 2001).

The vital role of critical care nurses in humanizing end of life care and shaping decision making processes around the event was evident in this study and has been recognized by several authors, including physicians (Selzer, 1994; Karlawish, 1996; Curtis et al., 2001) and nurses (Swigart et al., 1996; Jacob, 1998; Puntillo, 2001). Shared decision making requires ongoing dialogue among all participants, patients, family members, physicians, and nurses. Karlawish (1996) maintains that shared decision making necessitates a sense of understanding that means more than just an exercise in pure reason. To understand something, a person must fit that something into his or her sense of values. Achieving meaning may best be accomplished through the sharing of narratives (Karlawish, 1996; Charon, 2001). For example, the physician's narrative may include a biomedical interpretation of disease; the patient and/or 
family member's narrative may be one of suffering, illness, and loss; and the nurse's narrative may include a more holistic approach to care. Karlawish maintains that in the practice of critical care, narratives are the substance of shared decision-making and states:

Narratives enable those involved in the ICU to negotiate the meaning of critical care for the patient. Narrative functions as an interpretive procedure that allows diverse persons-nurses, physicians, patients, and patients' families to make sense of critical care... and supplies a theory and instrument for negotiating meaning throughout the process that respects the realities and limitations of such care (p. 395).

Indeed, Charon (2001), a physician, suggests that the effective practice of medicine requires "narrative competence...the ability to acknowledge, absorb, interpret, and act on the stories and plights of others" (p. 1897). I suggest that the narratives of many of the expert nurses in this study illustrate that competence.

The ICU environment presents several challenges to improving end of life care, the most fundamental being the discordance between the philosophy of palliative care (acceptance of death with an emphasis on the quality of dying) and the philosophy that underlies the existence of ICUs (save those who would otherwise die) (Mularski, Bascom, \& Osborne, 2001 b). To introduce palliative care into the ICU is to ask practitioners, including nurses, to work to cure those at high risk of dying while simultaneously using the principles of palliative care in their interactions with patients and families. This is a difficult task, one that is not commonly seen in practice. The emphasis on cure may be particularly important for ICU nurses, many of who chose this area of practice precisely for this curative focus. 
The difficulty in recognizing and acknowledging the transition from possible recovery to acceptance of death was a recurrent theme in the present study. It would seem, therefore, that postponing palliative care until death is obviously imminent is both impractical and inhumane. Integration of palliative care as a component of comprehensive intensive care would be more appropriate for all critically ill patients, including those pursuing aggressive treatments to prolong life. The development of a satisfactory, integrated model will require research and extensive interdisciplinary education. The Society of Critical Care Medicine (2001) recently proposed a beginning model of palliative care for the ICU that illustrates that the simultaneous goals of cure and care are compatible and recognizes the unique contribution of critical care nurses. In addition, Levy (2001) has identified four caregiver strategies and abilities necessary to improve end of life care in the ICU, many of which were demonstrated by the expert nurses in this study: the development of a personal relationship with death; the ability to communicate in a compassionate, direct manner; the ability to create a healing environment; and a willingness to express emotion and uncertainty.

\section{Education}

The expert nurses' narratives and comments revealed a number of opportunities for both improving and informing nursing education. Clinical and ethical practice models currently accepted and taught are generally linear and based on the scientific method and algorithmic application of ethical principles. 
Knowledge of scientific and ethical principles is important and necessary for competent care and informed discussion with other healthcare providers. The mastery of this knowledge, however, is not adequate for the development of expert practice in nursing.

The findings of this study suggest that expert nurses understand a world of particular rather than abstract ethical incidents to which they do not readily apply principles or theories. This is a common phenomenon that was also found in studies conducted by O'Connor (1996), Ray (1998), and Krishnasmy (1999). While it may have been possible to apply or extract principles from the expert participants' narratives and comments, this may have limited the interpretation. Interpretive understanding cannot be fully captured and represented by a linear approach to clinical or ethical problem resolution. The notion of expertise as the interpretation of meaning within the context of the patient situation is consistent with the meaning of narrative. Narratives from the practice of expert practitioners could provide a framework for the education of those less experienced. Through discussion and interpretation of such narratives and incidents, meaning becomes clear and is instructive to practitioners at all levels of expertise. Particularly for undergraduate nursing students, who are anxious about the care of the body and the specialized knowledge they must acquire to accomplish that care, shifting the focus to larger questions of what is good or right in a clinical situation is difficult. Reflection through narrative study of their own practice and those of others may assist them to approach a situation 
with multiple levels of concern and empathy and begin to create a balance between care of the physical body and care of the embodied person in context. Interdisciplinary educational strategies that address end of life and palliative care issues in the ICU and other practice areas are needed for all healthcare providers including nursing students and practicing nurses. This content is rarely covered in the basic preparation of nurses, nor included in many nursing textbooks. In a review of end of life content in the 50 most frequently used texts, Ferrell, Virani, and Grant (1999) found that only $2 \%$ of the overall content and $1.4 \%$ of chapters were related to end of life or palliative care. Several educational programs have recently been developed to address these deficits for the undergraduate nursing student and at the level of continuing education ( Wilkie et al., 2001). Their incorporation into the curricula and impact on end of life care remains to be seen.

\section{Practice}

The findings of this study suggest that expert nurses often perceive other nurses as the strongest support for their advocacy. Responsibility and empathy may be reinforced within a group, as members are encouraged to exchange narratives of patient and family care. As a group, or moral community, nurses can use this "collective authority" (Rushton, 1995, p. 395) to achieve what they believe to be optimal outcomes for patients and family members, including promotion of a dignified death. Expert ethical practice may also be enhanced by 
listening to and observing the actions of identified expert nurses such as clinical nurse specialists (Robichaux \& Clark, 2001).

The strategies expert nurses used to communicate their perceptions of poor patient prognosis to physicians and family members could be incorporated into an end of life teaching module. Practices such as determining patients' wishes and encouraging empathy might facilitate recognition of the need to transition from a curative to a palliative focus.

The integration of the expert nurses' clinical, relational, and ethical assessment that was requisite to taking action in this study was a process that took time. This has relevance for ICU practice settings in terms of adequate staffing and nurse-patient ratios. Continuity of care, when possible, is necessary for salutary patient outcome and the resolution of ethical conflict. Flexibility in patient assignments is also needed however, to prevent emotional distress and distancing.

Practice settings must provide support services for nurses contending with end of life conflicts. When nurses harbor frustration and emotional stress caused by unresolved ethical issues, they may withdraw from patients and family members. Institutional ethics committees should be proactive, available, and unbiased. However, if this is an unrealistic expectation within a facility, then the formation of a nursing ethics committee might be considered. This strategy would also serve to strengthen the moral community of nurses and provide a forum for those who are uncomfortable bringing their concerns forward in an Institutional 
Ethics Committee (IEC) setting. Additional resources such as pastoral and hospice care and grief counseling should also be provided.

Many expert nurses in this study indicated that they received strong support for their actions with physicians and family members from nurse managers. However, upper level administrative support was perceived as inadequate. To retain expert critical care nurses in the existing climate of increasing patient acuity and a persistent nursing shortage, hospital and nursing administrators must contribute to the creation of an ethical practice environment. For nurses to exercise their moral agency at the bedside, they must feel supported in their actions and not constrained or undermined by organizational economic and political forces. Leaders within institutions have a responsibility to develop an environment in which ethical practice is valued and the burdens and suffering of caregivers are appreciated and addressed in a supportive and constructive manner. For compassionate caring to occur, caregivers must be the recipients of compassion themselves.

\section{Research}

Hinshaw (2000) maintains that end of life research is a field of study in which nurses as clinicians and investigators should be major contributors. She notes that, although nurses have advanced palliative care perspectives, the focus of research should be broadened to encompass decision-making processes that occur for patients, families, and healthcare providers during the "end of life transition stage"(p.120). Hinshaw observes "How do nurses identify 
the time in a critical care unit when the goal is no longer to save a life at all cost but to facilitate a dignified death?" (p. 120). Analysis and interpretation of the expert critical care nurses' narratives and non-narrative responses provided a beginning answer to that question through an understanding of their practice during this equivocal transition. The findings also suggest the need for further research.

Additional research should be conducted to explore the practice of expert nurses during end of life transitions in different clinical areas such as the pediatric and neonatal ICU. The findings could then be compared to those of the present study to enhance understanding of expertise in nursing end of life practice.

A major assumption underlying this study is that expert nurses possess both clinical and ethical expertise and thus their practice is qualitatively different from that of non-experts. To support or refute that assumption, a comparable investigation could be performed with novice or competent nurses to ascertain differences or similarities.

The majority ( $81 \%)$ of the expert participants who volunteered to participate in this investigation practice in a teaching institution. Additional study is warranted to determine the reasons for the low response rate from the private facilities. Perhaps prolonging the living/dying process with inappropriate measures may occur less often in these institutions or result in less caregiver distress. 
In her study of oncology nurses' experiences with requests for assisted dying from terminally ill cancer patients, Volker (1999) noted that master's prepared nurses were more likely to tell richly detailed stories of clinical experiences than those without master's degrees. As there were only two expert participants holding master's degrees in the present study, conducting a similar investigation with expert advanced practice nurses might yield additional narrative data.

\section{Summary}

In this chapter, a summary of the study and conclusions from the data were provided. Recommendations for improving end of life care in the ICU by adoption of a shared decision making model and integration of palliative care were suggested. In addition, several proposals to develop and support clinical and ethical expertise in education and practice were offered. Finally, suggestions were made for future research. 


\section{APPENDICES}


APPENDIX A

STUDIES EXPLORING CLINICAL EXPERTISE IN NURSING

STUDIES USING INFORMATION PROCESSING THEORY AS A FRAMEWORK 


\begin{tabular}{|c|c|c|c|c|c|}
\hline $\begin{array}{c}\text { AUTHORS, } \\
\text { TITLE, } \\
\text { JOURNAL }\end{array}$ & $\begin{array}{l}\text { SAMPLE; } \\
\text { SPECIALTY }\end{array}$ & METHOD & PURPOSE & $\begin{array}{l}\text { THEORETICAL } \\
\text { FRAMEWORK }\end{array}$ & FINDINGS \\
\hline $\begin{array}{l}\begin{array}{l}\text { Corcoran, S. } \\
\quad(1986)\end{array} \\
\text { Task } \\
\text { Complexity } \\
\text { and Nursing } \\
\text { Expertise as } \\
\text { Factors in } \\
\text { Decision } \\
\text { Making. } \\
\text { Nursing } \\
\text { Research }\end{array}$ & $\begin{array}{c}11 \mathrm{RNs} \\
\text { identified as } \\
\text { either experts } \\
\text { or novices in } \\
\text { hospice } \\
\text { nursing based } \\
\text { on author } \\
\text { developed } \\
\text { criteria. }\end{array}$ & $\begin{array}{l}\text { Verbal protocol } \\
\text { analysis using } \\
\text { three written } \\
\text { case studies } \\
\text { about pain } \\
\text { management. }\end{array}$ & $\begin{array}{l}\text { To describe } \\
\text { initial and overall } \\
\text { approaches to } \\
\text { planning used } \\
\text { by experts and } \\
\text { novices in three } \\
\text { patient cases of } \\
\text { varying } \\
\text { complexity. }\end{array}$ & $\begin{array}{c}\text { Newell \& } \\
\text { Simon; Hayes } \\
\text { \& Roth. }\end{array}$ & $\begin{array}{c}\text { Experts used } \\
\text { opportunistic } \\
\text { planning when the } \\
\text { case presented } \\
\text { was complex. This } \\
\text { is a } \\
\text { multidirectional } \\
\text { method, which } \\
\text { may appear } \\
\text { chaotic and } \\
\text { disorderly as the } \\
\text { planner seeks to } \\
\text { develop promising } \\
\text { aspects of the } \\
\text { plan in progress. } \\
\text { Novices used a } \\
\text { systematic rule- } \\
\text { based approach. }\end{array}$ \\
\hline $\begin{array}{l}\quad \begin{array}{l}\text { Davis, B. } \\
\quad(1972)\end{array} \\
\text { Clinical } \\
\text { Expertise as } \\
\text { a Function of } \\
\text { Educational } \\
\text { Preparation. } \\
\text { Nursing } \\
\text { Research. }\end{array}$ & $\begin{array}{l}20 \text { master's } \\
\text { prepared } \\
\text { clinical nurse } \\
\text { specialists } \\
\text { and } 20 \text { BSN } \\
\text { nurses } \\
\text { matched on } \\
\text { years of } \\
\text { nursing } \\
\text { experience (1- } \\
10 \text { years, with } \\
\text { an average of } \\
5 \text { ). }\end{array}$ & $\begin{array}{l}\text { Subjects } \\
\text { viewed five } \\
\text { scenarios } \\
\text { depicting } \\
\text { common } \\
\text { patient } \\
\text { situations. }\end{array}$ & $\begin{array}{l}\text { To differentiate } \\
\text { skills possessed } \\
\text { by the clinical } \\
\text { nurse specialist } \\
\text { from skills } \\
\text { possessed by } \\
\text { the } \\
\text { baccalaureate } \\
\text { nurse. To } \\
\text { determine if } \\
\text { different levels of } \\
\text { education make } \\
\text { a difference in } \\
\text { quality and } \\
\text { quantity of } \\
\text { nursing care. }\end{array}$ & & $\begin{array}{l}\text { Clinical nurse } \\
\text { specialists made } \\
\text { more observations } \\
\text { and suggested } \\
\text { more actions than } \\
\text { did baccalaureate } \\
\text { nurses. } \\
\text { The quality and } \\
\text { quantity of nursing } \\
\text { care declined with } \\
\text { increasing years } \\
\text { of experience for } \\
\text { both groups. }\end{array}$ \\
\hline \begin{tabular}{l}
\multicolumn{1}{c}{$\begin{array}{c}\text { Davis, B. } \\
\quad(1974)\end{array}$} \\
Effects of \\
Levels of \\
Nursing \\
Education on \\
Patient Care; \\
A \\
Replication. \\
Nursing \\
Research.
\end{tabular} & $\begin{array}{l}20 \text { additional } \\
\text { clinical nurse } \\
\text { specialists } \\
\text { with } 11 \text { to } 35 \\
\text { years of } \\
\text { experience } \\
\text { (average of } 15 \\
\text { years). } 27 \\
\text { diploma } \\
\text { nurses with 1- } \\
35 \text { years of } \\
\text { experience. } \\
50 \text { subjects } \\
\\
\text { with medical- } \\
\text { surgical, } 37\end{array}$ & $\begin{array}{c}\text { Subjects } \\
\text { viewed five } \\
\text { scenarios } \\
\text { depicting } \\
\text { common } \\
\text { patient } \\
\text { situations. }\end{array}$ & $\begin{array}{l}\text { To assess the } \\
\text { effect of } \\
\text { education on } \\
\text { performance; the } \\
\text { effect of } \\
\text { increased years } \\
\text { of experience on } \\
\text { quality and } \\
\text { quantity of } \\
\text { nursing care; the } \\
\text { effect of area of } \\
\text { specialization on } \\
\text { nursing care. }\end{array}$ & & $\begin{array}{c}\text { Education, not } \\
\text { experience, found } \\
\text { to be the } \\
\text { determining factor } \\
\text { in quality and } \\
\text { quantity of nursing } \\
\text { care. Clinical } \\
\text { nurse specialists } \\
\text { made more } \\
\text { observations and } \\
\text { provided more } \\
\text { actions than BSN } \\
\text { and diploma } \\
\text { nurses. BSN } \\
\text { nurses made } \\
\text { more observation } \\
\text { and took more } \\
\text { actions than } \\
\text { diploma nurses. }\end{array}$ \\
\hline
\end{tabular}




\begin{tabular}{|c|c|c|c|c|c|}
\hline & $\begin{array}{l}\text { subjects with } \\
\text { psychiatric } \\
\text { experience. }\end{array}$ & & & & $\begin{array}{l}\text { Medical-surgical } \\
\text { nurses made } \\
\text { more observations } \\
\text { and took more } \\
\text { actions than } \\
\text { psychiatric nurses } \\
\text { in both medical } \\
\text { and psychiatric } \\
\text { situations. } \\
\text { The quality and } \\
\text { quantity of nursing } \\
\text { care declined with } \\
\text { increasing years } \\
\text { of experience for } \\
\text { all groups. }\end{array}$ \\
\hline $\begin{array}{l}\text { Fothergill- } \\
\text { Bourbonnais, } \\
\text { F. \& Wilson- } \\
\text { Barnett, J. } \\
\text { (1992). } \\
\text { A } \\
\text { comparative } \\
\text { study of } \\
\text { intensive } \\
\text { therapy and } \\
\text { hospice } \\
\text { nurses' } \\
\text { knowledge of } \\
\text { pain } \\
\text { management. } \\
\text { Advanced }\end{array}$ & $\begin{array}{l}48 \text { experts ( } 3 \\
\text { or more years } \\
\text { of } \\
\text { experience); } \\
52 \text { beginners } \\
\text { ( } 1 \text { year } \\
\text { experience or } \\
\text { less). }\end{array}$ & $\begin{array}{l}\text { Author- } \\
\text { developed } \\
\text { questionnaires. }\end{array}$ & $\begin{array}{l}\text { To identify the } \\
\text { knowledge and } \\
\text { perceived } \\
\text { adequacy and } \\
\text { acquisition of } \\
\text { knowledge of } \\
\text { beginner and } \\
\text { expert intensive } \\
\text { therapy and } \\
\text { hospice nurses } \\
\text { pertaining to the } \\
\text { theoretical, } \\
\text { pharmacological, } \\
\text { and non- } \\
\text { pharmacological } \\
\text { aspects of pain } \\
\text { and it's } \\
\text { management. }\end{array}$ & $\begin{array}{l}\text { Hammond; } \\
\text { Lockstone. }\end{array}$ & $\begin{array}{l}\text { Hospice nurses } \\
\text { scored } \\
\text { significantly higher } \\
\text { on the multiple- } \\
\text { choice } \\
\text { questionnaire; } \\
\text { there were no } \\
\text { differences } \\
\text { between } \\
\text { beginners/experts. } \\
\text { No differences } \\
\text { noted between } \\
\text { ITU/hospice } \\
\text { nurses or } \\
\text { beginners/experts } \\
\text { on short answer } \\
\text { questions. }\end{array}$ \\
\hline
\end{tabular}




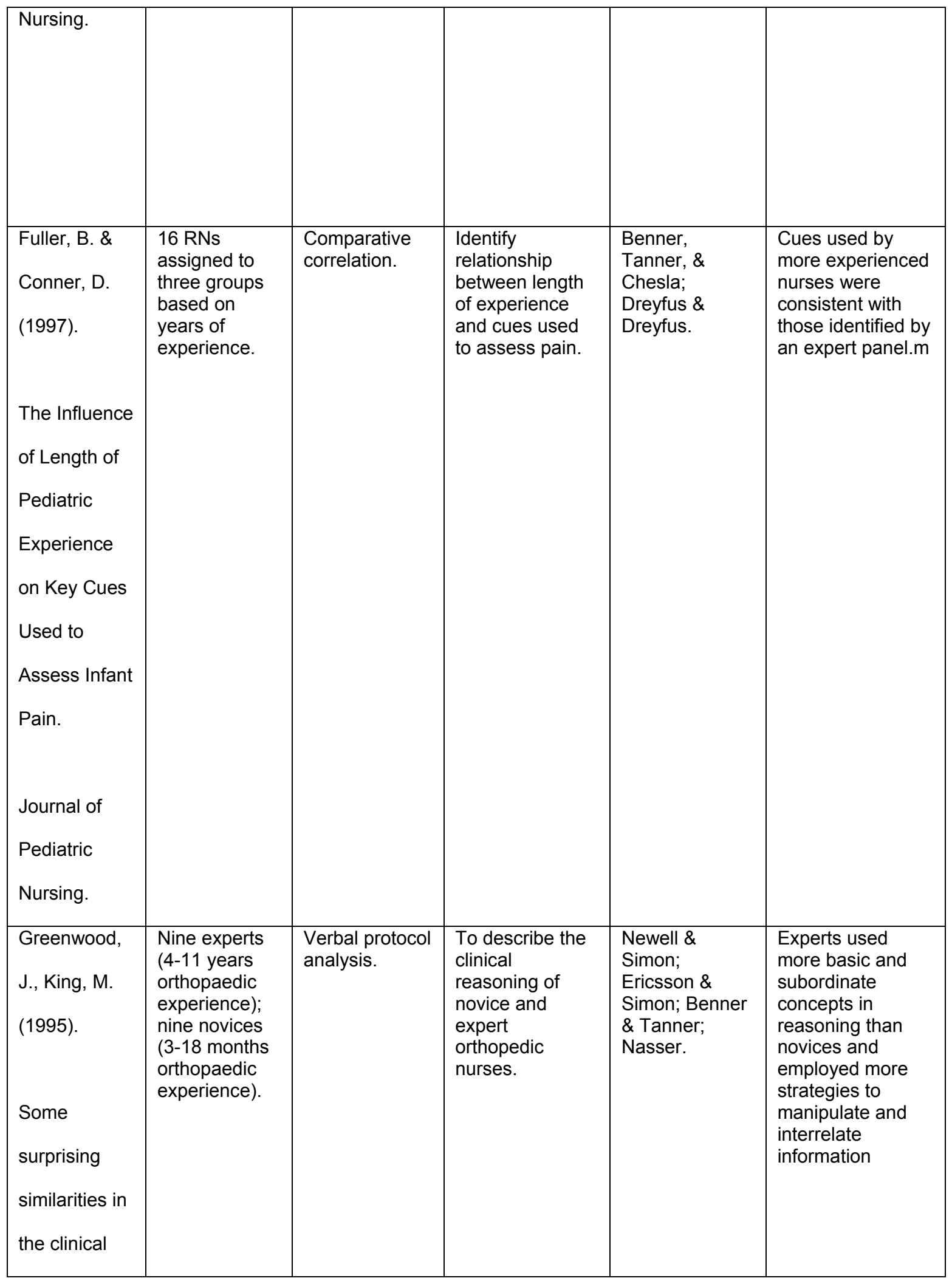




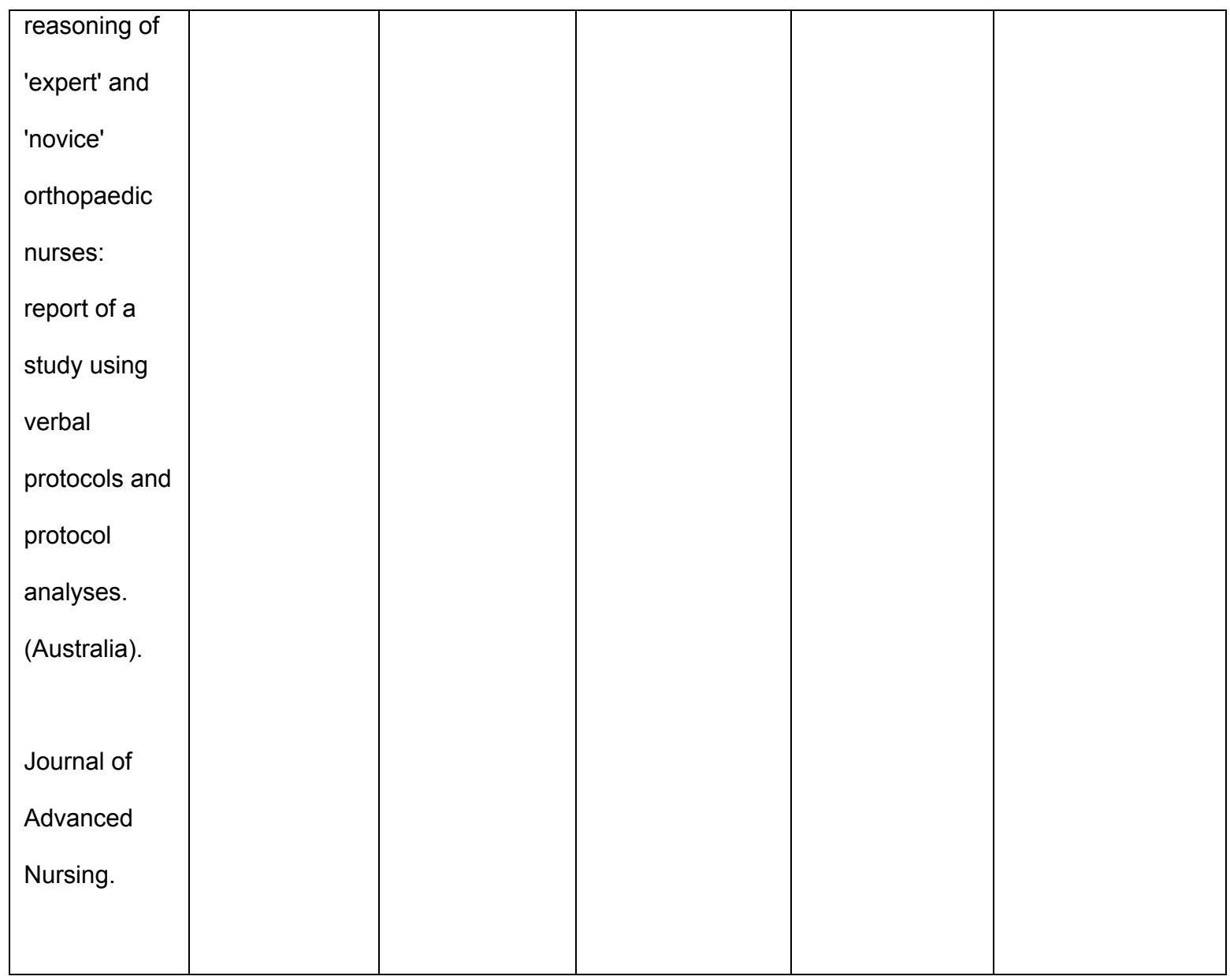




\begin{tabular}{|c|c|c|c|c|c|}
\hline $\begin{array}{l}\text { Guyton- } \\
\text { Simmons, J. } \\
\text { \& Mattoon, } \\
\text { M. (1991). } \\
\text { Analysis of } \\
\text { Strategies in } \\
\text { the } \\
\text { Management } \\
\text { of Coronary } \\
\text { Patients' } \\
\text { Pain. } \\
\text { Dimensions } \\
\text { of Critical } \\
\text { Care } \\
\text { Nursing. }\end{array}$ & $\begin{array}{c}12 \text { coronary } \\
\text { care nurses } \\
\text { with at least } \\
\text { two years } \\
\text { experience } \\
\text { identified as } \\
\text { experts by } \\
\text { peers. }\end{array}$ & $\begin{array}{l}\text { Observation } \\
\text { and interview. }\end{array}$ & $\begin{array}{l}\text { To identify and } \\
\text { describe expert } \\
\text { knowledge and } \\
\text { strategies in the } \\
\text { management of } \\
\text { acute chest pain. }\end{array}$ & $\begin{array}{c}\text { Elstein \& } \\
\text { Shulman; } \\
\text { Benner \& } \\
\text { Tanner. }\end{array}$ & $\begin{array}{l}\text { Experts did not } \\
\text { follow } \\
\text { standardized } \\
\text { assessment } \\
\text { guides but } \\
\text { selectively } \\
\text { gathered data - } \\
\text { they "knew" what } \\
\text { they needed to } \\
\text { know; they did not } \\
\text { use a linear } \\
\text { "nursing process" } \\
\text { approach and } \\
\text { appeared to think, } \\
\text { act, and do } \\
\text { simultaneously. }\end{array}$ \\
\hline $\begin{array}{l}\text { Haggerty, L. } \\
\text { (1996) } \\
\text { Assessment } \\
\text { Parameters } \\
\text { and } \\
\text { Indicators in } \\
\text { Expert } \\
\text { Intrapartal } \\
\text { Nursing } \\
\text { Decisions. } \\
\text { Journal of } \\
\text { Gynecologic } \\
\text { and Neonatal } \\
\text { Nursing. }\end{array}$ & $\begin{array}{l}18 \mathrm{RNs} \\
\text { designated as } \\
\text { experts by } \\
\text { nurse } \\
\text { managers. }\end{array}$ & $\begin{array}{l}\text { Verbal protocol } \\
\text { analysis. }\end{array}$ & $\begin{array}{l}\text { Identify and } \\
\text { describe } \\
\text { cues/parameters } \\
\text { used to } \\
\text { determine } \\
\text { severity of fetal } \\
\text { distress. }\end{array}$ & $\begin{array}{l}\text { Benner; } \\
\text { Ericsson \& } \\
\text { Simon; Newell } \\
\text { \& Simon. }\end{array}$ & $\begin{array}{l}\text { Four contextual } \\
\text { parameters } \\
\text { identified: (1) } \\
\text { duration of stress, } \\
\text { (2) quality of fetal } \\
\text { reserve, (3) } \\
\text { potential } \\
\text { reversibility of the } \\
\text { stress, and (4) } \\
\text { specific stress } \\
\text { manifestations. }\end{array}$ \\
\hline
\end{tabular}




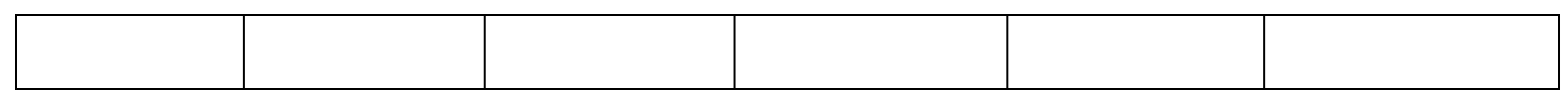




\begin{tabular}{|c|c|c|c|c|c|}
\hline $\begin{array}{l}\text { Holden, G. \& } \\
\text { Klingner, A. } \\
\quad(1988) . \\
\text { Learning } \\
\text { From } \\
\text { Experience: } \\
\text { Differences in } \\
\text { How Novice } \\
\text { vs. Expert } \\
\text { Nurses } \\
\text { Diagnose } \\
\text { Why an } \\
\text { Infant is } \\
\text { Crying. } \\
\text { Journal of } \\
\text { Nursing } \\
\text { Education. }\end{array}$ & $\begin{array}{c}26 \text { first } \\
\text { semester } \\
\text { junior year } \\
\text { nursing } \\
\text { students; } 29 \\
\text { graduating } \\
\text { senior nursing } \\
\text { students; } 15 \\
\text { nursing } \\
\text { students who } \\
\text { were parents } \\
\text { of one or more } \\
\text { children (8 } \\
\text { juniors, } 7 \\
\text { seniors); } 30 \\
\text { pediatric } \\
\text { nurses with an } \\
\text { average of } \\
\text { five years } \\
\text { experience. }\end{array}$ & $\begin{array}{l}\text { Two interactive } \\
\text { computer } \\
\text { scenarios } \\
\text { named "The } \\
\text { Cry Problem" } \\
\text { and The } \\
\text { Insomnia } \\
\text { Problem" } \\
\text { which involved } \\
\text { searching for } \\
\text { relevant facts } \\
\text { from } 25 \\
\text { information } \\
\text { units available } \\
\text { (for each } \\
\text { problem) and } \\
\text { determining } \\
\text { the single } \\
\text { correct } \\
\text { hypothesis } \\
\text { from among } \\
\text { nine provided. }\end{array}$ & $\begin{array}{l}\text { To examine the } \\
\text { effects of } \\
\text { nursing } \\
\text { education and } \\
\text { experience on } \\
\text { problem solving. }\end{array}$ & $\begin{array}{l}\text { Benner; } \\
\text { Hammond; } \\
\text { Newell \& } \\
\text { Simon. }\end{array}$ & $\begin{array}{l}\text { Pediatric nurses } \\
\text { were the most } \\
\text { efficient in } \\
\text { diagnosing why } \\
\text { an infant is crying } \\
\text { (used five or less } \\
\text { information units), } \\
\text { however, they } \\
\text { made some } \\
\text { diagnostic errors. } \\
\text { Students who } \\
\text { were parents were } \\
\text { most accurate in } \\
\text { diagnosing but } \\
\text { required more } \\
\text { information units. } \\
\text { Junior and senior } \\
\text { students required } \\
\text { more information } \\
\text { units and made } \\
\text { more diagnostic } \\
\text { errors. }\end{array}$ \\
\hline $\begin{array}{l}\begin{array}{l}\text { Itano, J. } \\
(1989) .\end{array} \\
\text { A } \\
\text { Comparison } \\
\text { of the Clinical } \\
\text { Judgment } \\
\text { Process in } \\
\text { Experienced } \\
\text { Registered } \\
\text { Nurses and } \\
\text { Student } \\
\text { Nurses. } \\
\text { Journal of } \\
\text { Nursing } \\
\text { Education. }\end{array}$ & $\begin{array}{c}13 \text { medical- } \\
\text { surgical RNs } \\
\text { identified as } \\
\text { "highly skilled } \\
\text { judgement } \\
\text { makers" by } \\
\text { three clinical } \\
\text { nurse } \\
\text { specialists } \\
\text { based on } \\
\text { Benner's } \\
\text { criteria; } 13 \\
\text { senior BSN } \\
\text { students. }\end{array}$ & $\begin{array}{c}\text { Analysis and } \\
\text { observation of } \\
\text { nurse-patient } \\
\text { interviews } \\
\text { performed at } \\
\text { the beginning } \\
\text { of a shift. }\end{array}$ & $\begin{array}{l}\text { To explore the } \\
\text { type and number } \\
\text { of cues elicited } \\
\text { and the } \\
\text { judgment } \\
\text { process. }\end{array}$ & $\begin{array}{l}\text { Hammond; } \\
\text { Gordon; Newell } \\
\text { \& Simon; } \\
\text { Tanner. }\end{array}$ & $\begin{array}{c}\text { Highly skilled } \\
\text { judgment makers } \\
\text { collected } \\
\text { significantly more } \\
\text { cues (39.8) per } \\
\text { interview than } \\
\text { students (28.3) } \\
\text { per interview. }\end{array}$ \\
\hline
\end{tabular}




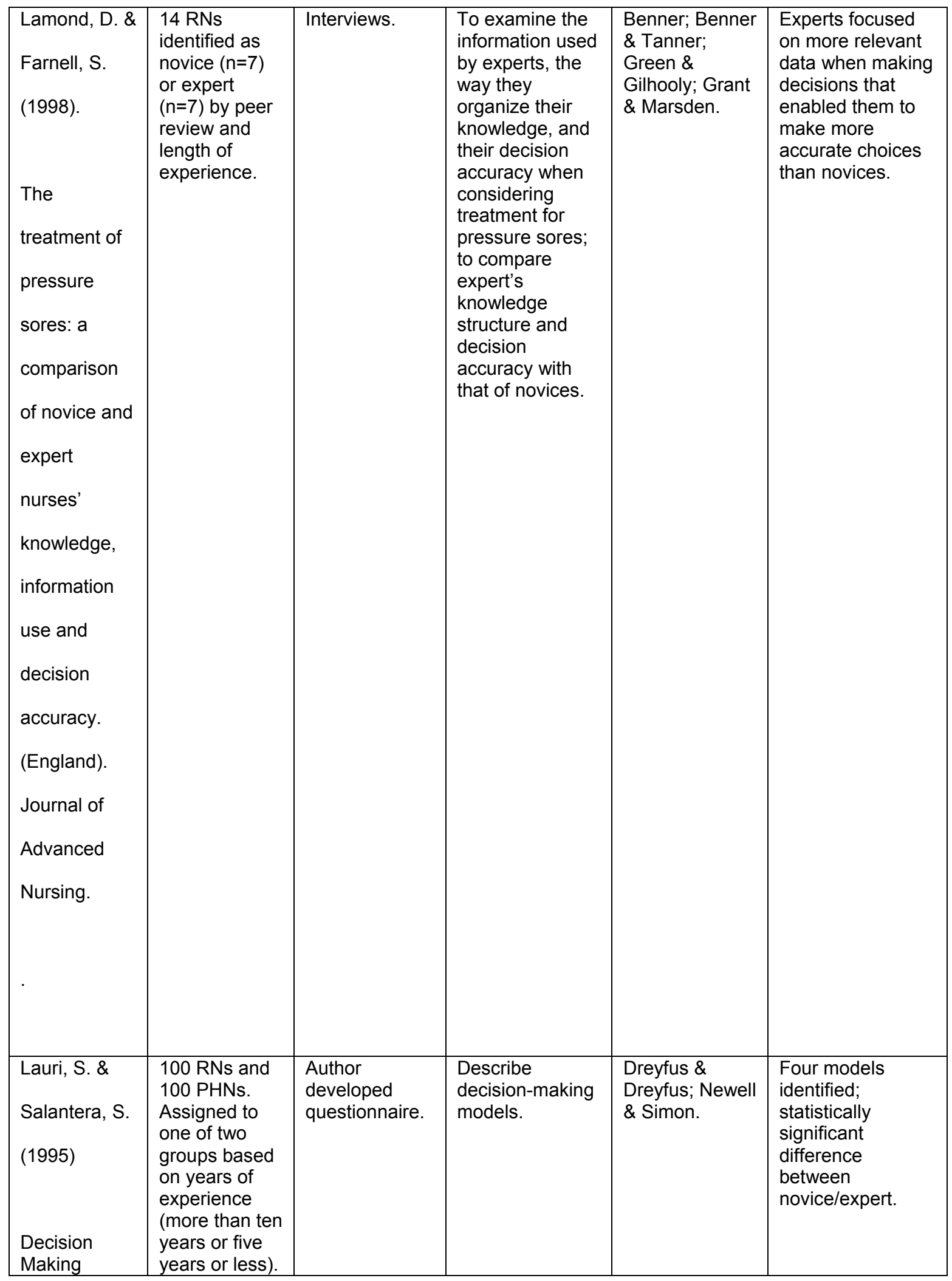




\begin{tabular}{|c|c|c|c|c|c|}
\hline $\begin{array}{l}\text { models of } \\
\text { Finnish } \\
\text { nurses and } \\
\text { public health } \\
\text { nurses. } \\
\text { (Finland). } \\
\text { Journal of } \\
\text { Advanced } \\
\text { Nursing. }\end{array}$ & & & & & \\
\hline $\begin{array}{l}\text { Martin, K. } \\
\text { (1994). } \\
\text { Patient cues } \\
\text { used by } \\
\text { expert nurses } \\
\text { to identify } \\
\text { mild head } \\
\text { injury. } \\
\text { Journal of } \\
\text { Neuroscience } \\
\text { Nursing. }\end{array}$ & $\begin{array}{l}\text { Ten RNs } \\
\text { identified as } \\
\text { experts by unit } \\
\text { managers and } \\
\text { peers. }\end{array}$ & $\begin{array}{l}\text { Grounded } \\
\text { theory; } \\
\text { observation } \\
\text { and interviews }\end{array}$ & $\begin{array}{l}\text { Describe the } \\
\text { cues used to } \\
\text { establish a } \\
\text { diagnosis of mild } \\
\text { head injury. }\end{array}$ & & $\begin{array}{l}\text { Several identified } \\
\text { cues consistent } \\
\text { with those found } \\
\text { in literature; } \\
\text { additional cues } \\
\text { also identified by } \\
\text { the expert } \\
\text { respondents. }\end{array}$ \\
\hline $\begin{array}{l}\text { O'Neill, E. } \\
\text { (1994). } \\
\text { The Influence } \\
\text { of Experience } \\
\text { on } \\
\text { Community }\end{array}$ & $\begin{array}{l}214 \\
\text { community } \\
\text { health nurses } \\
\text { designated to } \\
\text { three groups } \\
\text { based on } \\
\text { experience: } \\
\text { novice, less } \\
\text { than two years } \\
(n=25) ; \\
\text { intermediate, } \\
2-4 \text { years } \\
\text { ( } n=35) ; \\
\text { experts, four } \\
\text { years or more } \\
(n=154) .\end{array}$ & $\begin{array}{l}\text { Author } \\
\text { developed } \\
\text { clinical } \\
\text { inference } \\
\text { questionnaire } \\
\text { with eight } \\
\text { diagnostic } \\
\text { problems. }\end{array}$ & $\begin{array}{l}\text { To examine } \\
\text { expert nurses' } \\
\text { use of the } \\
\text { similarity } \\
\text { heuristic when } \\
\text { making clinical } \\
\text { judgments and } \\
\text { to determine if } \\
\text { knowledge } \\
\text { influences } \\
\text { similarity } \\
\text { reasoning. }\end{array}$ & $\begin{array}{l}\text { Kahneman, } \\
\text { Slovic, \& } \\
\text { Tversky; } \\
\text { Anderson; } \\
\text { Benner. }\end{array}$ & $\begin{array}{l}\text { Experts were } \\
\text { more prone to } \\
\text { judging by } \\
\text { similarity than less } \\
\text { experienced } \\
\text { nurses. }\end{array}$ \\
\hline
\end{tabular}




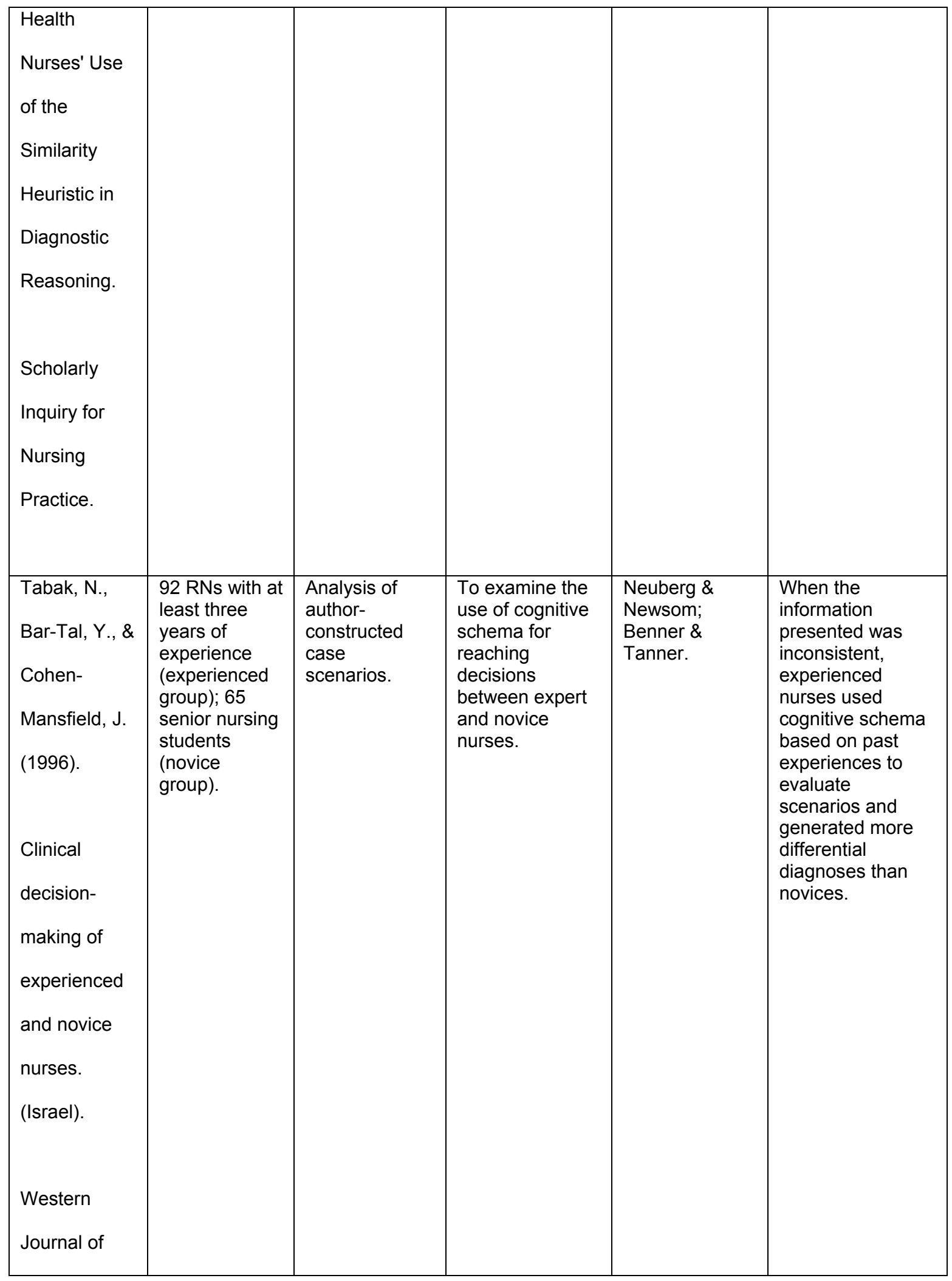




\begin{tabular}{|c|c|c|c|c|c|}
\hline $\begin{array}{l}\text { Nursing } \\
\text { Research. }\end{array}$ & & & & & \\
\hline $\begin{array}{l}\text { Taylor, C. } \\
\text { (1997). } \\
\text { Problem } \\
\text { solving in } \\
\text { Clinical } \\
\text { Nursing } \\
\text { Practice. } \\
\text { (Australia). } \\
\text { Journal of } \\
\text { Advanced } \\
\text { Nursing. }\end{array}$ & $\begin{array}{l}15 \\
\text { undergraduate } \\
\text { BSN students } \\
\text { (novices) and } \\
15 \text { RNs who } \\
\text { had } \\
\text { completed a } \\
\text { tertiary course } \\
\text { as entry to } \\
\text { practice into } \\
\text { nursing } \\
\text { (experts). }\end{array}$ & $\begin{array}{l}\text { Observation } \\
\text { and in-depth } \\
\text { interviews. }\end{array}$ & $\begin{array}{l}\text { To provide a } \\
\text { detailed account } \\
\text { of the cognitive } \\
\text { processes } \\
\text { involved in } \\
\text { carrying out } \\
\text { nursing } \\
\text { procedures } \\
\text { observed in } \\
\text { clinical practice. }\end{array}$ & $\begin{array}{l}\text { Ericsson \& } \\
\text { Simon; Newell } \\
\text { \& Simon; } \\
\text { Benner. }\end{array}$ & $\begin{array}{l}\text { Differences noted } \\
\text { between novices } \\
\text { and experts in } \\
\text { reasoning } \\
\text { concerning the } \\
\text { following: pre- } \\
\text { encounter data, } \\
\text { cues in the } \\
\text { presenting } \\
\text { situation, } \\
\text { hypothesis } \\
\text { activation, support } \\
\text { and evaluation, } \\
\text { and internal cues. } \\
\text { Experts asked in- } \\
\text { depth questions } \\
\text { and used a wide } \\
\text { range of cues. }\end{array}$ \\
\hline $\begin{array}{l}\text { Thorens, J., } \\
\text { Ranier, M., } \\
\text { Jolliet, P., \& } \\
\text { Chevrolet, J. } \\
\text { (1995). }\end{array}$ & $\begin{array}{l}\text { RNs working } \\
\text { in a medical } \\
\text { ICU who were } \\
\text { designated as } \\
\text { certified } \\
(n=14) \text { or non- } \\
\text { certified } \\
(n=11) \text { by the } \\
\text { authors. }\end{array}$ & $\begin{array}{l}\text { Prospective } \\
\text { study using an } \\
\text { "index of } \\
\text { nursing" which } \\
\text { compares the } \\
\text { effective } \\
\text { workforce of } \\
\text { certified nurses } \\
\text { with the ideal } \\
\text { workforce } \\
\text { required by the } \\
\text { number of } \\
\text { patients and } \\
\text { the severity of } \\
\text { their disease. } \\
\text { The index of } \\
\text { nursing then } \\
\text { compared with } \\
\text { the } \\
\text { complications } \\
\text { and duration of } \\
\text { weaning from }\end{array}$ & $\begin{array}{l}\text { To evaluate the } \\
\text { influence of } \\
\text { nursing on the } \\
\text { duration of } \\
\text { weaning from } \\
\text { mechanical } \\
\text { ventilation in } \\
\text { patients with } \\
\text { chronic } \\
\text { obstructive } \\
\text { pulmonary } \\
\text { disease. }\end{array}$ & None noted. & $\begin{array}{l}\text { The quality of } \\
\text { nursing was found } \\
\text { to be a critical } \\
\text { factor in the } \\
\text { duration of the } \\
\text { weaning process } \\
\text { and prevention of } \\
\text { associated } \\
\text { complications. } \\
\text { Improved patient } \\
\text { outcome was } \\
\text { significantly } \\
\text { related to the } \\
\text { number and } \\
\text { presence of } \\
\text { certified nurses. }\end{array}$ \\
\hline
\end{tabular}




\begin{tabular}{|l|l|l|l|l|}
\hline from & mechanical & & & \\
ventilation. & & & \\
Ventilation in & & & & \\
Patients with & & & & \\
Chronic & & & & \\
Obstructive & & & & \\
Pulmonary & Disease. & & & \\
(Switzerland) & & & & \\
Critical Care & & & & \\
Medicine. & & & & \\
\hline
\end{tabular}


STUDIES USING AN INTUITIVE/QUALITATIVE FRAMEWORK

\begin{tabular}{|c|c|c|c|c|c|}
\hline $\begin{array}{c}\text { AUTHORS } \\
\text { TITLE } \\
\text { JOURNAL }\end{array}$ & $\begin{array}{r}\text { SAMPLE; } \\
\text { SPECIALTY }\end{array}$ & METHOD & PURPOSE & $\begin{array}{l}\text { THEORETICAL } \\
\text { FRAMEWORK }\end{array}$ & FINDINGS \\
\hline $\begin{array}{l}\text { Brykczynski, K. } \\
\qquad(1989) . \\
\text { An Interpretive } \\
\text { Study Describing } \\
\text { the Clinical } \\
\text { Judgment of } \\
\text { Nurse } \\
\text { Practitioners. } \\
\text { Scholarly Inquiry } \\
\text { for Nursing } \\
\text { Practice. }\end{array}$ & $\begin{array}{l}22 \text { volunteer } \\
\text { nurse } \\
\text { practitioners } \\
\text { with at least } \\
\text { three years } \\
\text { experience } \\
\text { (mean of } 6.1 \\
\text { years). } 45 \% \\
\text { were } \\
\text { prepared in } \\
\text { graduate } \\
\text { programs; } 21 \\
\text { were } \\
\text { nationally } \\
\text { certified. }\end{array}$ & $\begin{array}{c}\text { Group and } \\
\text { individual } \\
\text { interviews using } \\
\text { phenomenological } \\
\text { techniques; } \\
\text { participant } \\
\text { observation. }\end{array}$ & $\begin{array}{l}\text { Describe the } \\
\text { knowledge } \\
\text { embedded in the } \\
\text { practice of nurse } \\
\text { practitioners. }\end{array}$ & Benner. & $\begin{array}{l}\text { Identified six themes: } \\
\text { assessment expertise, } \\
\text { vigilance, advocacy, } \\
\text { intimacy, continuity of } \\
\text { care, and } \\
\text { demystification of } \\
\text { health care. Identified } \\
\text { themes interpreted in } \\
\text { terms of Benner's } \\
\text { (1984) aspects of } \\
\text { practical knowledge } \\
\text { and } \\
\text { domains/competencies } \\
\text { of nursing practice. }\end{array}$ \\
\hline $\begin{array}{l}\text { Buhrer, R. \& } \\
\text { Mitchell, P. } \\
\text { (1996). } \\
\text { Peer-identified } \\
\text { Expert Nurses' } \\
\text { Approaches to } \\
\text { Risk Assessment } \\
\text { for Pressure } \\
\text { Ulcers. } \\
\text { Advances in } \\
\text { Wound Care. }\end{array}$ & $\begin{array}{l}5 \mathrm{RNs} \\
\text { identified as } \\
\text { experts at } \\
\text { pressure ulcer } \\
\text { prevention by } \\
\text { staff } \\
\text { development } \\
\text { and nursing } \\
\text { management } \\
\text { personnel. } \\
\text { Participants } \\
\text { worked in } \\
\text { primary care } \\
\text { (1), intensive } \\
\text { care (1), } \\
\text { acute care } \\
\text { (2), and long- } \\
\text { term care (1). }\end{array}$ & Interviews. & $\begin{array}{l}\text { To explore what } \\
\text { expert nurses look } \\
\text { for when assessing a } \\
\text { patient's level of risk } \\
\text { for pressure } \\
\text { ulceration. }\end{array}$ & $\begin{array}{l}\text { Benner \& } \\
\text { Tanner; } \\
\text { Dreyfus \& } \\
\text { Dreyfus. }\end{array}$ & $\begin{array}{l}\text { Five themes identified: } \\
\text { the interconnection of } \\
\text { wound healing and } \\
\text { pressure ulcer } \\
\text { prevention; the } \\
\text { importance of the } \\
\text { setting of care; the } \\
\text { anticipated trajectory } \\
\text { of illness; the use of } \\
\text { multisensory } \\
\text { assessment } \\
\text { modalities; the } \\
\text { inclusion of } \\
\text { psychosocial risk } \\
\text { factors. }\end{array}$ \\
\hline Crandall, B. \& & $\begin{array}{l}\text { Seventeen } \\
\text { RNs with an }\end{array}$ & $\begin{array}{l}\text { Critical decision } \\
\text { method }\end{array}$ & $\begin{array}{l}\text { To describe the } \\
\text { knowledge of expert }\end{array}$ & $\begin{array}{l}\text { Klein, } \\
\text { Calderwood, \& }\end{array}$ & $\begin{array}{l}\text { Experts identified early } \\
\text { sepsis indicators that }\end{array}$ \\
\hline
\end{tabular}




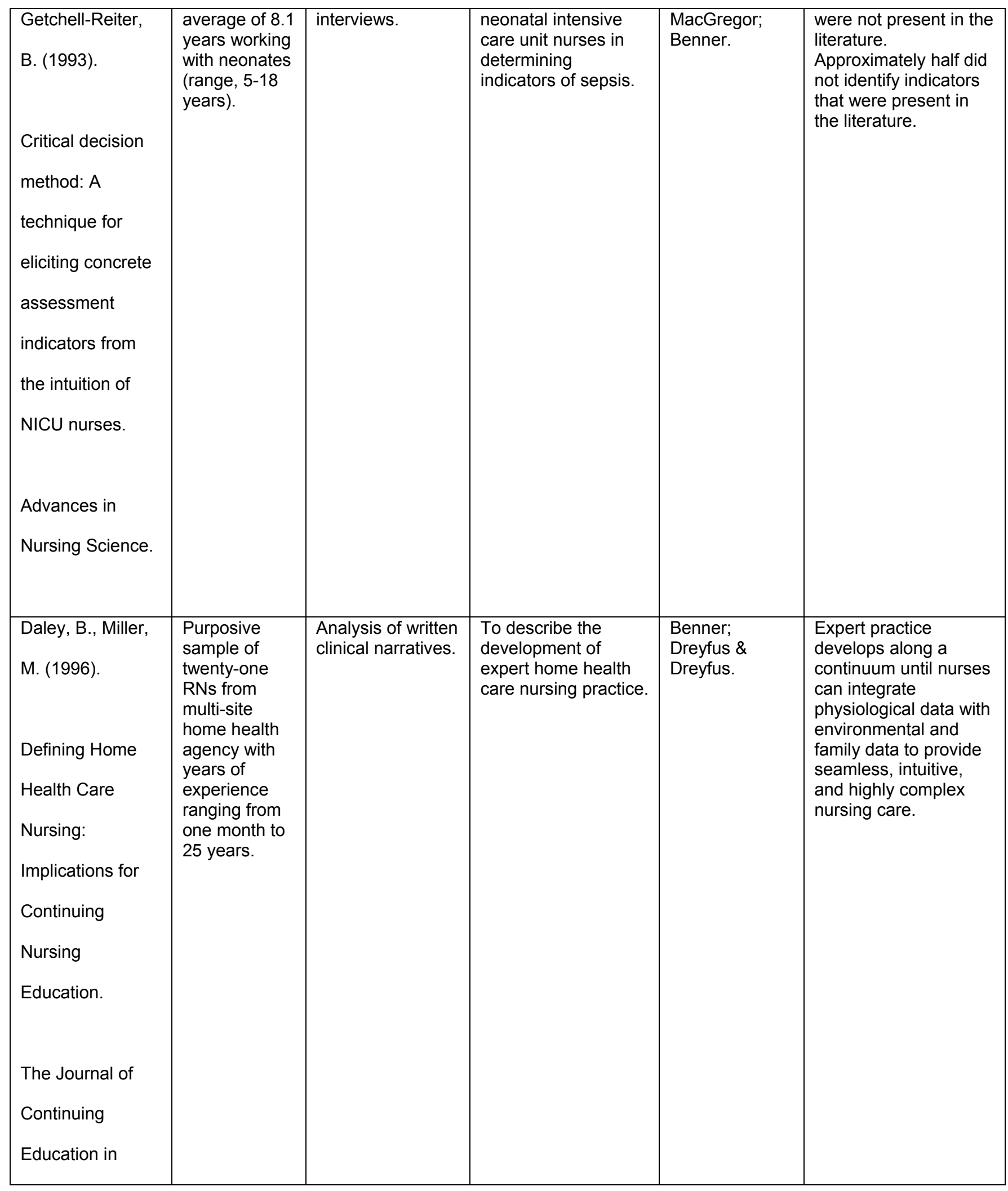




\begin{tabular}{|c|c|c|c|c|c|}
\hline Nursing. & & & & & \\
\hline $\begin{array}{l}\text { Guyton- } \\
\text { Simmons, J. \& } \\
\text { Thermin, J. } \\
\text { (1994). } \\
\text { Problem solving } \\
\text { in Pain } \\
\text { Management by } \\
\text { Expert ICU } \\
\text { Nurses. } \\
\text { Critical Care } \\
\text { Nurse. }\end{array}$ & $\begin{array}{l}\text { Six RNs } \\
\text { identified as } \\
\text { experts by } \\
\text { peers. }\end{array}$ & $\begin{array}{l}\text { Observation and } \\
\text { interviews. }\end{array}$ & $\begin{array}{l}\text { To identify practical } \\
\text { knowledge in the } \\
\text { management of } \\
\text { postoperative pain. }\end{array}$ & $\begin{array}{l}\text { Benner \& } \\
\text { Tanner; Elstein. }\end{array}$ & $\begin{array}{l}\text { Experts used selective } \\
\text { assessment, } \\
\text { behavioral } \\
\text { expressions, } \\
\text { physiologic symptoms, } \\
\text { questioning, pattern } \\
\text { prediction, pain } \\
\text { differentiation, comfort } \\
\text { measures, emotional } \\
\text { support, and physician } \\
\text { notification. }\end{array}$ \\
\hline $\begin{array}{l}\text { Jacavone, J. \& } \\
\text { Dostal, M. (1992). } \\
\text { A descriptive } \\
\text { study of nursing } \\
\text { judgment in the } \\
\text { assessment and } \\
\text { management of } \\
\text { cardiac pain. } \\
\text { Advances in } \\
\text { Nursing Science. }\end{array}$ & $\begin{array}{l}\text { Four coronary } \\
\text { care RNs with } \\
\text { more than five } \\
\text { years } \\
\text { experience } \\
\text { identified as } \\
\text { experts by } \\
\text { peers; four } \\
\text { coronary care } \\
\text { RNs with less } \\
\text { than one year } \\
\text { experience } \\
\text { identified by } \\
\text { peers as } \\
\text { beginners } \\
\text { who provide } \\
\text { high quality } \\
\text { patient care. }\end{array}$ & $\begin{array}{l}\text { Observation; } \\
\text { informal/formal } \\
\text { interviews. }\end{array}$ & $\begin{array}{l}\text { To bring forth the } \\
\text { clinical knowledge } \\
\text { and thought } \\
\text { processes of expert } \\
\text { nurses as they } \\
\text { assessed and } \\
\text { treated cardiac pain } \\
\text { and to compare them } \\
\text { with beginners in } \\
\text { similar situations. }\end{array}$ & $\begin{array}{l}\text { Benner; Benner } \\
\text { \& Tanner. }\end{array}$ & $\begin{array}{l}\text { Two main themes and } \\
\text { six sub-themes } \\
\text { identified practical } \\
\text { knowledge of drug } \\
\text { titration (aggressive } \\
\text { titration for myocardial } \\
\text { salvage; aggressive } \\
\text { titration when } \\
\text { diagnosis is uncertain; } \\
\text { vigilance during pain } \\
\text { management; } \\
\text { individual responses); } \\
\text { qualitative distinctions } \\
\text { in pain assessment } \\
\text { (inward focusing and } \\
\text { energy conservation; } \\
\text { residual pain;). } \\
\text { Beginners were } \\
\text { hesitant and passive } \\
\text { with titration and } \\
\text { concentrated on their } \\
\text { role/action instead of } \\
\text { on patient. }\end{array}$ \\
\hline $\begin{array}{l}\text { Jenny, J. \& } \\
\text { Logan, J. (1992). }\end{array}$ & $\begin{array}{l}16 \text { critical } \\
\text { care nurses } \\
\text { identified as } \\
\text { experts by } \\
\text { peers and } \\
\text { supervisors. }\end{array}$ & $\begin{array}{l}\text { Analysis of critical } \\
\text { incidents; } \\
\text { grounded theory. }\end{array}$ & $\begin{array}{l}\text { To identify nurses' } \\
\text { perceptions of their } \\
\text { weaning practice and } \\
\text { to describe the } \\
\text { knowledge, } \\
\text { judgments, and } \\
\text { actions employed by }\end{array}$ & $\begin{array}{l}\text { Benner; Benner } \\
\text { \& Wrubel; } \\
\text { Carper. }\end{array}$ & $\begin{array}{l}\text { Knowing the patient is } \\
\text { a process of acquiring } \\
\text { and using a form of } \\
\text { particularistic } \\
\text { knowledge that } \\
\text { includes: }\end{array}$ \\
\hline
\end{tabular}




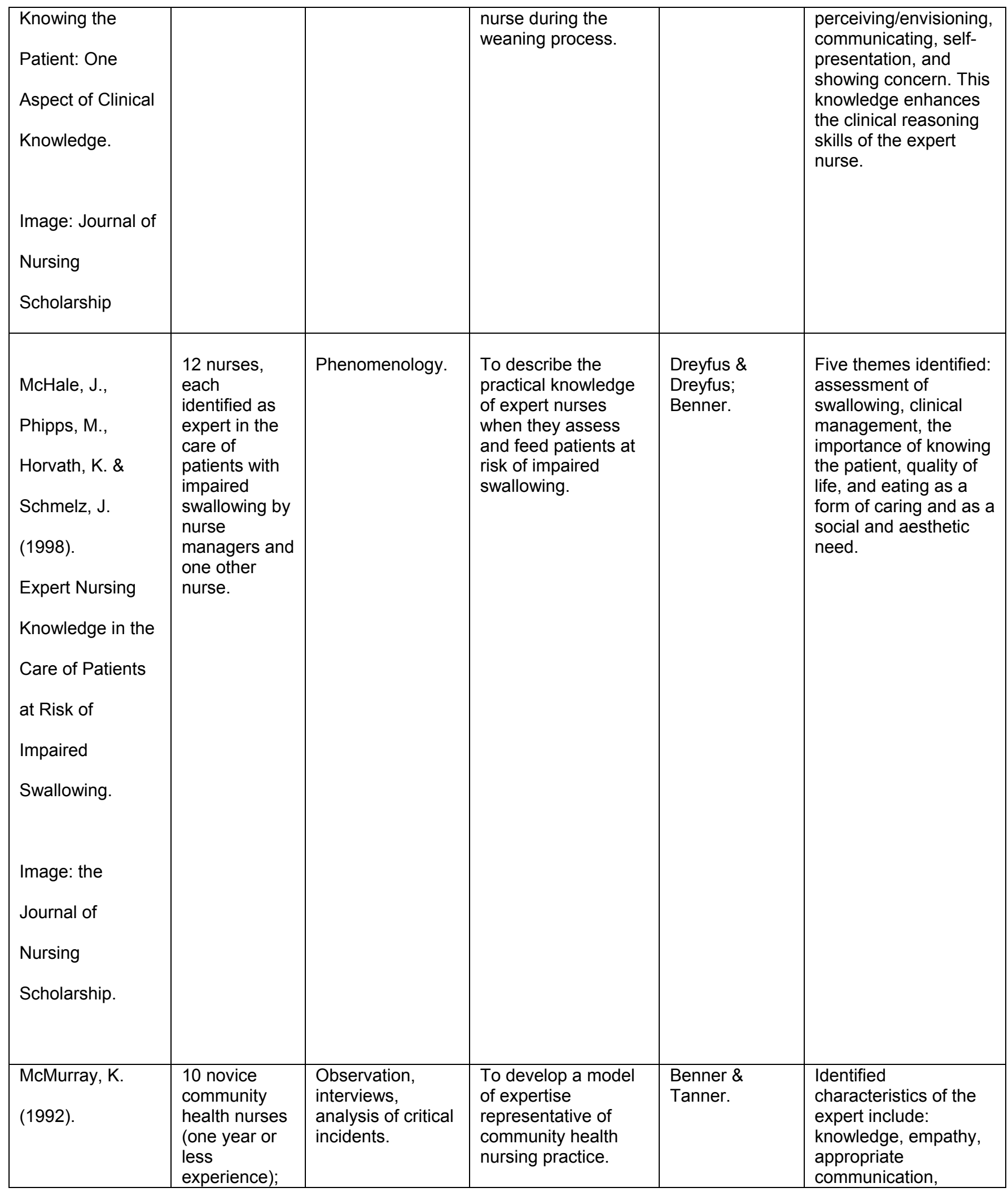




\begin{tabular}{|c|c|c|c|c|c|}
\hline $\begin{array}{l}\text { Expertise in } \\
\text { Community } \\
\text { Health Nursing. } \\
\text { Journal of } \\
\text { Community } \\
\text { Health Nursing. }\end{array}$ & $\begin{array}{l}27 \text { peer- } \\
\text { identified } \\
\text { experts. }\end{array}$ & & & & $\begin{array}{l}\text { holistic understanding, } \\
\text { an ability to get right to } \\
\text { the problem at hand, } \\
\text { and self-confidence. } \\
\text { Development of } \\
\text { expertise involves } \\
\text { educational, personal, } \\
\text { and experiential } \\
\text { factors. } \\
\text { Novices tended to } \\
\text { stereotype situations } \\
\text { based on } \\
\text { preconceived notions. }\end{array}$ \\
\hline $\begin{array}{l}\text { Parker, C., } \\
\text { Minick, P., \& Kee, } \\
\text { C. (1999). } \\
\text { Clinical Decision- } \\
\text { making } \\
\text { Processes in } \\
\text { Perioperative } \\
\text { Nursing. }\end{array}$ & $\begin{array}{l}6 \\
\text { perioperative } \\
\text { nurses with a } \\
\text { minimum of } \\
\text { five years } \\
\text { experience. } \\
\text { Participants } \\
\text { identified } \\
\text { themselves as } \\
\text { experts and } \\
\text { recommended } \\
\text { others. }\end{array}$ & $\begin{array}{l}\text { Analysis of critical } \\
\text { incidents. }\end{array}$ & $\begin{array}{l}\text { To reveal the } \\
\text { processes used by } \\
\text { expert perioperative } \\
\text { nurses as they make } \\
\text { clinical decisions. }\end{array}$ & $\begin{array}{l}\text { Benner; } \\
\text { Benner, } \\
\text { Tanner, \& } \\
\text { Chesla. }\end{array}$ & $\begin{array}{l}\text { One overriding theme, } \\
\text { "seeing the big picture: } \\
\text { engendered through } \\
\text { caring", and three } \\
\text { subthemes identified: } \\
\text { connecting with } \\
\text { patients, advocating } \\
\text { for patients, and } \\
\text { embodied knowing. }\end{array}$ \\
\hline AORN Journal. & & & & & \\
\hline
\end{tabular}




\begin{tabular}{|c|c|c|c|c|c|}
\hline $\begin{array}{l}\text { Peden-McAlpine, } \\
\quad \text { C. (2000). } \\
\text { Early Recognition } \\
\text { of Patient } \\
\text { Problems: A } \\
\text { Hermeunetic } \\
\text { Journey Into } \\
\text { Understanding } \\
\text { Expert Thinking } \\
\text { in Nursing. } \\
\text { Scholarly Inquiry } \\
\text { for Nursing } \\
\text { Practice. }\end{array}$ & $\begin{array}{c}15 \text { peer } \\
\text { nominated } \\
\text { expert critical } \\
\text { care nurses. }\end{array}$ & $\begin{array}{c}\text { Analysis of } \\
\text { interview } \\
\text { narratives using } \\
\text { an interpretive } \\
\text { approach based } \\
\text { on the philosophy } \\
\text { of human action. }\end{array}$ & $\begin{array}{l}\text { To explicate the } \\
\text { unconscious activity } \\
\text { of early recognition of } \\
\text { patient problems to } \\
\text { understand the } \\
\text { thinking of expert } \\
\text { critical care nurses. }\end{array}$ & $\begin{array}{c}\text { Benner, } \\
\text { Tanner, \& } \\
\text { Chesla; Schon. }\end{array}$ & $\begin{array}{c}\text { Three common } \\
\text { characteristics } \\
\text { identified in the } \\
\text { nurses' thinking were } \\
\text { different types of } \\
\text { information, a mode of } \\
\text { situational } \\
\text { understanding, and a } \\
\text { temporal component } \\
\text { of thinking in practice. } \\
\text { The findings } \\
\text { demonstrated an } \\
\text { integrated model of } \\
\text { situational } \\
\text { understanding and } \\
\text { informed action, } \\
\text { thinking in action, } \\
\text { similar to Aristotle's } \\
\text { notion of practical } \\
\text { wisdom. }\end{array}$ \\
\hline $\begin{array}{l}\text { Pyles, S. \& Stern, } \\
\quad \text { P. (1983). } \\
\text { Discovery of } \\
\text { Nursing Gestalt: } \\
\text { The Importance } \\
\text { of the Gray } \\
\text { Gorilla } \\
\text { Syndrome. } \\
\text { Journal of } \\
\text { Nursing } \\
\text { Scholarship. }\end{array}$ & $\begin{array}{l}\text { Twenty-eight } \\
\text { RNs with } \\
\text { varied length } \\
\text { of experience. }\end{array}$ & Interviews. & $\begin{array}{l}\text { To determine how } \\
\text { nurses know if a } \\
\text { patient is developing } \\
\text { cardiogenic shock. }\end{array}$ & $\begin{array}{c}\text { Bruner; } \\
\text { Wertheimer. }\end{array}$ & $\begin{array}{l}\text { More experienced } \\
\text { nurses use "nursing } \\
\text { gestalt" in the early } \\
\text { detection and } \\
\text { prevention of } \\
\text { cardiogenic shock in } \\
\text { patients with acute } \\
\text { myocardial infarction. } \\
\text { "Nursing gestalt" was } \\
\text { identified as a } \\
\text { cognitive and sensory } \\
\text { process consisting of: } \\
\text { knowledge, cue } \\
\text { identification, } \\
\text { categorization, and } \\
\text { differentiation, and gut } \\
\text { feelings. }\end{array}$ \\
\hline $\begin{array}{l}\text { Radwin, L. } \\
\text { (1998). } \\
\text { Empirically } \\
\text { generated } \\
\text { attributes of } \\
\text { experience. } \\
\text { Journal of } \\
\text { Advanced } \\
\text { Nursing. }\end{array}$ & $\begin{array}{l}13 \text { cardiology } \\
\text { nurses } \\
\text { identified as } \\
\text { expert } \\
\text { decision- } \\
\text { makers by } \\
\text { nurse } \\
\text { managers or } \\
\text { peers. }\end{array}$ & Grounded theory. & $\begin{array}{l}\text { To identify, describe, } \\
\text { and provide a } \\
\text { theoretical analysis } \\
\text { of the strategies } \\
\text { expert nurses use } \\
\text { when making clinical } \\
\text { decisions. }\end{array}$ & $\begin{array}{l}\text { Benner; Benner } \\
\text { \& Tanner; } \\
\text { Benner, } \\
\text { Tanner, \& } \\
\text { Chesla; } \\
\text { Dreyfus \& } \\
\text { Dreyfus. }\end{array}$ & $\begin{array}{l}\text { Three attributes of } \\
\text { expert nurses' } \\
\text { experience identified: } \\
\text { a focus on the patient, } \\
\text { confidence in practice, } \\
\text { and knowledge of } \\
\text { antecedents and } \\
\text { consequences of } \\
\text { similar patient } \\
\text { situations. }\end{array}$ \\
\hline
\end{tabular}




\begin{tabular}{|c|c|c|c|c|c|}
\hline $\begin{array}{l}\text { Schraeder, B. \& } \\
\quad \text { Fischer, D. } \\
\qquad(1987) . \\
\text { Using Intuitive } \\
\text { Knowledge in the } \\
\text { Neonatal } \\
\text { Intensive Care } \\
\text { Nursery. } \\
\text { Holistic Nursing } \\
\text { Practice. }\end{array}$ & $\begin{array}{l}15 \text { RNs with } \\
\text { years of } \\
\text { experience } \\
\text { ranging from } \\
\text { one to seven. }\end{array}$ & $\begin{array}{c}\text { Ethnographic } \\
\text { interviews, } \\
\text { observation, and } \\
\text { examination of } \\
\text { primary } \\
\text { documents. }\end{array}$ & $\begin{array}{c}\text { Describe the } \\
\text { experiences, } \\
\text { rationales, actions, } \\
\text { and consequences } \\
\text { involved when } \\
\text { intensive care nurses } \\
\text { act on } \\
\text { feelings/assessments } \\
\text { that infants do not } \\
\text { "look like } \\
\text { themselves". }\end{array}$ & $\begin{array}{l}\text { Benner; Pyles } \\
\text { \& Stern. }\end{array}$ & $\begin{array}{c}\text { Use of intuitive } \\
\text { knowledge } \\
\text { characterized by four } \\
\text { themes: in depth } \\
\text { knowledge of the field } \\
\text { and wide experience; } \\
\text { feeling of relatedness } \\
\text { to the infant; } \\
\text { perception of the } \\
\text { individual infant's } \\
\text { physiological cues; } \\
\text { linkage of present } \\
\text { perceptions with past } \\
\text { experiences. Nurses } \\
\text { with more experience } \\
\text { (4-5 years) possessed } \\
\text { and acted on intuitive } \\
\text { knowledge. }\end{array}$ \\
\hline $\begin{array}{l}\text { Smith, S. (1988). } \\
\text { An Analysis of } \\
\text { the Phenomenon } \\
\text { of Deterioration in } \\
\text { the Critically III. }\end{array}$ & $\begin{array}{l}6 \text { RNs with at } \\
\text { least two } \\
\text { years critical } \\
\text { care } \\
\text { experience. }\end{array}$ & $\begin{array}{l}\text { Author developed } \\
\text { questionnaires } \\
\text { and interviews. }\end{array}$ & $\begin{array}{l}\text { To describe the } \\
\text { characteristics of } \\
\text { deterioration. }\end{array}$ & $\begin{array}{l}\text { Benner; Pyles } \\
\text { \& Stern. }\end{array}$ & $\begin{array}{l}\text { Identified four } \\
\text { characteristics of } \\
\text { deterioration and cues } \\
\text { used to assess/ } \\
\text { intervene. The expert } \\
\text { was more likely to use } \\
\text { confrontational } \\
\text { strategies with the } \\
\text { physician. }\end{array}$ \\
\hline $\begin{array}{l}\text { SmithBattle, L., } \\
\text { Drake, M. \& } \\
\text { Diekemper, M. } \\
\text { (1997). } \\
\text { The Responsive } \\
\text { Use of Self in } \\
\text { Community } \\
\text { Health Nursing } \\
\text { Practice. } \\
\text { Advances in } \\
\text { Nursing Science. }\end{array}$ & $\begin{array}{l}24 \text { RNs (16 } \\
\text { with more } \\
\text { than four } \\
\text { years } \\
\text { experience } \\
\text { and eight with } \\
\text { four years or } \\
\text { less. }\end{array}$ & Phenomenology. & $\begin{array}{l}\text { To describe the } \\
\text { unrecognized } \\
\text { expertise in } \\
\text { community health } \\
\text { nursing practice. }\end{array}$ & $\begin{array}{l}\text { Benner; } \\
\text { Benner, } \\
\text { Tanner, \& } \\
\text { Wrubel; } \\
\text { Benner, } \\
\text { Tanner, \& } \\
\text { Chesla. }\end{array}$ & $\begin{array}{l}\text { Less } \\
\text { experienced CHNs } \\
\text { identified problems } \\
\text { based on normative } \\
\text { criteria and tended to } \\
\text { get hung up on little } \\
\text { things. Expert CHNs } \\
\text { shared knowledge and } \\
\text { power with clients, } \\
\text { identified problems } \\
\text { collaboratively, and } \\
\text { employed the } \\
\text { responsive use of self } \\
\text { to develop a } \\
\text { partnership with clients }\end{array}$ \\
\hline
\end{tabular}




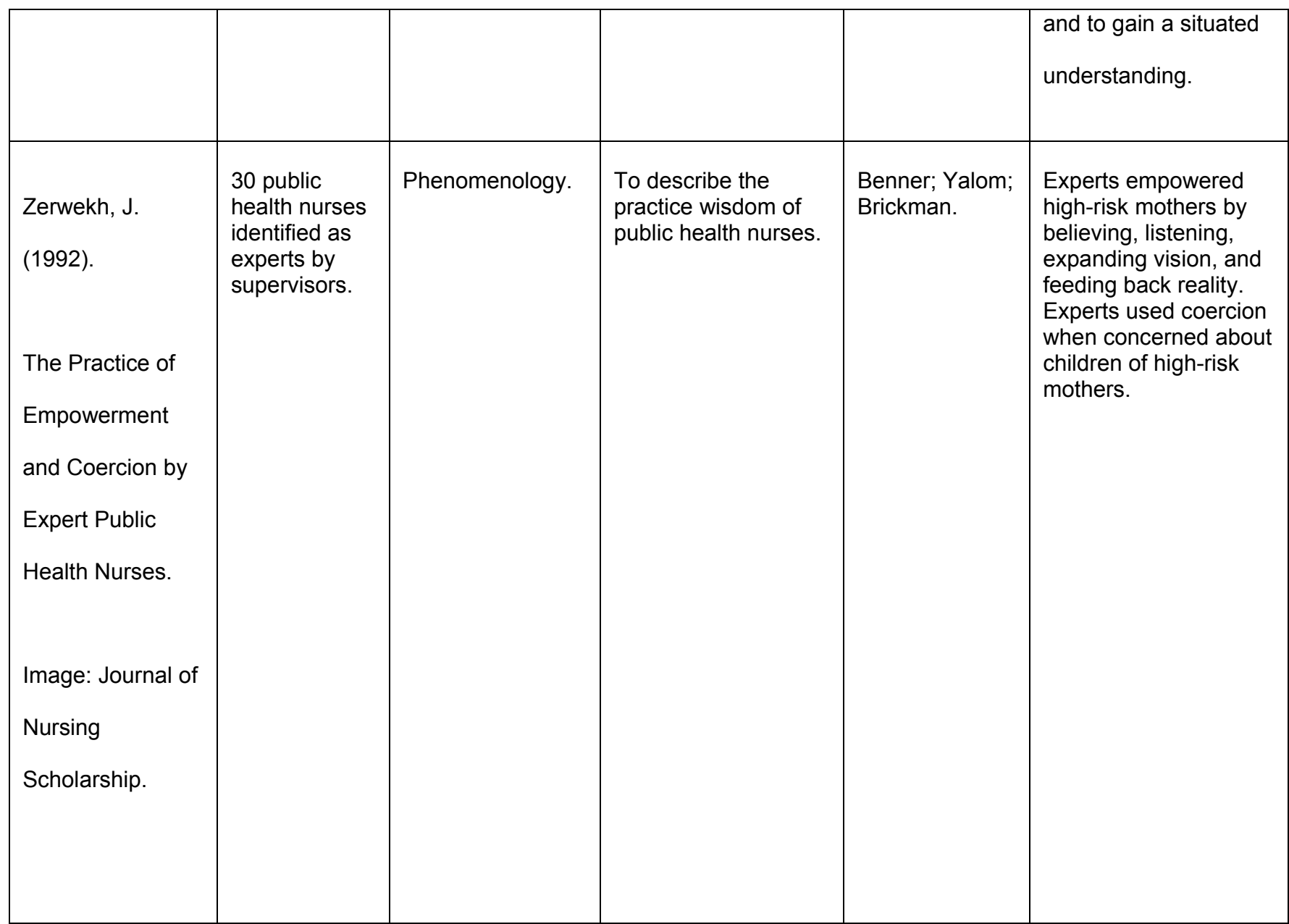


STUDIES EXPLORING THE ETHICAL PRACTICE OF THE EXPERT NURSE

\begin{tabular}{|c|c|c|c|c|c|}
\hline $\begin{array}{c}\text { AUTHORS, } \\
\text { TITLE, } \\
\text { JOURNAL }\end{array}$ & $\begin{array}{l}\text { SAMPLE; } \\
\text { SPECIALITY }\end{array}$ & METHOD & PURPOSE & $\begin{array}{l}\text { THEORETICAL } \\
\text { FRAMEWORK }\end{array}$ & FINDINGS \\
\hline $\begin{array}{l}\text { Cooper, M. } \\
\text { (1993). } \\
\text { The intersection } \\
\text { of technology } \\
\text { and care in the } \\
\text { ICU. }\end{array}$ & $\begin{array}{l}\text { Nine } \\
\text { cardiothoracic } \\
\text { ICU nurses } \\
\text { with a mean } \\
\text { of } 5.6 \text { years } \\
\text { experience } \\
\text { (range, } 1-12 \\
\text { years). }\end{array}$ & $\begin{array}{l}\text { Observation; } \\
\text { formal/informal } \\
\text { interviews. }\end{array}$ & $\begin{array}{l}\text { To identify } \\
\text { and } \\
\text { categorize } \\
\text { the behaviors } \\
\text { and } \\
\text { interactions } \\
\text { that } \\
\text { characterizes } \\
\text { the moral } \\
\text { experience of } \\
\text { ICU nurses. }\end{array}$ & $\begin{array}{l}\text { Benner, } \\
\text { Tanner, \& } \\
\text { Chesla; } \\
\text { Watson. }\end{array}$ & $\begin{array}{l}\text { The expert nurse } \\
\text { demonstrates the } \\
\text { union of } \\
\text { technological } \\
\text { competence and } \\
\text { care which } \\
\text { enriches the } \\
\text { human } \\
\text { experience. }\end{array}$ \\
\hline $\begin{array}{l}\text { Advances in } \\
\text { Nursing } \\
\text { Science. }\end{array}$ & & & & & \\
\hline $\begin{array}{l}\text { McClement, S. } \\
\text { \& Degner, L. } \\
\text { (1995). } \\
\text { Expert Nursing } \\
\text { Behaviors in } \\
\text { Care of the } \\
\text { Dying Adult in } \\
\text { the Intensive } \\
\text { Care Unit. } \\
\text { (Canada). }\end{array}$ & $\begin{array}{l}10 \text { intensive } \\
\text { care unit RNs } \\
\text { identified as } \\
\text { experts in } \\
\text { care of the } \\
\text { dying by their } \\
\text { peers. }\end{array}$ & Interviews. & $\begin{array}{l}\text { To identify } \\
\text { expert } \\
\text { nursing } \\
\text { behaviors in } \\
\text { care of the } \\
\text { dying adult in } \\
\text { the intensive } \\
\text { care unit. }\end{array}$ & $\begin{array}{l}\text { Quint; Dreyfus } \\
\text { \& Dreyfus; } \\
\text { Benner. }\end{array}$ & $\begin{array}{l}\text { Six critical } \\
\text { nursing } \\
\text { behaviors } \\
\text { identified: } \\
\text { responding after } \\
\text { the death has } \\
\text { occurred; } \\
\text { responding to the } \\
\text { family; facilitating } \\
\text { transition from } \\
\text { cure to palliation; } \\
\text { responding to } \\
\text { anger; } \\
\text { responding to } \\
\text { colleagues; } \\
\text { providing } \\
\text { comfort; } \\
\text { enhancing } \\
\text { personal growth. }\end{array}$ \\
\hline
\end{tabular}




\begin{tabular}{|c|c|c|c|c|c|}
\hline Heart \& Lung. & & & & & \\
\hline $\begin{array}{l}\text { Ray, M. (1987) } \\
\text { Technological } \\
\text { Caring: A New } \\
\text { Model in Critical } \\
\text { Care. } \\
\text { Dimensions of } \\
\text { Critical Care } \\
\text { Nursing. }\end{array}$ & $\begin{array}{l}\text { Purposive } \\
\text { sample of } \\
\text { eight critical } \\
\text { care nurses. }\end{array}$ & Phenomenology. & $\begin{array}{l}\text { To uncover } \\
\text { the meaning } \\
\text { of caring for } \\
\text { the nurses } \\
\text { working in } \\
\text { critical care. }\end{array}$ & $\begin{array}{l}\text { Leininger; } \\
\text { Watson; } \\
\text { Thompson \& } \\
\text { Thompson. }\end{array}$ & $\begin{array}{c}\text { Five themes of } \\
\text { caring identified: } \\
\text { maturation, } \\
\text { technical } \\
\text { competence, } \\
\text { transpersonal } \\
\text { caring, } \\
\text { communication, } \\
\text { and } \\
\text { judgement/ethics. }\end{array}$ \\
\hline $\begin{array}{l}\text { Wros, P. (1994). } \\
\text { The Ethical } \\
\text { Context of } \\
\text { Nursing Care of } \\
\text { Dying Patients } \\
\text { in Critical Care. } \\
\text { In P. Benner } \\
\text { (Ed.), } \\
\text { Interpretive } \\
\text { phenomenology, } \\
\text { embodiment, } \\
\text { caring and } \\
\text { ethics in health } \\
\text { and illness. }\end{array}$ & $\begin{array}{l}15 \text { nurses } \\
\text { identified as } \\
\text { experts in the } \\
\text { care of dying } \\
\text { patients by } \\
\text { nurse } \\
\text { managers. }\end{array}$ & $\begin{array}{l}\text { Interviews, } \\
\text { observation. }\end{array}$ & $\begin{array}{l}\text { To identify } \\
\text { the caring } \\
\text { practices, } \\
\text { interpersonal } \\
\text { concerns, } \\
\text { and } \\
\text { background } \\
\text { meanings of } \\
\text { expert } \\
\text { nurses' } \\
\text { caring of } \\
\text { dying } \\
\text { patients. }\end{array}$ & $\begin{array}{l}\text { Bishop and } \\
\text { Scudder; } \\
\text { Benner. }\end{array}$ & $\begin{array}{l}\text { Analysis included } \\
\text { descriptions of an } \\
\text { ethic of care, the } \\
\text { role of judicial } \\
\text { ethics in decision } \\
\text { making and } \\
\text { specific moral } \\
\text { concerns of the } \\
\text { nurse. }\end{array}$ \\
\hline
\end{tabular}




\title{
APPENDIX B
}

\author{
Letter to Consortium
}

\section{Dear Consortium Group Member:}

I am a doctoral student at The University of Texas at Austin School of Nursing. I am currently writing the proposal for my dissertation entitled The Ethical Practice of Expert Critical Care Nurses in Situations of Prognostic Conflict. Specifically I am interested in what indicators expert critical care nurses describe about poor patient prognosis and what they communicate about their perceptions to the patient, family, physician(s), or peers. In addition, I would like to explore what these nurses do when their perceptions of the usefulness of aggressive medical therapies differ from those of the patient, family, physician(s), or peers and the reasons they give for their actions.

I am requesting your assistance in identifying expert critical care nurses in your facility. I have developed tentative criteria to assist in this process based on the work of Benner, Tanner, and Chesla (1996) and Benner, Hooper-Kyriakidis, and Stannard (1999). These authors propose that expert nursing practice has clinical and ethical components and includes both general and specific characteristics. General criteria are: (a) have been practicing for five years or more; (b) are sought out by others for advice in solving clinical problems; and (c) are considered excellent preceptors. Specific characteristics indicative of expert practice include: (a) clinical grasp and response based practice which is evident in the expert nurse's ability to "read" a clinical situation and respond quickly and 
fluidly with seemingly little conscious thought; (b) embodied or skilled know-how which includes behaviors such as teamwork, having the environment prepared, and sequencing activities as needed by the patient's clinical condition; (c) perceptual acuity which is evident in the expert's ability to identify or define a clinical or ethical problem and (d) moral agency which is the expert nurse's ability to act upon or influence a situation. Three behaviors associated with moral agency include: (1) involvement; (2) managing technology and preventing unnecessary technological intrusions; and (3) working with and through others.

I would appreciate your help in considering these criteria as a guide to identify expert nurses working in adult critical care units in your institution. Pending approval of my proposal, I would then contact them for an interview. If you have any questions regarding these criteria, I will be happy to discuss them with you at your meeting.

Catherine Robichaux R.N., M.S.N., CCRN

Home phone-479-3458

e-mail-hrobicha@earthlink.net

References:

Benner, P., Tanner, C., \& Chesla, C. (1996). Expertise in nursing practice: Caring, clinical judgment, and ethics. New York: Springer Publishing Company.

Benner, P., Hooper-Kyriakidis, P., \& Stannard, D. (1999). Clinical wisdom and interventions in critical care. Philadelphia, PA: W.B. Saunders Company. 


\section{APPENDIX C \\ COVER LETTER \\ The Ethical Practice of Expert Critical Care Nurses}

You are invited to participate in a study of expert nurses' ethical practice in situations of prognostic conflict. My name is Catherine Robichaux. I am a graduate student at The University of Texas at Austin School of Nursing. I am conducting this research for my dissertation. I hope to learn more about what indicators expert critical care nurses describe about poor patient prognosis, what they communicate about their perceptions, and what they do when their perceptions differ from those of the patient, family, physician(s), or peers. You were selected as a possible participant in this study because you were identified by the nurse educator/clinical nurse specialist or nurse manager in your facility as an expert critical care nurse. You will be one of 20 subjects chosen to participate in this study.

If you decide to participate, I will interview you at a place of your choosing. You may also choose the time of the interview. The interview will be taperecorded and will last approximately 90 minutes. A second interview may be necessary to clarify information discussed in the initial interview. You may also be asked to participate in a focus group to validate the obtained data after completion of the interviews and analysis. The interview questions pertain to a patient care situation in which you felt the patient would not regain an acceptable quality of life despite the provision of all therapies and interventions. The interview may benefit you by allowing you to discuss your perceptions and 
concerns. A potential risk or discomfort is discussion of information that may be of a sensitive or disturbing nature. There is no compensation for being in the study.

Any information that is obtained in connection with this study and that can be identified with you will remain confidential and will be disclosed only with your permission. Audiotapes, transcripts, and a list linking participant names and code numbers will be kept in a locked file and destroyed after completion of the study.

Your decision whether or not to participate will not affect your future relations with The University of Texas at Austin or your place of employment. If you decide to participate, you are free to discontinue participation at any time by contacting me or requesting an interview be discontinued.

If you have any questions please contact me. If you have any additional questions at a later time, you may contact either me, Catherine Robichaux at 210-479-3458, or Angela Clark, R.N., PhD, FAAN, Associate Professor of Nursing, Adult Health Division, who is my faculty sponsor, at The University of Texas at Austin School of Nursing, 1700 Red River, Austin, Texas, 78701, (512471-7311). You may retain the Cover/Information Letter that explains the nature of your participation and the handling of the information you supply.

If you are interested in participating and/or would like more information, please call me at:

Home: 479-3458 
Work: 829-6029

Pager: 205-1572

e-mail: hrobicha@earthlink.net

Cathy Robichaux 


\section{APPENDIX D}

\section{Demographic Data Form}

1. Age of respondent

2. Male___ Female

3. Highest degree obtained in nursing___ Diploma __ ADN BSN_MSN_PhD

4. Number of years in nursing

5. Number of years in critical care nursing

6. Number of years in present position

7. Type of critical care unit you are currently working in: $\mathrm{CCU} \_$_ SICU __ other (please specify)

8. Present position is in a __ private hospital ___ teaching hospital

9. CCRN certification: ___ yes __ no

10. Other certification (please specify):

11. Are you currently enrolled in any nursing courses? Please specify:

12. Have you taken any college courses during the past year? Please specify:

13. Are you a member of a professional organization(s)? Please specify: 


\section{APPENDIX E Interview Introductory Statement}

Sometimes critical care nurses find themselves in situations in which they believe the patient will not regain an acceptable quality of life despite the provision of all therapies and interventions. Caring for the patient at this time can become an ethical dilemma for the nurse if aggressive medical treatment is continued. I would like you to think about whether you have experienced this situation and tell me what you chose to do. 


\section{APPENDIX F}

\section{Example of Field Note/ Analytic Memo}

Note: I'm having a difficult time getting some participants to tell me a narrative or a story about a particular patient. Today, the nurse said that "there were so many" she couldn't recall just one particular person because "they seemed to run together." I remember reading in one of Benner's books that one of the characteristics associated with experts was the ability to recall the patients they cared for in great detail. Recall is associated with expertise in general-so perhaps this participant may not be considered an expert?

Memo: I'm starting to see some common threads in several narratives that revolve around the nurses' attempts to encourage family members to see what's happening with the patients. They are using some common terms like "presenting reality" and "painting a realistic picture". Some of the strategies they use go beyond just giving information to the family and involve having them "see" what the patients' experiences every day. 


\section{REFERENCES}

Agar, M., \& Hobbs, J. (1982). Interpreting discourse: Coherence and the analysis of ethnographic interviews. Discourse Processes, 5, 1-32.

Akerlund, B. \& Norberg, A. (1985). An ethical analysis of double bind conflicts as experienced by care workers feeding severely demented patients. International Journal of Nursing Studies, 22 (2), 207-216.

Alexander, L. (1991). Explication of the meaning of clinical judgment in nursing practice using Ricourean hermeneutics. Dissertation Abstracts International, B52/02, 744. (University Microfilms No. AAC 9119796).

Allan, J., \& Hall, B. (1988). Challenging the focus on technology: A critique of the medical model in a changing health care system. Advances in Nursing Science, 10 (2), 22-33.

American College of Chest Physicians, Society of Critical Care Medicine Consensus Panel (1990). Ethical and moral guidelines for the initiation, continuation, and withdraawl of intensive care. Chest, 97, 949-958.

American Nurses Association. (1992). Code for nurses with interpretive statements. Kansas City, MO: Author.

Anderson, J. (1982). Acquisition of cognitive skill. Psychological Review, 89, 369-406.

Annas, G. (1995). How we lie. The Hastings Center Report, 25 (6), S1620. 
Anspach, A. (1987). Prognostic conflict in life and death decisions; The organization as an ecology of knowledge. Journal of Health and Social Behavior, $\underline{28}(9), 215-231$.

Aristotle. (1953). Nicomachean ethics (J.K. Thomson, Trans.) as $\underline{\text { The }}$ Ethics of Aristotle. New York: Penguin.

Arney, W., \& Bergen, B. (1984). Medicine and the management of living. Chicago: University of Chicago Press.

Asch, D. (1996). The role of critical care nurses in euthanasia and assisted suicide. The New England Journal of Medicine, 334 (21), 1374-1379.

Atkinson, P. (1997). Narrative turn or blind alley? Qualitative Health

Research, 7 (3), 325-344.

Attanucci, J. (1991). Changing subjects: Growing up and growing older. Journal of Moral Education, 20 (2), 317-328.

Ayers, L. (2000). Narratives of family caregiving: Four story types. Research in Nursing and Health, 23, 359-71.

Baggs, J. (1993). Collaborative interdisciplinary bioethical decision making in the intensive care unit. Nursing Outlook, 41 (3), 108-112.

Baggs, J., \& Schmitt, M. (2000). End-of-life decisions in adult Intensive Care: Current research base and directions for the future. Nursing Outlook, $\underline{48}$ (4), 158-163.

Bailey (1996). Assuring quality in narrative analysis. Western Journal of Nursing Research, 18 (2), 186-195. 
Barnard, A., \& Sandelowski, M. (2001). Technology and humane nursing care: (Ir)reconcilable or invented differences? Journal of Advanced Nursing, 34 (3), 367-375.

Beauchamp, T. \& Childers, J. (1989). Principles of biomedical ethics. New York: Oxford University Press.

Benner, P. \& Wrubel, J. (1989). The primacy of caring. Menlo Park, CA: Addison-Wesley.

Benner, P. (1982). From novice to expert. American Journal of Nursing, 82 (6), 402-407.

Benner, P. (1984). From novice to expert: Excellence and power in clinical nursing practice. Menlo Park, CA: Addison-Wesley Publishing Company.

Benner, P., Hooper-Kyriakidis, P., \& Stannard, D. (1999). Clinical wisdom and interventions in critical care. Philadelphia, PA: W.B. Saunders Company.

Benner, P., Tanner, C., \& Chesla, C. (1996). Expertise in nursing practice: Caring, clinical judgment, and ethics. New York: Springer Publishing Company.

Bereiter, C., \& Scardamalia, M. (1993). Surpassing ourselves: an inquiry into the nature and implications of expertise. Chicago; Open Cour Press.

Bernstein, R. (1983). Beyond objectivism and relativism: Science, hermeneutics, and praxis. Philadelphia: University of Pennsylvania Press.

Bertaux, G., \& Kohli, A. (1984). The life story approach: A continental view. Annual Review of Sociology, 10, 215-237. 
Bishop, A., \& Scudder, J. (1987). Nursing ethics in an age of controversy. Advances in Nursing Science, 9 (3), 34-43).

Bishop, A., \& Scudder, J. (1990). The practical, moral, and personal sense of nursing: A phenomenological philosophy of practice. Albany, NY: National League for Nursing.

Blackhall, L., Frank, G., Murphy, S., Michel, V., Palmer, J., \& Azen, S. (1999). Ethnicity and attitudes toward life sustaining technology. Social Science and Medicine, 48, 1779-1789.

Blum, Lawrence. (1994). Moral Perception and Particularity. Cambridge, MA: Cambridge University Press.

Boyatzis, R. (1998). Transforming qualitative information. Thousand Oaks, CA: Sage.

Brink, P., \& Wood, M. (1988). Basic steps in planning nursing research: From question to proposal. Boston, MA: Jones \& Bartlett.

Brody, H. (1994). My story is broken: can you help me fix it? Medical ethics and the joint construction of narrative. Literature and Medicine, 13 (1), 7992.

Brody, J. (1988). Virtue ethics, caring and nursing. Scholarly Inquiry for Nursing Practice, 2 (2), 87-96.

Brown, I., Tappan, M., Gilligan, C., Miller, B., \& Argyris, D. (1989). Reading for self and moral choice: A method for interpreting narratives of real-life moral choice and conflict. In M. Packer \& R. Addison (Eds.), Entering the circle: 
Hermeneutic investigation in psychology (pp. 141-164). Albany: State University of New York Press.

Bruner, J. (1990). Acts of meaning. Cambridge, MA: Harvard University Press.

Bruner, J. (1990). The narrative construction of reality. Critical Inquiry, 18 (12), 1-21.

Brykczynski, K. (1989). An interpretive study describing the clinical judgment of nurse practitioners. Scholarly Inquiry for Nursing Practice, 3

Buhrer, R., \& Mitchell, P. (1996). Peer-identified expert nurses' approaches to risk assessment for pressure ulcers. Advances in Wound Care, 9 (1), 41-47.

Burrell, D. \& Hauerwas, S. (1977). From system to story: An alternative pattern to rationality in ethics. In H. Englehardt \& D. Callahan (Eds.), Knowledge and belief: Vol. 2. The foundation of ethics and its relationship to science (pp. 111-152). Hastings-on-Hudson, NY: The Hastings Center.

Callahan, D. (1993). The troubled dream of life. New York: Touchstone.

Callahan, D. (1995). Once again, reality: Now where do we go? Hastings Center Report, 25, S33-S36.

Callahan, S. (1988). The role of emotion in ethical decision making. Hastings Center Report, 18 (3), 9-14.

Carnevali, D. \& Thomas, M. (1993). Diagnostic reasoning and treatment decision making. Philadelphia: J.B. Lippincott. 
Carper, B. (1978). Fundamental patterns of knowing in nursing. Advances in Nursing Science, I (1), 13-23.

Carper, B. (1979). The ethics of caring. Advances in Nursing Science, 2 (3), 11-19.

Carse, A. (1991). The voice of care: Implications for bioethical education. Journal of Medicine and Philosophy, 16 (1), 5-28.

Cassidy, V., \& Oddi, L. (1988). Professional autonomy and ethical decisiion making among graduate and undergraduate nursing majors. Journal of Nursing Education, 27 (9), 405-410.

Charon, R. (1994). Narrative contributions to medical ethics. In E. Dubose (Ed.), A matter of principles: Ferment in U.S. bioethics (pp. 260-283). Valley Forge, PA: Trinity Press International.

Charon, R. (2000). Reading, writing, and doctoring. The American Journal of the Medical Sciences, 319 (5), 285-291.

Charon, R. (2001). Narrative medicine: A model for empathy, reflection, profession, and trust. The Journal of the American Medical Association, 286 (15), 1897-1902.

Chase, H. \& Simon, W. (1973). Skill in chess. American Scientist, 61, 393403.

Chesla, C. (1997). Reconciling technologic and family care in critical care nursing. Journal of Nursing Scholarship, 28 (3), 199-203. 
Chi, M., Feltovich, P., \& Glaser, R. (1981). Categorization and representation of physics problems by experts and novices. Cognitive Science, 5 (2), 121-152.

Clouser, K., \& Gert, B. (1990). A critique of principlism. The Journal of Medicine and Philosophy, 15 (2), 219-236.

Coffey, A., \& Atkinson, P. (1996). Making sense of qualitative data:

Complementary strategies. Thousand Oaks, CA: Sage.

Connelly, R. (1997-1998). The medicalization of dying: A positive turn on a new path. Omega, 36 (4), 331-341.

Cooper, M. (1991). Principle oriented ethics and the ethic of care: A creative tension. Advances in Nursing Science, 14 (2), 22-31.

Cooper, M. (1993). The intersection of technology and care in the ICU. Advances in Nursing Science, 15 (3), 23-32.

Copp, L. (1986). The nurse as advocate for vulnerable persons. Journal of Advanced Nursing, 11 (8). 255-263.

Corcoran, S. (1986). Planning by expert and novice nurses in cases of varying complexity. Research in Nursing and Health, 9 (4), 155-162.

Corcoran, S. (1986). Task complexity and nursing expertise as factors in decision making. Nursing Research, 35 (2), 107-112.

Corley, M., \& Selig, P. (1994). Prevalence of principled thinking by critical care nurses. Dimensions of Critical Care Nursing, 13 (2), 96-103.

Cortazzi, M., (1993). Narrative Analysis. London: Falmer Press. 
Council on Ethical and Judicial Affairs, American Medical Association (1991). Guidelines for the appropriate use of do-not-resuscitate orders. Journal of the American Medical Association, 265 (11), 1868-1871.

Council on Ethical and Judicial Affairs, American Medical Association (1992): Decisions near the end of life. Journal of the American Medical Association, 267 (22), 2229-2233.

Crandall, B., \& Getchell-Reiter, K. (1993). Critical decision method: A technique for eliciting concrete assessment indicators from the intuition of NICU nurses. Advances in Nursing Science, 16 (1), 42-51.

Crisham, P. (1981). Measuring moral judgment in nursing dilemmas. Nursing Research, 30 (4), 104-110.

Csikszentmihalhyi, M. (1990). Flow: the psychology of optimal experience. New York: Harper \& Row.

Curtin, L. (1979). The nurse as advocate: A philosophical foundation for nursing. Advances in Nursing Science, 1 (1), 1-10.

Curtis, J., \& Patrick, D. (2001). How to discuss dying and death in the ICU. In J. Curtis \& G. Rubenfeld (Eds.), Managing death in the intensive care unit: The transition from cure to comfort (pp. 85-102). New York: Oxford University Press.

Curtis, J., Patrick, D., Shannon, S., Treece, P., \& Rubenfeld, G. (2001). The family conference as a focus to improve communication about end-of-life care in the intensive care unit: Opportunities for improvement. $\underline{\text { Critical Care }}$ Medicine, 29 (2), N26-N33. 
Daley, B., \& Miller, M. (1996). Defining home health care nursing: Implications for continuing nursing education. The Journal of Continuing Education in Nursing, 27 (5), 228-237.

Danis, M., Federman, D., Fins, J., Fox, E., Kastenbaum, B., Long, K., \& Tulsky, J. (1999). Incorporating palliative care into critical care education; Principles, challenges, and opportunities. Critical Care Medicine, 27 (9), 20052013.

Danis, M., Jarr, S., \& Nocella, P. (1987). A comparison of patient, family, and nurse evaluation of intensive care. Critical Care Medicine, 152 (6), 138-143.

Danis, W. (1998). Who decides? Physicians' willingness to use life sustaining treatments. Archives of Internal Medicine, 156 (7), 785-790.

Danis, W. (1998). Who decides? Physicians' willingness to use life sustaining treatments. Archives of Internal Medicine, 156 (7), 785-790.

Davis, A. J. (1989). Clinical nurses' ethical decision making in situations of informed consent. Advances in Nursing Science, 11 (3), 63-69.

Davis, A., \& Aroskar, M. (1978). Ethical dilemmas and nursing pratice. New York: Appleton-Century-Crofts.

Davis, B. (1972). Clinical expertise as a function of educational preparation. Nursing Research, 21 (6), 530-534.

Davis, B. (1974). Effects of levels of nursing education on patient care: a replication. Nursing Research, 23 (2), 150-155. 
De Groot, A. (1978). Thought and choice in chess. The Hague: Mouton Publishers.

Dikelmann, N. (1992). Learning-as-testing: a Heideggerian hermeneutical analysis of the lived experiences of students and teachers in nursing. Advances in Nursing Science, 14 (3), 72-83.

Donovan, M. (1985). Nursing; The finest art. St. Louis, MO: C.V. Mosby.

Dowdy, M., Robertson, C., \& Bander, J. (1998). A study of proactive ethics consultation for critically and terminally ill patients with extended lengths of stay. Critical Care Medicine, 26 (2), 252-259.

Dreyfus, H. \& Dreyfus, S. (1986). Mind over machine, the power of human intuition and expertise in the era of the computer. New York: The Free Press.

Dreyfus, H. (1979). What computers can't do: The limits of artificial intelligence. New York: Harper \& Row.

Drought, T., \& Liaschenko, J. (1995). Ethical practice in a technological age. Critical Care Nursing Clinics of North America, 7 (2), 297-304.

Dwyer, J. (1994). Primum non tacere; An ethics of speaking up. Hastings Center Report, 24 (1), 13-18.

Elizondo, A.P. (1991). Nurse participation in ethical decision-making in the neonatal intensive care unit. Neonatal Network, 10 (2), 55-59.

Ellos, W. (1994). Narrative Ethics. Brookfield, VT: Averbury.

Elstein, A., \& Shulman, L. (1978). Medical problem solving: An analysis of clinical reasoning. Cambridge, MA: Harvard University Press. 
Englehardt, H.T. (1986). The foundation of bioethics. New York: Oxford University Press.

Ericsson, K., \& Simon, H. (1993). Protocol analysis: Verbal reports $\underline{\text { as }}$ data. Cambridge, MA: Harvard University Press.

Erlen, J., \& Frost, B. (1991). Nurses' perceptions of powerlessness in influencing ethical decisions. Western Journal of Nursing Research, 13 (3), 397407.

Fagermoen, M. (1997). Values embedded in meaningful nursing practice. Journal of Advanced Nursing, 25 (3), 434-441.

Falk, R. (1996). Power and caring: a dialectic in nursing. Advances in Nursing Science, 19 (1), 3-17.

Falk, R. (1998). Nurses who run with the wolves: The power caring dialectic revisited. Advances in Nursing Science, 21 (1), 29-42.

Ferrell, B., Virani, R., \& Grant, M. (1999). Analysis of end-of-life content in nursing textbooks. Oncology Nursing Forum, 26 (5), 869-875.

Field, M., \& Cassel, C. (1997). Approaching death: Improving care at the end of life. Committee on Care at the End of Life, Institute of Medicine. Washington, D.C: National Academy Press.

Fins, J., \& Solomon, M. (2001). Communication in intensive care settings: The challenge of futility disputes. Critical Care Medicine, 29 (2), N10-N15. 
Fisher, W. (1987). Human communication as narration: toward a philosophy of reason, value, and action. Columbia: University of South Carolina Press.

Fothergill-Bourbonnais, F., \& Wilson-Barnett, J. (1992). A comparative study of intensive therapy unit and hospice nurses' knowledge on pain management. Journal of Advanced Nursing, 17 (2), 362-372.

Frank, A., (1995). The wounded storyteller. Chicago: University of Chicago Press.

Frankena, W. (1973). Ethics ( $2^{\text {nd }}$. edition). Englewood Cliffs, NJ:PrenticeHall.

Fry, S. (1991). Nursing ethics; Current state of the art. The Journal of Medicine and Philosophy, 16 (2), 231-234.

Fry, S., \& Redman, B. (2000). Nurses' ethical conflicts: What is really known about them? Nursing Ethics, 7 (4), 360-366.

Fuller, B., \& Conner, D. (1996). Distribution of cues across assessed levels of infant pain. Clinical Nursing Research, 5 (2), 167-185.

Gadow, S. (1980). Existential advocacy: A philosophical foundation for nursing. In S.F. Spicker \& S. Gadow (Eds.), Nursing: Images \& ideals

Gadow, S. (1984). Touch and technology: Two paradigms of patient care. Journal of Religion and Health, 23, 63-69. 
Gadow, S. (1990). The advocacy covenant: Care as clinical subjectivity. In J. Stevenson \& T. Tripp-Reimer (Eds.), Knowledge about care and caring (pp. 33-40). Kansas City, MO: American Academy of Nursing.

Gadow, S. (1996). Aging as death rehearsal: the oppressiveness of reason. Journal of Clinical Ethics, 7 (1), 35-40.

Gadow, S. (1996). Ethical Narratives in Practice. Nursing Science Quarterly, 9 (1), 8-9.

Gadow, S. (1999). Relational narratives: The postmodern turn in nursing ethics. Scholarly Inquiry for Nursing Practice, 13 (1), 57-70.

Gee, J. (1986). Units in the production of narrative discourse. Discourse Processes, 9, 391-422.

Gilligan, C. (1982). In a different voice. Cambridge, MA: Harvard University Press.

Gordon, M. (1980). Predictive strategies in diagnostic tasks. Nursing Research, 29 (8), 39-45.

Greeno, J. (1977). Associative learning: a cognitive analysis. Englewood Cliffs, NJ: Prentice-Hall.

Greenwood, J., \& King, M. (1995). Some surprising similarities in the clinical reasoning of "expert" and "novice" orthopedic nurses: report of a study using verbal protocols and protocol analyses. Journal of Advanced Nursing, 22 (5), 907-913. 
Grobe, S., Drew, j. \& Fonteyn, M.(1991). A descriptive analysis of experienced nurses' clinical reasoning during a planning task. Research in Nursing and Health, 14 (6), 305-314.

Groeger, J., \& Price, K. (1998). Multicenter outcome study of cancer patients admitted to the intensive care unit: A probability of mortality model. Journal of Clinical Oncology, 16, 761-770.

Grundstein-Amado, A. (1992). Differences in ethical decision making processes among nurses and doctors. Journal of Advanced Nursing, 17 (12), $129-137$.

Grundstein-Amado, R. (1993). Ethical decision-making processes used by health care providers. Journal of Advanced Nursing, 18, 1701-1709.

Guyton-Simmons, J., \& Ehrmin, J. (1994). Problem solving in pain management by expert intensive care nurses. Critical Care Nurse, 14 (5), 37-44.

Guyton-Simmons, J., \& Mattoon, M. (1991). Analysis of strategies in the management of coronary patients' pain. Dimensions of Critical Care Nursing, 10 (1), 21-27.

Haggerty, L. (1996). Assessment parameters and indicators in expert intrapartal nursing decisions. Journal of Obstetric, Gynecologic, \& Neonatal Nursing, 25 (6), 492-499.

Hamers, J., van den Hout, M., Halfens, R., Abu-Saad, H., \& Heijltles, A. (1997). Differences in pain assessment and decisions regarding the 
administration of analgesics between novices, intermediates and experts in pediatric nursing. International Journal of Nursing Studies, 34 (5), 325-334.

Hamm, R. (1988). Clinical Intuition and Clinical Analysis: Expertise and the Cognitive Continuum. In J. Donovan \& A. Elstein (Eds.), Professional judgment: A reader in clinical decision making (pp. 78-105). Cambridge: Cambridge Press.

Hammond, K. (1966). Clinical inference in nursing: analyzing tasks representative of nursing problems. Nursing Research, 15 (4), 134-138.

Hammond, K. (1996). Human judgment and social policy. New York: Oxford University Press.

Hampton, D. (1994). Expertise: The true essence of nursing art. Advances in Nursing Science, 17 (1), 15-24.

Hayes-Roth, B., \& Hayes-Roth, F. (1979). A cognitive model of planning. Cognitive Science, 3 (7), 275-310.

Henry, S. (1991). Effect of level of patient acuity on clinical decision making of critical care nurses with varying levels of knowledge and experience. Heart \& Lung, 20 (5), 478-485.

Hinshaw, A. (2000). Nursing knowledge for the $21^{\text {st }}$ century: Opportunities and challenges. Journal of Nursing Scholarship, 32 (2), 117-123.

Holden, G., \& Klingner, A., (1988). Learning from experience: Differences in how novice and expert nurses diagnose why an infant is crying. Journal of Nursing Education, 27 (1), 23-29. 
Hunter, K. (1991). Doctor's stories: The narrative structure of medical knowledge. Princeton, NJ: Princeton University Press.

Itano, J. (1989). A comparison of the clinical judgment process in experienced registered nurses and student nurses. Journal of Nursing Education, $\underline{28}(3), 120-125$.

Jacavone, J., \& Dostal, M. (1992). A descriptive study of nursing judgment in the assessment and management of cardiac pain. Advances in Nursing Science, 15 (1), 54-63.

Jacobs, B. (2001). Respect for human dignity: A central phenomenon to philosophically unite nursing theory and practice through consilience of knowledge. Advances in Nursing Science, 24 (1), 17-35.

Jameton, A. (1993). Dilemmas of moral distress: Moral responsibility and nursing practice. AWHONN's Clinical Issues in Perinatal Women's Health Nursing, 4 (4), 542-551. Jastremski, C. (1998). Caring for the families of those who die in the critical care unit. Critical Care Medicine, 26 (7), 1150-1151. Jenny, J., \& Logan, J. (1992). Knowing the patient: One aspect of clinical knowledge. Image: Journal of Nursing Scholarship, 24 (4), 254-258.

Jezewski, M., Scherer, Y., Miller, C., \& Battista, E. (1993). Consenting to DNR: Critical Care Nurses' Interactions With Patients and Family Members. American Journal of Critical Care, 2 (4), 302-309. 
Johnson, J. (1996). Dialectical analysis concerning the rational aspect of the art of nursing. Image: Journal of Nursing Scholarship, 28 (2), 169-175. Johnson, M. (1993). Moral Imagination. Chicago: The University of Chicago Press.

Johnson, R. (1976). Elementary statistics. MA: Duxbury Press.

Kalisch, P., \& Kalisch, B. (1986). The changing image of the nurse. Glenview, IL: Addison Wesley.

Kant, I. (1959). Foundations of the metaphysics of morals and what is enlightenment. NY: McMillan.

Karlawish, J. (1996). Shared decision making in critical care: A clinical reality and an ethical necessity. American Journal of Critical Care, 5 (6), 391-396.

Kaufman, S. (1998). Intensive care, old Age, and the problem of death in America. The Gerontologist, 38 (6), 715-725.

Ketefian, S. (1981). Moral reasoning and moral behavior among selected groups of practicing nurses. Nursing Research, 30 (3), 171-176.

Ketefian, S. (1985). Professional and beauracratic role conception and moral behavior among nurses. Nursing Research, 34 (4), 248-253.

Kirchoff, K. \& Beckstrand, R. (2000). Critical care nurses' perceptions of obstacles and helpful behaviors in providing end-of-life care to dying patients. American Journal of Critical Care, 9 (4), 96-105.

Kleinman, A. (1988). The illness narratives: Suffering, healing, and the human condition. New York: Basic Books. 
Knaus, W.. \& Draper, G. (1995). The APACHE III prognostic system. Chest, 100 (10), 1619-1636.

Kohlberg, L. (1981). Essays on moral development: The psychology of moral development. New York: Harper \& Row.

Kohlberg, L. (1984). The nature and validity of moral stages. Essays on moral development. San Francisco: Harper \& Row.

Labov, W. (1972). The transformation of experience in narrative syntax. In W. Labov (Ed.), Language in the inner city (pp. 354-396). Philadelphia: University of Pennsylvania Press.

Labov, W. (1997). Some further steps in narrative analysis. The Journal of Narrative and Life History, 27 (7), 1-17.

Lamond, D., \& Farnell, S. (1998). The treatment of pressure sores: a comparison of novice and expert nurses' knowledge, information use and decision accuracy. Journal of Advanced Nursing, 27 (2), 280-286.

Lantrell, P. (1997). Clinical reasoning strategies used during care planning. Clinical Nursing Research, 6 (4), 349-363.

Larson, D., \& Tobin, D. (2000). End-of life conversations: Evolving practice and theory. Journal of the American Medical Association, 284 (12), 1573-1577. Levy, M. (2001). End-of-life care in the intensive care unit: Can we do better? Critical Care Medicine, 29 (2), N56-N61.

Liaschenko, J. (1993). Feminist ethics and cultural ethos: Revisiting a nursing debate. Advances in Nursing Science, 15 (2), 71-81. 
Liaschenko, J. (1995). Ethics in the work of acting for patients. Advances in Nursing Science, 18 (2), 1-12.

Liaschenko, J. (1997). Ethics and the geography of the nurse-patient relationship: Spatial vulnerabilities and gendered space. Scholarly Inquiry for Nursing Practice, 11 (1), 45-60.

Liaschenko, J., \& Davis, A. (1991). Nurses and physicians on nutritional support: A comparison. Journal of Medicine and Philosophy, 16 (3), 259-283. Liaschenko, J., \& Fisher, A. (1999). Theorizing the knowledge that nurses use in the conduct of their work. Scholarly Inquiry for Nursing Practice, $\underline{13}$ (1), 29-41.

Lincoln, Y., \& Guba, E. (1985). Naturalistic Inquiry. Beverly Hills, CA: Sage.

Lo, B. (1995). End of life care after termination of SUPPORT (Study to Understand Prognosis and Preferences for Outcomes and Risks of Treatment). Hastings Center Report, 25 (6), 53-56.

Luce, J. (1990). Withholding and withdrawl of life support: Ethical, legal, and clinical aspects. New Horizons, 5 (1), 32-37.

Mac Leod, M. (1993). On knowing the patient: experiences of nurses undertaking care. In Worlds of illness: Biographical and cultural perspectives on health and disease. A. Radley, (Ed.) London: Routledge.

Maeve, K. (1998). Weaving a fabric of moral meaning: How nurses live with suffering and death. Journal of Advanced Nursing, 27 (6), 1136-1142. 
Mahon, K., \& Fowler, M. (1979). Moral development and clinical decision making. Nursing Clinics of North America, 14 (1), 3-12.

Mallik, M. (1997). Advocacy in nursing: Perceptions of practicing nurses. Journal of Clinical Nursing, 6 (4), 303-313.

Mann, R. (1992). Preserving humanity in an age of technology. Intensive and Critical Care Nursing, 8 (11), 54-59.

Marck, P. (2000). Nursing in a technological world: Searching for healing communities. Advances in Nursing Science, 23 (2), 62-81.

Marshall, P. (1995). The SUPPORT Study: Who's talking?. The Hastings Center Report, 25 (6), S13-15.

Martin, D. (1989). Nurses' involvement in ethical decision-making with severely ill newborns. Issues in Comprehensive Pediatric Nursing. 12 (4), 263473.

Mattingly, C. (1991). The narrative nature of clinical reasoning. American Journal of Occupational Therapy, 45 (6), 988-1005.

Maxwell, J. (1996). Qualitative research design: An interactive approach. Thousand Oaks, CA: Sage.

May, C., \& Fleming, C. (1997). The professional imagination: Narrative and symbolic boundaries between medicine and nursing. Journal of Advanced Nursing, 25 (6), 1094-1100.

May, R. (1969). Love and will. New York: Dell. 
Mayberry, M. (1986). Ethical decision making: a response of hospital nurses. Nursing Administration Quarterly, 10 (3), 75-81.

Mayeroff, M. (1971). On caring. New York: Harper \& Row.

McCance, T., \& McKenna, H. (2001). Exploring caring using narrative methodology: An analysis of the approach. Journal of Advanced Nursing, 33 (3), 350-356.

McClement, S., \& Degner, L. (1995). Expert nursing behaviors in care of the dying patient in the ICU. Heart and Lung, 24 (5), 408-419.

McHale, J., Phipps, M., Horvath, K., \& Schmelz, J. (1998). Expert knowledge in the care of patients at risk of impaired swallowing. Image: Journal of Nursing Scholarship, 30 (2), 137-141.

McMurray, A. (1992). Expertise in community health nursing. Journal of Community Health Nursing, 9 (2), 65-75.

Mei, A. (2000). Collusion in doctor-patient communication about imminent death: An ethnographic study. British Medical Journal, 321, 1376-1381.

Membership Data FAQ (1999). American Association of Critical Care Nurses. CA: Author.

Mezey, M., Leitman, R., Mitty, E., Bottrell, M., \& Ramsey, G. (2000). Why hospital patients do and do not execute an advance directive. Nursing Outlook, 48, $165-171$.

Miles, M., \& Huberman, M. (1994). Qualitative data analysis. Thousand Oaks, CA: Sage. 
Miller, G. (1956). The magical number seven plus or minus two: some limits on our capacity to process information. Psychological Review, 63, 81-97.

Miller, P., Forbes, S., \& Boyle, D. (2001). End-of-Life care in the intensive care unit: A challenge for nurses. American Journal of Critical Care, 10 (4), 23237.

Millette, B. (1993). Client advocacy and the moral orientation of nurses. Western Journal of Nursing Research, 15 (5), 607-618.

Mishler, E. (1986). Research interviewing: Context and narrative. Cambridge, MA: Harvard University Press.

Mishler, E. (1991). Representing discourse: The rhetoric of transcription. Journal of Narrative and Life History, 1 (4), 255-280.

Morse, J., Solberg, S., Neander, W., Bottorff, J., \& Johnson, J. (1991). Comparative analysis of conceptualizations and theories of caring. Image: The Journal of Nursing Scholarship, 23 (2), 119-126.

Moskowitz, E. \& Lindemann-Nelson, H., (1995). The best laid plans. The Hastings Center Report, 25 (6), S22-26.

Moulter, N. (1979). Needs of relatives of critically ill patients: A descriptive study. Heart and Lung, 8 (10), 332-339.

Mularski, R., Bascom, P., \& Osborne, M. (2001 b). Educational agendas for interdisciplinary end-of-life curricula. Critical Care Medicine, 29 (2), N16-N23.

Munhall, P., \& Oiler, C. (1986). Nursing research: A qualitative perspective. Norwalk, CT: Appleton, Century, Crofts. 
Murphy, P. (1981). Moral reasoning in a selected group of nurse practitioners. In S. Ketefian (Ed.), Perspectives on nursing leadership: Issues and Research (pp. 45-75). New York: Teacher's College Press.

Nelson, J., and Danis, M. (2001). End-of -life care in the intensive care unit: Where are we now? Critical Care Medicine, 29 (2), N2-N9.

Nelson, J., Meier, D., \& Oei, E. (2001). The symptom experience of critically ill cancer patients receiving intensive care. Critical Care Medicine, 29 (2), 277-282.

Neuberg, S., \& Newsom, J. (1993). Personal needs for structure: Individual differences in the desire for simple structure. Journal of Personality and Social Psychology, 65 (4), 113-131.

Newell, A., \& Simon, H. (1972). Human problem solving. Englewood Cliffs, NJ: Prentice-Hall.

Nightingale, F. (1969). Notes on nursing: What it is and what it is not. New York: Dover.

Nisbett, R., \& Ross, L. (1980). Human inferences: Strategies and shortcomings of social judgment. Englewood Cliffs, NJ: Prentice- Hall.

Noddings, N. (1984). Caring: A feminine approach to ethics and moral education. Berkeley:University of California Press.

Nokes, K.M. (1989). Rethinking moral reasoning theory. Image: The Journal of Nursing Scholarship, 21 (3), 172-175. 
Norman, G., \& Boshuizen, F. (1990). Knowledge and clinical problem solving. Medical Education, 19 (7). 344-356.

Nussbaum, M. (1990). Love's knowledge: Essays on philosophy and literature. London: Oxford University Press.

O'Connor, K. (1996). Ethical/moral experiences of oncology nurses. Oncology Nursing Forum, 23 (5), 787-794.

O'Neil, E. (1994). The influence of experience on community health nurses' use of the similarity heuristic in diagnostic reasoning. Scholarly Inquiry for Nursing Practice, 8 (3), 261-273.

Oberle, K. \& Hughes, D. (2001). Doctors' and nurses' perceptions of ethical problems in end-of-life decisions. Journal of Advanced Nursing, 33 (6), 707-715.

Oddi, V., \& Cassidy, L., (1998). The message of SUPPORT: change is long overdue. Journal of Professional Nursing, 14 (3), 156-174.

Oliver, K. (1998). A journey into narrative analysis: A methodology for discovering meanings. Journal of Teaching in Physical Education, 17, 244-259.

Oliverio, R., \& Fraulo, B. (1998). SUPPORT revisited: The nurse clinician's perspective. Holistic Nursing Practice,13 (1), 1-7.

Olsen, D. (2001). Empathetic maturity: Theory of moral point of view in clinical relations. Advances in Nursing Science, 21 (1), 36-46.

Olson, L. (1998). Hospital nurses' perceptions of the ethical climate of their work setting. Image:Journal of Nursing Scholarship, 30 (4), 345-349. 
Omery, A. (1985). The moral reasoning of nurses who work in the adult intensive care unit. (Doctoral dissertation, University of Massachusetts at Amherst, 1984). Dissertation Abstracts International, 45.

Omery, A. (1989). Values, moral reasoning and ethics. Nursing Clinics of North America, 24 (2), 499-508.

Omery, A., \& Henneman, E., (1995). Ethical issues in hospital based nursing practice. Journal of Cardiovascular Nursing, 9 (3), 43-55.

Omnibus budget reconciliation act (1990). Publication No. 10150842064751. Washington, DC: Government Printing Office.

Parker, C., Minick, P., \& Kee, C. (1999). Clinical decision-making processes in perioperative nursing. AORN Journal, 70 (1), 45-56.

Parker, R. (1990). Nurses' stories: The search for a relational ethic of care. Advances in Nursing Science, 13 (1), 31-40.

Patel, V. (1996). The acquisition of medical expertise in complex dynamic environments. In K. Ericsson, (Ed.), The road to excellence: The acquisition of expert performance in the arts, sciences, sports, and games, (pp. 127-166). Mahwah, New Jersey: Erlbaum.

Peden-McAlpine, C. (2000). Early recognition of patient problems: a hermeneutic journey into understanding expert thinking in nursing. Scholarly Inquiry for Nursing Practice, 14 (3), 191-226.

Pelligrino, E. (1981). A philosophical basis of medical practice: Toward philosophy and ethic of healing professions. Oxford: Oxford University Press. 
Penticuff, J. (1991). Conceptual issues in nursing ethics research. Journal of Medicine and Philosophy, 16 (3), 235-258.

Penticuff, J., \& Walden, M. (2000). Influence of practice environment and nurse characteristics on perinatal nurses' responses to ethical dilemmas. Nursing Research, 49 (2), 64-72.

Polanyi, L. (1985). Telling the American story: A structural and cultural analysis of conversational storytelling. Norwood, NJ: Ablex.

Polanyi, M. (1962). The tacit dimension. Garden City, NY: Anchor Books. Polit, D, \& Hungler, B. (1998). Nursing research: Principles and methods. Philadelphia, PA: Lippincott.

Polkinghorne, D. (1988). Narrative knowing and the human sciences. Albany, NY: SUNY Press.

Polkinghorne, D. (1995). Narrative configuration in qualitative analysis. In J. Hatch \& R. Wisniewski (Eds.), Life History and Narrative (pp. 5-23). London: The Falmer Press.

Prendergast, L., Claessens, k., \& Luce, H. (1998). A national survey of end of life care for critically ill patients. American Journal of Respiratory Care, 158 (4), 1163-1167.

Prendergast, T. (2001). Advance care planning: Pitfalls, progress, promise. Critical Care Medicine, 29 (2), N34-N39.

Puntillo, K., Benner, P., Drought, T., Drew, B., Stotts, N., Stannard, D., Rushton, C., Scanlon, C., White, C. (2001). End-of-life issues in intensive care 
units: A national random survey of nurses' knowledge and beliefs. American Journal of Critical Care, 10 (4), 216-229.

Pyles, S. \& Stern, P. (1983). Discovery of nursing gestalt in critical care nursing: The importance of the gray gorilla syndrome. Image: The Journal of Nursing Scholarship, 15, 42-45.

Quint, J. (1967). The nurse and the dying patient. New York: MacMillan.

Radwin, I. (1998). Empirically generated attributes of experience in nursing. Journal of Advanced Nursing, 27 (12), 590-595.

Rawls, J. (1971). A theory of justice. Cambridge, MA: Harvard University Press.

Ray, M. (1998). A phenomenologic study of the interface of caring and technology in intermediate care: Toward a reflexive ethics for clinical practice. Holistic Nursing Practice, 12, 69-77.

Rew, L. (1988). Intuition in decision making. Image: Journal of Nursing Scholarship, 20 (3), 150-154.

Reynolds, W., Scott, P., \& Austin, W. (2000). Nursing, empathy, and the perception of the moral. Journal of Advanced Nursing, 32 (1), 235-242.

Riessman, C. (1993). Narrative Analysis. Newbury Park, CA: Sage.

Riessman, C. (2000). Analysis of personal narratives. In J. Gubrium \& J. Holstein (Eds.), Handbook of interviewing (pp. 1-27). Newbury Park, CA: Sage. 
Robichaux, C. \& Clark, A.P. (2001). Ethical dilemmas: How can the clinical nurse specialist provide ethical expertise? Clinical Nurse Specialist, 15 (6), 272273.

Rubenfeld, G., \& Curtis, R. (2001). End-of-life care in the intensive care unit: a research agenda. Critical Care Medicine, 29 (10), 2001-2006.

Rubin, J. (1996). Impediments to the development of clinical knowldege and ethical judgment in critical care nursing. In P. Benner (Ed.), Expertise in nursing practice: Caring clinical judgment, and ethics (pp. 170-192). New York: Springer.

Ruohamaki, V. (1992). What makes an expert? Paper presented at the $25^{\text {th }}$ International Congress of Psychology, Brussels.

Rushton, C. \& Brooks-Brunn, J. (1997). Environments that support ethical practice. New Horizons, 5 (2), 20-29.

Rushton, C. (1995). Creating an ethical practice environment: A focus on advocacy. Critical Care Nursing Clinics of North America, 7 (2), 387-397.

Saariluoma, P. (1994). Location coding in chess. The Quarterly Journal of Experimental Psychology, $47 \mathrm{~A}, 607-630$.

Sandelowski, M. (1991, a). Telling stories: Narrative approaches in qualitative research. Image: Journal of Nursing Scholarship, 23 (3), 161-165.

Sandelowski, M. (1991, b). We are the stories we tell: Narrative knowing in nursing practice. Holistic Nursing Practice, 12 (1), 23-33. 
Sandelowski, M. (1998). Looking to care or caring to look? Technology and the rise of spectacular nursing. $\underline{\text { Holistic Nursing Practice, }} 12$ (4), 1-11.

Sandelowski, M. (2002). Visible humans, vanishing bodies, and virtual nursing: Complications of life, presence, place, and identity. Advances in Nursing Science, 24 (3), 58-70.

Sarvimaki, A. (1995). Aspects of moral knowledge in nursing. Scholarly Inquiry for Nursing Practice: An International Journal, 9 (4), 343-353.

Schraeder, B., \& Fischer, R. (1987). Using intuitive knowledge in the neonatal intensive care nursery.

Segesten, R. (1993). Patient advocacy: An important part of the daily work of the expert nurse. Scholarly Inquiry for Nursing Practice, 7 (2), 12-135.

Selzer, R. (1994). Raising the dead. New York: Viking Press.

Shadbolt, N., \& Burton, M. (1990). Knowledge elicitation. In Evaluation of human work: A practical ergonomics methodology. J. Wilson \& E. Cornett (Eds.). London: Taylor and Francis.

Shannon, S. (1997). The roots of interdisciplinary conflict around ethical issues. Critical Care Nursing Clinics of North America, 9, 13-28.

Shanteau, J. (1988). How much information does an expert use? Is it relevant? Acta Psychologica, 81 (2), 75-86.

Sherwin, S. (1992). No longer patient: Feminist ethics and healthcare. Philadelphia; Temple University Press.

Shuter-Dyson, R. (1982). The psychology of musical ability. NY: Methuen. 
Siedentop, G., \& Eldar, H. (1989). Sports education: quality physical education through positive sports experience. Champaign, ILL: Humkin Publications.

Sloboda, J. (1996). The acquisition of musical performance expertise. In K. Ericsson, (Ed.), The road to excellence: The acquisition of expert performance in the arts, sciences, sports, and games, (pp. 167-182). Mahway, New Jersey: Erlbaum.

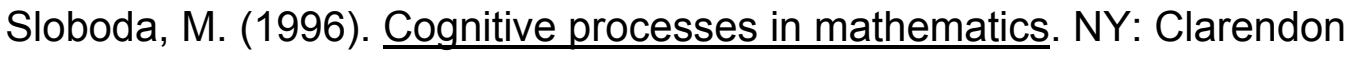
Press.

Smith, D. (1986). The limits of narrative. Literature and Medicine, 5 (3), 54-57.

Smith, S. (1988). An analysis of the phenomenon of deterioration on the critically ill. Image: Journal of Nursing Scholarship, 20 (1), 12-16.

SmithBattle, L., Drake, S., \& Diekemper H. (1997). The responsive use of self in community health nursing practice. Advances in Nursing Science, 20 (2), 75-89.

Society of Critical Care Medicine (1997). Consensus statement regarding futile and other possibly inadvisable treatments. Critical Care Medicine, 25 (5), 887-892.

Solomon, M., Jennings, B., Fins, J. (1997). Decisions near the end of life. Newton, MA: Education Development Center. 
Somogyi-Zalud, E., Zhong, Z., \& Lynn, J. (2000). Dying with acute respiratory failure or multiple organ system failure with sepsis. Journal of the American Geriatric Society, 48, S140-S145.

Stannard, D. (1997). Reclaiming the house: An interpretive study of nursefamily interactions and activities in critical care. Unpublished doctoral dissertation, University of California at San Francisco, San Francisco.

Steeves, R., Kahn, D., \& Benoliel, J. (1990). Nurses' interpretation of the suffering of their patients. Western Journal of Nursing Research, 12 (6), 715-731.

Stein, L. (1967). The doctor-nurse game. Archives of General Psychiatry, 16, 278-284.

Steinhauser, K., Clipp, E., McNeilly, M., Christakis, N., Mclntyre, L., \& Tulsky, J. (2000). In search of a good death: Observations of patients, families, and providers. Annals of Internal Medicine, 132 (10), 825-831.

Stenberg, M.J. (1979). The search for a conceptual framework as a philosophic basis for nursing ethics: An examination of code, contract and covenant. Military Medicine, 144, 9-22.

Strauss, A. \& Corbin, J. (1990). Basics of qualitative research: Grounded theory procedures and techniques. Newbury Park, CA: Sage.

SUPPORT Principal Investigators (1995). The SUPPORT Study. Annals of Internal Medicine, 122 (7), 191-203.

Swigart, V., Lidz, C., Butterworth, V., \& Arnold, R. (1996). Letting go: Family willingness to forgo life support. Heart \& Lung, 25 (6), 483-494. 
Tabak, N., Bar-Tal, Y., \& Cohen-Mansfield, J. (1997). Clinical decision making of experienced and novice nurses. Western Journal of Nursing Research, $\underline{18}$ (5), 534-548.

Tappan, M. (1990). Hermeneutics and moral development: Interpreting narrative representations of moral experience. Developmental Review, 10, 239265.

Ten Have, H. (1994). The hyperreality of clinical ethics: A unitary theory and hermeneutics. Theoretical Medicine, 15 (2), 141-148.

Thorens, J., Kaelin, R., Jolloiet, P., Chevrolet, J. (1995). Influence of the quality of nursing on the duration of weaning from mechanical ventilation in patients with chronic obstructive pulmonary disease. Critical Care Medicine, 23 (11). $1807-1815$.

Tiedje, L. (2000). Moral distress in perinatal nursing. Journal of Perinatal and Neonatal Nursing, 14 (2), 36-47.

Tilden, V., Tolle, S., Garland, M., \& Nelson, C. (1995). Decisions about life-sustaining treatment: Impact of physicians' behaviors on the family. Archives of Internal Medicine, 155 (6), 633-638.

Timmermans, S. (1998). Resuscitation technology in the emergency department: Towards a dignified death. Sociology of Health and Illness, 38 (20) 150-167.

Tversky, A., \& Kahneman, D. (1974). Subjective probability: A judgment of representativeness. $\underline{\text { Cognitive Science, } 3}$ (10), 430-454. 
Vehonick, P. (1968). I came, I saw, I responded: Nursing observations and action survey. Nursing Research, 35 (11), 38-44.

Vetlesen, A. (1994). Perception, empathy, and judgment. Pennsylvania: The Pennsylvania State University Press.

Vezeau, T. (1993). Caring: from philosophical concerns to practice. Journal of Clinical Ethics, 3 (1), 23-34.

Viney, I., \& Bousfield, L. (1991). Narrative analysis: a method of psychosocial research for AIDS-affected people. Social Science in Medicine, 32 (7), 757-765.

Vitz, P. (1990). The use of stories in moral development. American Psychologist, 45 (6), 709-720.

von-Gunten, C., Ferris, F., \& Emanuel, L. (2000). Ensuring competency in end-of-life are: Communication and relational skills. Journal of the American Medical Association, 284 (23), 3051-3057.

Wagner, R., \& Stanovich, K. (1996). Expertise in reading. In: K. Ericcsson (Ed.), The road to excellence: The acquisition of expert performance in the arts, sciences, sports, and games, (pp. 189-226). Mahway, New Jersey: Erlbaum.

Walker, M. (1992). Feminism, ethics and the question of theory. Hypatia, 7 (3), 23-37.

Walters, A. (1995). A Heideggerian hermeneutic study of the practice of critical care nurses. Journal of Advanced Nursing, 21 (4), 492-498. 
Warren, V. (1989). Feminist directions in medical ethics. Hypatia, 4 (2), 73-87.

Watkins, M. (1998). Decision making phenomena described by expert nurses working in urban community health settings. Journal of Professional Nursing, 14 (1), 22-33.

Weis, D. \& Schank, M. (2000). An instrument to measure professional nursing Values. Journal of Nursing Scholarship, 32 (2), 201-204.

Wilkie, D., Judge, M., \& Wells, M.(2001). Excellence in teaching end of life care: A new multimedia toolkit for nurse educators. Nursing and Health $\underline{\underline{C a r e}}$ Perspectives, 22 (5), 226-230.

Wilkinson, J.M. (1987/1988). Moral distress in nursing practice: Experience and effect. Nursing Forum, 23 (1), 16-29.

Winland-Brown, J. (1983). A comparison of student nurses, nurses and non-nurses with regard to their moral judgment on nursing dilemmas. (Doctoral dissertation, Florida Atlantic University, 1982). Dissertation Abstracts International, 44, 335B.

Wlody, G. (1994). Critical care nurse as moral agent. In W. Jefers (Ed.), Managing clinical practice in critical care nursing (pp. 25-43). St. Louis: Mosby.

Woods, M. (1999). A nursing ethic: The moral voice of experienced nurses. Nursing Ethics, 6 (5), 423-433. 
Wros, P. (1994). The ethical context of nursing care of dying patients in critical care. In P. Benner (Ed.), Interpretive phenomenology: Embodiment, caring and ethics in health and illness (pp. 255-277). Thousand Oaks, CA: Sage.

Wurzbach, M. (1999). The moral metaphors of nursing. Journal of

Advanced Nursing, 30 (1), 94-99.

Yarling, R., \& McElmurry, B. (1986). The moral foundation of nursing. Advances in Nursing Science, 8 (2), 63-73.

Zerwekh, J. (1994). Transcending life: The practice wisdom of nursing hospice experts. Nursingworld Journal, 20 (3), 7, 22-23. 


\section{VITA}

Catherine McBride Robichaux was born in Queens, New York on October 12, 1950, the daughter of Catherine McKenna McBride and Charles Peter McBride. After completing work at Mater Christi High School in Queens, she entered D'Youville College in Buffalo, New York. She subsequently transferred to Cornell University-New York Hospital School of Nursing, where she received a Bachelor of Science Degree in Nursing in 1972. Her initial positions were as a staff nurse in neonatal intensive care in New York Hospital and in a medical oncology unit at Memorial Sloan-Kettering Cancer Center. From 1975 to 1982, she was employed as a staff nurse in several adult intensive care units in Cedars-Sinai Medical Center and The University of California at Los Angeles Medical Center. After relocating to San Antonio, Texas, she continued to work in adult intensive care units in several institutions. Upon receiving the Master of Science in Nursing from The University of the Incarnate Word in 1991, she assumed a position there as a clinical instructor. At present, she is an Assistant Professor in the Acute Care Nursing Department at The University of Texas Health Science Center at San Antonio. In September1992, she entered the Graduate program at the School of Nursing at The University of Texas at Austin.

Permanent Address: 13156 Queens Forest, San Antonio, Texas 78230 This dissertation was typed by the author. 